\title{
Beyond OralDigital: Ghanaian Electronic Literature as a Paradigm for African Digital Textuality
}

Kwabena Opoku-Agyemang

Follow this and additional works at: https://researchrepository.wvu.edu/etd

\section{Recommended Citation}

Opoku-Agyemang, Kwabena, "Beyond OralDigital: Ghanaian Electronic Literature as a Paradigm for African Digital Textuality" (2017). Graduate Theses, Dissertations, and Problem Reports. 6355.

https://researchrepository.wvu.edu/etd/6355

This Dissertation is protected by copyright and/or related rights. It has been brought to you by the The Research Repository @ WVU with permission from the rights-holder(s). You are free to use this Dissertation in any way that is permitted by the copyright and related rights legislation that applies to your use. For other uses you must obtain permission from the rights-holder(s) directly, unless additional rights are indicated by a Creative Commons license in the record and/ or on the work itself. This Dissertation has been accepted for inclusion in WVU Graduate Theses, Dissertations, and Problem Reports collection by an authorized administrator of The Research Repository @ WVU.

For more information, please contact researchrepository@mail.wvu.edu. 


\title{
Beyond Oral/Digital: Ghanaian Electronic Literature as a Paradigm for African Digital Textuality
}

\author{
Kwabena Opoku-Agyemang \\ Dissertation submitted \\ to the \\ Eberly College of Arts and Sciences \\ at West Virginia University \\ in partial fulfillment of the requirements for the degree of \\ Doctor of Philosophy in English
Brian Ballentine, Ph.D., Chair
Sandy Baldwin, Ph.D.
John Jones, Ph.D.
Janice Spleth, Ph.D. \\ Dorothy Odartey-Wellington, Ph.D. \\ Department of English
}
Morgantown, West Virginia
2017

Keywords: African Electronic Literature, Ghana, Concrete Poetry, Conceptual Poetry, Mobile Video Games, African Literature Copyright 2017: Kwabena Opoku-Agyemang 


\section{ABSTRACT \\ Beyond Oral/Digital: Ghanaian Electronic Literature as a Paradigm for African Digital Textuality Kwabena Opoku-Agyemang}

This dissertation speaks to a massive dearth of research in African electronic literature (African e-lit), a discipline that boasts a growing number of works but little scholarship. With African literature incorporating digital technology into its creative process, and with electronic literary criticism focusing on areas outside its predominantly western cannon, African e-lit positions itself as an important area of scholarly endeavor. After considering the implications of placing African e-lit as the direction in which both African literature and electronic literature take, this dissertation looks at three different genres of African elit in the context of oral literature. There are analyses of examples of concrete poetry, conceptual poetry, and mobile video games, all from Ghana. Ultimately, the aim of this project is to ascertain the ways in which oral tradition influences the nature, form, and shape of African electronic literature. 


\section{Dedication}

I dedicate this work to anyone I consider family. 


\section{Acknowledgements}

I am grateful to a vibrant community of scholars including my committee for invaluable critique, as well as to my family for the support. 
Abstract __ ii

Dedication __ iii

Acknowledgements __ iv

Table of Contents __ v

Chapter 1 - Definitions__ 1

Introduction: The "Africa" Narrative and Digital Advancement___ 1

Background: The Space Between African Lit and E-Lit___ 2

Justification: Why African E-lit?

African Literature: A Brief Look

Electronic Literature: A Brief Look__ 9

A Preliminary Look at Scholarship

Limitations _ 15

Structure 17

Conclusion _ 21

Chapter 2 - Literature Review and Theoretical Frameworks _ 22

Introduction: Ghana as a Metonym for Africa 22

African Literary Scholarship: A Technological Affair __ 25

Electronic Literary Scholarship: Technological Relationships in Western Contexts __ 34

African E-Lit Scholarship: Beginnings __ 41

Logistics, Orality, and the Digital ___ 42

Conclusion __ 48

Chapter 3 - Looking Back while Moving Forward: The Case of Concrete Poetry and

Sankofa__ $\mathbf{5 0}$

Introduction $\quad 50$

Conceptual Poetry, Shape, and Context__ 51

Adinkra and Sankofa: A Brief History _ 57

Sankofa, Concrete Poetry (and Visual Poetry)___ 61

Sankofa as an International Signifier __ 70

Conclusion _ 72

Appendix — 74

Chapter 4 - Magpie Poetry: My Book of \#GHCoats and African Conceptual Poetry 76

Introduction 76

Concrete Poetry and Africa _ 77

Definitions _ 79

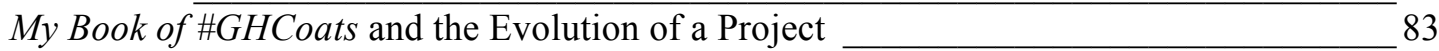

Categorizations 87

Fictional Quotes Misattributed to Famous People___ 87

Real/Modified Quotes Misattributed to a Well-Known Person___ 88

Proverbs Misattributed to a Famous Person 88

Common Ghanaian Parlance Misattributed to Famous Names ___ 89

Modified Quotes from Actual Authors __ 89

Analyzing My Book of \#GHCoats___ 90

Socio-Political Satire and \#GHCoats___ 95 
Relationship with Traditional and Modern Poetry 103

Conclusion: The Political, the Contextual, Place, and Ownership __ 106 Epilogue 108

Chapter 5 - Lost/Gained in Translation: Oware 3D and Ananse: the Origin 109 Introduction: The Ghanaian Video Game Space 109 New Global South Frontiers in Video Gaming 110 Oware 3D and Ananse: The Origin 113

The Heresy of Paraphrasing and Translating Video Games 115

The paraphrase of Oware $3 D$

The Translation of Ananse: The Origin 120

Conclusion: The Implications of "Translation" 124

Appendix

Chapter 6 - Conclusions and Further Directions 127

Why, What, and How: A Summation 127

Moving Forward and Outward: Further Research 131

Connections with Digital Humanities 134

Works Cited 


\section{Chapter 1 - Definitions}

\section{Introduction: The "Africa" Narrative and Digital Advancement}

The March 12, 2005, edition of The Economist ran a front cover under the title "The Real Digital Divide" with an accompanying image of a young Black African boy in wornout clothes and ashy skin holding a clay-like object to his ear. This object was molded into the shape of a mobile phone, and with a smile on his face, the boy appeared to be engaging in play-conversation. The conversation in the article itself concerned factors that could help bridge the so-called "digital divide," with the author touting the mobile phone as having the most potent impact on digital development, especially in the "developing world." Even though the article admitted that "the world's poorest people are already rushing to embrace mobile phones," the irony of having an African child hold an imitation of a mobile phone was visual rhetoric that reinforced stereotypes of Africans lagging behind standards related to "development," which, like "developing world" or even "third world" is itself a contested term. ${ }^{1}$ The conflation of negative stereotypes including poverty, happiness, and faux-technology has signified Africa for centuries. ${ }^{2}$ Unfortunately, the images borne out of this conflation (The Economist example is just one of many) are still commonplace even in the twenty-first century, a time when digital technology is not only familiar but also widespread across the continent.

The opportunities afforded by digital technology in Africa are multifarious, with

\footnotetext{
${ }^{1}$ In "Why is Africa Poor?" for instance, Daron Acemoglu and James A. Robinson use scanty examples to argue that technology has tended to be "backward" in Africa; for debates on development, see Development Theory: Deconstructions/Reconstructions by Jan Nederveen Pieterse; and in an interview with Forrest Colburn, the Algerian diplomat Lakhdar Brahimi criticizes the "third world" label as "disappointing" (81).

${ }^{2}$ In The Idea of Africa, V. Y. Mudimbe traces the negative depiction of Africa to the fifteenth century (39).
} 
scholarship examining areas ranging from health through education to communication, development, and governance. ${ }^{3}$ Aside from these areas, digital technology also impacts modes of creativity; however, one relatively untouched area of exploration concerns the use of this technology to create and engage with literature. The lack of attention to this unexplored area is striking due to the potential for technology to affect the production, forms, and nature of literature in Africa (and vice versa). This dissertation accordingly examines this field, which I term "African electronic literature", or "African e-lit". In doing so, this project starts from a general examination of the relationship between electronic literature and African literature, before zoning in to consider the development of electronic literature in Ghana using specific examples as a basis. Prior to assessing this relationship, however, there is a brief overview of, and reflection, on the boundaries and features that characterize the two disciplines.

\section{Background: The Space Between African Lit and E-Lit}

Consensus is hardly ever present when scholars provide interpretations for a discipline or genre in literature. It is in line with this convention that electronic literature and African literature do not have universally accepted definitions; and yet there are characteristics that make each discipline unique. ${ }^{4}$ Accordingly, this dissertation is premised on a definition of electronic literature as creative expression that requires an electronic device such as a computer, a mobile phone, or a tablet to be created, function, and to be engaged with. African literature on the other hand is understood as literary works of art that are crafted by a creative artist or creative artists of African descent. Both

\footnotetext{
${ }^{3}$ See work by Royall et al., Selwyn, Megwa, Oyedokun and Salawu, and Bowman.

${ }^{4}$ See "Rethinking and Mainstreaming African Literature in the Academia" by Naomi Shitemi and "Electronic Literature: What is It?" by Katherine Hayles respectively.
} 
definitions are neither necessarily adequate nor shorn of controversy ${ }^{5}$; however, these offerings reveal an intention to demarcate both disciplines and therefore serve more as a springboard than as a binding definition.

Beyond definitions, these two disciplines are vibrant in terms of creative production and academic scholarship. A cursory perusal of literary and scholarly databases will, for instance, reveal a plethora of titles that can be categorized under imaginative and academic writing related to either discipline. People are creating African literature and electronic literature works, and scholars are researching into them. However, underneath the veneer of significant progress lie sustained efforts in both disciplines towards recognition, if not legitimacy. These efforts have been spearheaded in response to comparisons with more established disciplines that have questioned their status within literary canons. Electronic literature scholars such as Katherine Hayles and Rita Raley for example have had to strengthen the position of electronic literature in relation to print-based literature, which enjoys a more mainstream reception. ${ }^{6}$ African literature counterparts including Abiola Irele and Chinua Achebe have similarly argued for an appreciation of African literature as different from but equally as valuable as other regional and cultural traditions like European and American literature. ${ }^{7}$ Such scholars, among many others, have succeeded in improving the image and scope of their respective disciplines.

\footnotetext{
${ }^{5}$ It is controversial, for instance, to call the French author Albert Camus's work African literature, even though he was born in Algeria. On the other hand, the work of a French born poet of Senegalese descent like David Diop is considered African literature. Again, can one call work that is created by an electronic device but then engaged with on printed paper electronic literature?

${ }^{6}$ See Hayles's "Electronic Literature: What is It?", and Rita Raley's Tactical Media.

${ }^{7}$ See Abiola Irele's The African Imagination: Literature in Africa and the Black Diaspora, for example.
} 
Despite their burgeoning reputations, African electronic literature, which would be the intersection between electronic literature and African literature, has unfortunately not been analyzed much by scholars. In regional terms, electronic literature scholarship, for instance, has a primarily Western concentration, with an appreciable level of interest in South American, and Middle Eastern varieties. ${ }^{8}$ In terms of modes of production, research into African literature on the other hand has oscillated between oral literature and print literature to the detriment of electronic varieties. Where interdisciplinary research has been done in either regard, the focus has been on the relationship between electronic literature and print literature on the one hand, or print literature and oral literature on the other hand. These comparisons hardly spill over to the space where African literature and electronic literature coalesce.

Consequently, the term African electronic literature is not yet well known, either within electronic literature or African literature circles. On a positive note, there are attempts by both sides to bridge the gap. Successive papers at the 2014 and 2015 Electronic Literature Organization conferences held in Milwaukee, USA, and Bergen, Norway, by this author have presented on African electronic literature, for instance. ${ }^{9}$ The African Studies Association and Africa Literature Association conferences have also experienced a steadily increasing level of interest in digitally produced literature since

\footnotetext{
${ }^{8}$ See for instance, Claudia Kozak's "Digital Literature and Materiality. How We Read." and "Manifestations of the Arab Spring in Literature: "Video Clip Poems" on You Tube as a Model" by Eman Younis.

9 “"'Coat and Uncoat!": The My Book of \#GHcoats Project and Implications for Conceptual Writing" was presented in June 2014 while "Sankofa, or Looking Back while Moving Forward: An African Case for E-Lit" was presented in August 2015.
} 
2010, while this author has organized the first two panels on African electronic literature at the 2016 and 2017 Modern Language Association conferences in Austin, Texas, and Philadelphia, Pennsylvania, respectively. The inchoate scholarship still lags behind the increase in the use of digital technology in Africa and by Africans for literary purposes as Olaniyan and Quayson remind us, African literary and critical production are not discrete entities but relate in a "supportive and critical, mutually affective intimacy" (1). These two scholars make this point at the beginning of the first ever published anthology of African literary criticism; this collection of scholarly voices does not talk about electronically produced work - yet their point still holds for digital works that fall outside their scope. It is therefore incumbent upon scholars to explore African electronic literature in order to speak in academic and technical terms to the creative endeavors being made. Using this proposition as a broad base, this dissertation accordingly narrows to specific examples of electronic literature and African literature in order to theorize on the relationship therein. Eventually, these theorizations will, albeit indirectly, speak to larger connections between other classifications of literature.

\section{Justification: Why African E-lit?}

Scholars classify literature regionally, geographically, temporally, ideologically, culturally, and nationally — to name a few—and each categorization is not exclusive but rather overlaps with others, thus making it difficult to use a single categorization to label a type of writing. ${ }^{10}$ Again, the value of grouping literature in one way does not supersede

\footnotetext{
${ }^{10}$ For example, the author Manu Herbstein's work tends to be classified as Ghanaian literature, partly because his subject matter and settings are Ghanaian, and he is an active member of the Ghana Association of Writers - yet, he is terms of identity, he is a white South African with Jewish heritage. Again, a novel like Americanah by Chimamanda Ngozi Adichie can be classified as women's literature, African literature, Nigerian
} 
the importance of another method of categorization; furthermore, it is self-evident that the implications of studying an issue in one classification of literature can reflect in, or at least influence, another category. This dissertation embraces two major forms of classification - modes of production through an examination of electronic literature; and cultural and regional via an employment of oral African literature. In a general sense, with regards to modes of production, literature is seen as oral based, print based, and electronic based: each technology has its own set of tools for production and engagement. While scholars explore the relationship between these three modes, majority of scholarship concerns print literature in tandem with either oral literature or electronic literature, probably due to its popularity or because it temporally exists as the middle category.

Despite having print literature positioned in a temporal milieu between oral literature and electronic literature, this dissertation seeks to embrace the implications of comparing oral literature and electronic literature to each other. This choice is deliberate, even though oral literature flourishes in Africa while electronic literature - regardless of its widespread nature - is now gaining a foothold relative to orality and print. Such a focus will not only reveal nuances embedded within both disciplines, but will also eventually respond to incorrect assumptions that oral literature lags behind other modes of production due to it being an "older" genre (Finnegan 4). While such a call for action can be interpreted in different ways, for the purposes of this dissertation, the interest lies in oral African literature and its connections with electronic literature.

In examining the relationship between electronic literature and oral African

literature, and American immigrant literature, to name a few. The terms are thus nebulous and can be easily critiqued. 
literature, this dissertation speaks to a massive dearth in existing scholarship. This examination is worthwhile, in other words, because even though the relationship that both genres have with print literature has been extensively explored to various ends, there is hardly any work done on African electronic literature. While on a temporal scale, one can argue that print literature forms a bridge between the two genres and is therefore important, it is not enough to assume that print literature is always crucial to understanding the nature of electronic and oral African literature. This is not to imply that print literature is not vital to the relationship between the two genres; nevertheless, in foregrounding electronic literature and oral literature, we better understand the ways in which the two influence each other directly. In order to further explore this space between African and electronic literature, it is important to historicize both disciplines with the added benefit of indicating the importance for African electronic literature.

\section{African Literature: A Brief Look}

Thanks to work done by scholars such as Abiola Irele and Simon Gikandi, African literature is typically categorized into oral literature - known for its performative power steeped in traditional African settings - and print literature, also termed "modern" African literature, with its print related features. Aside from other reasons, African literature has comprised these two sub-sections because of available technology; using this criterion for categorization implies a definition of literature in technological terms. Confining African literature to the two categories of oral and print suggests it lags behind contemporary technology and that the future effects of digital writing will see a new and distinct third category of literature. This phenomenon is consistent with the gradual adoption of new media technology and its associations with multimedia, social media networks, digital 
narrative, and computer gaming, among others.

From this observation one could posit that the focus of technology in African literature is shifting from oral based practices through print and analog to digital media. This argument risks the assumption that a more "advanced" form of technology replaces a so-called "archaic" one, thus eliding the more complex relationships at play. The mere fact that oral tradition, print literature, and digital technology all co-exist in the twenty first century, for instance, suggests that none is necessarily replaced by another; rather, all three relate to each other in multiple ways. Like other types of regional literature then, African literature has always been media savvy.

The media savvy that governs this relationship helps to complicate any notions of the three categories existing as a progression. Rather, the evolution of African literature is connected to the ways in which literary artists appropriate contemporary technology to creative ends. Thus, as Ruth Finnegan argues in her introduction to Oral Literature in Africa, oral literature for instance is neither primitive nor "pre technological", but rather functions as a media-technical way of dealing with a certain kind of community and space of communication (3). With this idea in mind and as digital technology complements its print and oral counterparts in Africa, rather than serve as a move "forward", the adoption of digital technology mainly extends the scope of African literature. In other words, both oral literature and modern African literature have always anticipated new media technology; their relationships are accordingly productive and revealing. In a sense then, oral African literature re-casts our understanding of digital textuality by foregrounding the strategies for handling the so-called oral/literate dimension, and - in doing so - leads to a different, more nuanced and global media savvy view of electronic literature. 
In narrowing the scope of research to elements of African orality, this dissertation therefore allows for an achievement of depth while considering a unique set of implications. This is because these elements of orality are essentially different from features that are found in other regional varieties of literature. Thus, the relationship with electronic literature as outlined in this research presents an African dimension markedly different from what would be found in a relationship with print literature, which has a long tradition in scholarship.

\section{Electronic Literature: A Brief Look}

Bringing African voices into existing conversations about electronic literature is important because of Western biases in the understanding of digital textuality, that play out in the practice of and the scholarship in electronic literature. The Electronic Literature Organization (ELO), which is the foremost gathering of academics and artists in electronic literature, for instance, has an almost exclusively white/Euro-American membership with very few members of "non-Western" descent and even fewer of African lineage. Moreover, the works produced and exhibited by the ELO in their collections, which effectively function as an electronic literature "canon," are overwhelmingly American and West European. The latest edition of the Electronic Literature Collection (Volume 3), released in February 2016, has no work from Africa - Antarctica is the only other continent without representation. While it might be a stretch to find work from Antarctica, the failure of the ELO to find work from Africa indicates the work that needs to be done to shed light on Africa's contribution to digitally produced works of creative expression.

On a theoretical level, Hayles notes that a committee convened by the ELO defined electronic literature as "works with important literary aspects that take advantage of the 
capabilities and contexts provided by the stand-alone or networked computer." ${ }^{11}$ Such a definition, while useful (due to the obvious distinguishing features that arise) is limited because most of the subsequent explications assume that external circumstances and contexts are relatively homogenized. Such assumptions thus skew the definition toward a Western understanding of electronic literature, because the capabilities and contexts of a computer could easily be seen to benefit more from a "First World" setting than a "Third World" setting. Again, this definition rests purely on form, thus lending to these formal aspects a neutral and universalizing tone, whereas in reality such issues serve to authorize a specific geographical practice.

Therefore, when thought of in an African context, the definition becomes even more inadequate, and perhaps is redeemable if we expand the notion of the computer, while foregrounding culture and difference as the drivers of electronic literature. The One Laptop Per Child program developed by Sugar Labs for instance is an example of an expanded, if not reimagined, notion of both a computer and a computer network. Functioning via the laptop's Sugar Operating System (which abandons the conventional desktop and folder icons present on the mainstream Mac and Windows Operating Systems, but rather requires users to use one program at a time), and with ventures in countries ranging from Kenya through Uruguay and Afghanistan to the United States, such programs push against any suggestion that the computer has a static identity.

It is again worth noting that electronic literature is largely informed by Internet technology, which is related very closely with the World Wide Web. On a purely semantic level, the word "World" presents a homogenous outlook. Yet "World" is tenuous on

\footnotetext{
${ }^{11}$ See Hayles's "Electronic Literature: What is It?"
} 
different levels. First, it implies that the web allows access to the world, a notion that is false because online data does not literally map out the whole world. Again, there is the impression that the whole world in turn has access to the Web, a supposition that is debunked by any set of data that talks about internet access. Third, the quality of access is not uniform, as "First World" countries experience fewer constraints as compared to "Third World" countries. Finally, the language of the World Wide Web is English. Even though English is the most widespread language in the world, it trails behind Mandarin Chinese as the world's most spoken language; this is a statistic that hints at the extra layer of difficulty that non-English speakers (or non-native speakers of English) could theoretically have in engaging with electronic devices. With such issues in mind, this project attempts to examine the state of electronic literature through an African perspective, focusing the relationship between new media and literature in the context of cultural signifiers and therefore situating itself within existing scholarship.

\section{A Preliminary Look at Scholarship}

As noted earlier, both electronic literature and African literature have enjoyed a considerable level of research. Electronic literature for instance has moved from initially staking out claims of legitimacy to currently thinking about ways to extend its scope. In her seminal article "Electronic Literature: What is It?" Hayles reviews the major milestones and sub-categories associated with electronic literature and posits that while electronic literature and print literature share significant overlaps, it is important to process the former through new methods, which might not necessarily be congruent with the latter. Other scholars like Lori Emerson and Chris Funkhouser in their respective Reading Writing Interfaces (2014) and New Directions in Digital Poetry (2012) follow Hayles's 
two major directions by examining the relationship between electronic and print media in the former, and by arguing that digital poetry provides new ways for artists to engage with audience in the latter. These arguments and more are considered in detail in the next chapter. Electronic literature scholarship has moved beyond these conceptual arguments in order to extend the scope of the discipline.

The 2015 edition of the annual ELO conference held in Norway, for instance, was themed on the "End(s) of Electronic Literature". In the call for abstracts, scholars and artists were tasked to think about "ends" in terms of form and consciousness, the ends of the physical body, performative ends, and de-centering a western construct of electronic literature with the aim of more fully accommodating a globalized notion of electronic literature. Such alternative interpretations to the thematic concerns of the conference indicate the need to explore new avenues for broadening the perspective of electronic literature. Similarly, the 2016 ELO conference organized in Victoria in Canada centered on "Next Horizons," as the conference organizers asked participants to theorize on the "investigations, interventions, and creations [that] lie beyond the horizons of born digital writing." Such strides thus make space for African electronic literature, a new frontier due to its freshness and the unique cultural perspective that it brings. Electronic literature has thus sought to extend its scope after dealing with its legitimacy in relation to print literature.

African literature has similarly moved from staking claims of legitimacy, a move that was prominent in the 1960 s and 70 s when the continent was gaining political 
independence from colonial powers. ${ }^{12}$ A pioneering example was Chinua Achebe's "An Image of Africa" (1978), written in response to reading Joseph Conrad's Heart of Darkness (1899). In the article, Achebe critiqued the racist tendency inherent in setting up an idea of "Africa" as the background for "other work" (2) and reducing Africa to the role of a prop for European adventure, thus eliminating the African "as human factor", which perpetuated the "dehumanization of Africa and Africans" (9). Decades on from such arguments, scholarship has moved toward considering Africa as a more complex site than stereotypes indicate, by talking about African agents who influence, respond to, and wield agency in terms of global economic flows and pressures, as opposed to African subjects who passively experience Western and Asian capitalist actions. ${ }^{13}$ This focus on Africa and Africans helps avoid the tendency to examine other cultures and people to the detriment of Africa. Achille Mbembe in "African Modes of Self-Writing" (2002) posits that an undue focus on colonization, along with slavery and apartheid, results in self-alienation, "the violence of falsification and material expropriation," and "historical degradation," going on to further lambast the resultant "colonization" of the discourse by "instrumentalist" and "nativist" ideological currents (241). For Mbembe, it is important to redirect from such focuses to consider Africa and African thought in fresher lights.

Even though Mbembe's position (including other academic opinions within the discipline) can extend to any genre of African literature, the bulk of the scholarship has rooted its arguments in examples of modern African literature and oral literature. Research

${ }^{12}$ As Bernth Lindfors argues in African Textualities: Pre-texts, and Contexts of African Literature (1997), African literature tends to mirror its political situation (135); as a result, scholars spoke to the themes that were prevalent in African literature.

${ }^{13}$ See the introduction of Africa Writes Back to Self: Metafiction, Gender, Sexuality (2009) by Evan Mwangi for instance. 
on African electronic literature itself is, at best, at a promising stage, and scholars tackle the state of electronic literature in Africa through various lenses. Shola Adenekan, for example, wrote a dissertation that examined the technological production of classed and sexualized bodies in cyberspace-based writing by emerging young writers from Nigeria and Kenya. Stephanie Bosch Santana also has a dissertation entitled "Ephemeral Genres, Enduring Geographies: Nationalism and Globalism in Southern African Literary Media, 1950-present," which has some analysis of new media in Southern Africa. In "Borders of Knowledge: Transnationalism and the Agenda of African Literature in a Digital Age" (2014), Adenekan further explores the ways in which African literature is being shaped using cyberspace as a medium of production. Again, a special edition of Research in African Literatures published in 2012 surveys the use of new media in reconfiguring popular culture across the African landscape. While most of this scholarship is interested in the question of logistics, the closest example of work related to this project is Meg Arenberg's "The Digital Ukumbi: New Terrains in Swahili Identity and Poetic Dialogue" (2016), which examines the relationship between Swahili poetry and Facebook.

In other words, not much has been done in terms of historicizing African electronic literature by connecting it to its oral tradition and/or print literature antecedents; this is the starting point from which this project seeks to enter conversations on African electronic literature. It must be noted, however, that the relationship between digital technology and literature has not always been lauded for its potential. In their preface to the 2013 special issue of American Literature, Tara McPherson, Patrick Jagoda, and Wendy Chun note that the terms "new media" and "American literature" hardly ever relate in the same sentence "except, of course, as opposites" (615). This observation is informed by a disjunction that 
stems from equating new media with entertainment, quick communication, and ephemeral information; and understanding literature as signifying density and lasting artistic merit. This premise is nevertheless shaky, because new media and literature can and do coalesce and complicate each other in much more intimate ways, as has been proven by the likes of Hayles, Raley, and Lori Emerson, among many others. Again, associating "new media" with the ephemeral while yoking "literature" with density elides deeper relationships that cut across this simplistic binary. Nevertheless, despite evidence to support a more complex relationship, misinterpretations run deep. When it comes to Africa, these misconceptions combine with other constraints.

For instance, there is the larger challenge of access, which is not always addressed in a satisfactory manner by stakeholders such as governments and NGOs. Gado Alzouma argues for advocating the use of digital technology in African countries in tandem with an adequate consideration of the existing social conditions in "Myths of Digital Technology in Africa: Leapfrogging Development?" (2005). Alzouma further questions the expectation that integration into the so-called "global village" will automatically deal with marginalization in Africa; history informs his skepticism. Such concerns are useful, as they contribute to framing the conversation about using digital technology in African literature.

\section{Limitations}

Research into the intersections between electronic literature and African literature has a wide range to choose from; broadly speaking, this dissertation is restricted to examples of electronic literature from a Ghanaian context. Ghana has been chosen because of familiarity of the author with the country, history, and terrain. Ghana is more crucially 
seen as a metonym for Africa, an idea that is explored in the next chapter. Furthermore, and as the subsequent analysis chapters will demonstrate, there is enough engagement with electronic literature among Ghanaians to serve as an adequate argument to augment conversations on African electronic literature. In other words, for the purposes of this research, Ghana is representational without making overreaching claims as to the nature of African electronic literature. As such, any examples of African electronic literature that are taken from other countries serve mainly to contextualize and augment Ghanaian examples. Relative to major Ghanaian literary artists such as Ayi Kwei Armah, Kofi Awoonor, Ama Ata Aidoo, and to an extent Taiye Selasi (all of whom are associated with print and/or oral literature), the artists and users under this study are largely unknown. In this light, there is similarity with directions in other literary genres such as modernist literature where "minor" writers like Djuna Barnes were given attention. ${ }^{14}$ This dissertation thus sees merit in arguments by the likes of Karin Barber's The Anthropology of Texts, Persons and Publics (2008), which is an argument that African texts with less traction - the "other Africa", as Okome and Newell put it in "Measuring Time: Karin Barber and the Study of Popular Arts in Contemporary Africa" (2012) - also deserve consideration.

The field is largely untouched. While this fact could imply that there is not much of interest for scholars to engage with, there is more crucially the counter-argument to be made that this road less traveled contains much more of value to be explored. This dissertation focuses on specific examples of electronic literature-concrete poetry, conceptual poetry, and mobile video games. These examples are chosen because of their

${ }^{14}$ See Djuna: The Life and Work of Djuna Barnes (1996) by Phillip Herring for example. 
presence in Ghana, as well as the fact that they are vastly different from each other. Again, the findings from studying them present enough material from which to make concrete conclusions about their nature. Thus, other prominent examples of electronic literature such as hypertext fiction, flash fiction, animated poetry, and computer-generated literature are not found within the scope of the study.

\section{Structure}

This chapter serves as the introduction, seeking to lay the foundation for the rest of the project by situating African electronic literature within the parent frameworks of both electronic literature and African literature. This framing leads into the next chapter, which adds a theoretical and scholarly bent to situate African electronic literature as descending from two vibrant disciplines - this positioning is supplemented by a connection between oral literature and electronic literature. Examining theories associated with orality is important because the dissertation has some focus on elements of orality in African electronic literature.

The next three chapters constitute the analysis sections of the dissertation. Chapter three for instance examines the potential of traditional Ghanaian symbols known as Adinkra symbols to contribute to concrete poetry in an electronic space. The relationship between Adinkra symbols and concrete poetry is complex; using the Sankofa symbol as the major representation allows for a sustained conversation on the influence that tradition has on the use of digital technology in African literature, and vice versa. A major aspect of oral tradition in Ghana involves Adinkra symbols, which are usually known as visual symbols that represent concepts, aphorisms, and ideas. Beyond the visual, these symbols have significant oral and aural features, and these are examined in the context of electronic 
literature.

The main Adinkra symbol to be looked at in this chapter is Sankofa, which is represented by a bird that arches its back to retrieve an object there. This action signifies a return to cultural roots in order to re-conceptualize approaches to cultural evolution. Sankofa is used in many ways both within and outside Ghana: on ceremonial and everyday clothing, as tattoos, in communicating messages, and as a symbol of connection for Africans in the Diaspora, among others. In the chapter, Sankofa is placed in conversation with mainstream concrete literature examples by Poundstone, Kiringer, Weber, and Kim Stefans. One area to explore in the resultant comparative analysis is the uniqueness of Sankofa relative to conventional concrete poetry. For example, Sankofa's connection to orality largely lies in its association with community and folklore, while these individually created works typically have individualistic notions and interpret the question of sound very differently from African perspectives on orality.

Thus, apart from touching on the history of Adinkra and Sankofa, this chapter will also provide an overview of the history of concrete poetry and the visual in electronic literature. There will furthermore be a look at the ways in which Sankofa fits into the conversation through its association with oral tradition and the African diaspora. Finally, the chapter will conclude by arguing for a different take on the interplay between images and symbols in new media environments.

Following this examination of how a traditional symbol thrives in a new media environment, the next chapter moves from individually created works in concrete poetry to social media communities, where the examples of authorship tend to be communally based. Here, the argument is that the examples of social media-based literature under 
examination involve a sense of community as well as a public that relates in ways similar to what is found in oral tradition. This connection then complicates the definitions of and interplay between author, audience, and context.

The electronic literature genre in question here is conceptual poetry, which typically consists of a plethora of work by a multitude of "authors." The chapter will use as its case study My Book of \#GHCoats, which is a humorous digital book of fictional and wrongly attributed quotes born out of a viral project spearheaded by Ghanaians on Facebook. There is a categorization of the various types of quotes, which is followed by theorization that occurs when the book is viewed as conceptual poetry. Conceptual poetry, as created through a mixture of copy/paste and remixing, is typically the result of what both scholars and artists alike term "uncreative writing." Practitioners of conceptual poetry typically focus on the finalized product, with little or no recourse to the build-up. Due to the collective and collaborative nature of this project however, this chapter posits that the origins, directions, and eventual book are all important to understanding the position of the text.

In order to embrace the whole project as an example of conceptual poetry, this chapter then performs an overview of how the project began, took off, and ended. There is also analysis of some of the constituent posts, as they are grouped into sub-divisions. Eventually, the chapter proceeds to theorize on the implications of understanding My Book of \#GHCoats as African conceptual poetry. This example not only challenges and extends existing notions of conceptual poetry as a Western genre, but also demonstrate the ways in which context, culture, and collaboration relate to the creation of literature in digital spaces. 
In addition to concrete poetry and conceptual poetry, one area of scholarship that has not received much attention in African literary scholarship is electronic gaming, despite new and exciting endeavors in the field. Thus, this chapter examines two examples of mobile video games. The two games are Kobla Nyomi's Oware $3 D$, which is the virtual descendant of the Akan traditional board game Oware; and the Leti Arts produced Ananse: The Origin, which refashions the Akan folktale trickster Kweku Ananse into a superhero. This chapter processes the two adaptations as "paraphrase" and "translation" respectively: the paraphrase from a board game to a mobile video board game on the one hand, and the translation from an oral literature-based folktale to a mobile video action/adventure game. The terms paraphrase and translation are chosen because the transitions from a traditional board game to a mobile video game are markedly different from the change from a folktale to a mobile video game. This comparative study is undertaken in the context of globalization and cultural exchange by gesturing to similar adaptations in more mainstream spaces, thus expanding on the intersections between creative license and tradition.

The concluding chapter looks back at the project and then looks forward by considering electronic literature and the digital humanities from an African perspective. After gesturing to other ways in which digital technology can be used to create African electronic literature, this chapter explores beyond the confines of electronic literature to digital humanities-type projects like Eugenio Tisselli's Sauti ya wakulima Project in Tanzania. Tisselli and his colleagues gather audiovisual evidence of farmers in Tanzania for publication on the Internet. This chapter thus examines the ways in which such a project can relate to African electronic literature, thus placing Sauti ya wakulima in 
conversation with the larger question of the digital humanities. The digital humanities issue is taken further by looking at work such as the CELL project and collaborations between universities in America, Ghana, Benin, and France to further electronic literature in and outside Africa. The dissertation ends by questioning what it means for African literature to consider electronically generated work as an equally viable and valid branch of the discipline, as well as the implications of viewing electronic literature from a more globalized perspective.

\section{Conclusion}

This initial chapter has sought to provide an outline of the scope of the rest of the dissertation. The project will benefit from theoretical framing in the next chapter, which delves into orality before examining the ways in which African electronic literature stems from its parent genres. There is therefore an interplay between theory and scholarship, with the aim of portraying the ways in which examples of electronic literature in Ghana can represent African electronic literature. 


\section{Chapter 2 - Literature Review and Theoretical Frameworks}

\section{Introduction: Ghana as a Metonym for Africa}

In Writing Ghana, Imagining Africa: Nation and African Modernity (2004), Kwaku

Larbi Korang employs Ghana as a metonym to ultimately theorize on political

relationships in colonial Africa. He investigates the contributions of political thinkers in pre-independent nineteenth and early twentieth century Ghana (then known as the Gold Coast) to modernity, on both a national and continental level. Korang's decision to substitute a continent with a country is an approach that narrows the role of the former in the context of the latter, but risks positioning this representative country as a perfect replacement for the continent. In other words, the role of Larbi's chosen nationalists could be misrepresented as necessarily replicated across the whole of Africa - such an effect is problematic primarily because of the vast differences between the many countries that constitute Africa. ${ }^{15}$ Thus, it is possible to argue that a lack of attention to other countries in such a strategy is potentially misleading with regards to the outcomes of the investigation at hand (because these findings might vary from country to country).

Yet, there is the counter-advantage in using specific examples from a relatively homogenous setting as a foundation for claims that can eventually inform an understanding of the larger unit. This strategy is even more advantageous when the small and large entities share historical and cultural similarities, and when there is a clear understanding that these findings are not meant to overstep their boundaries. Furthermore, approaching a continent through a country places emphasis on the associations between

\footnotetext{
${ }^{15}$ The website Africa is a Country (www.africasacountry.com) is a popular example of a play on this idea.
} 
the two entities, ensuring that the country remains the locus for engaging with the wider context. ${ }^{16}$ Therefore, and despite the afore-mentioned risk, such positive counterbalances attached to this metonymic tactic can ensure a relatively straightforward way of understanding both the representative and the whole. The strengths embedded in such a move thus inform the thrust of this dissertation which, despite its different setting, content, and context, adopts Korang's methodology.

Similar to Writing Ghana, this dissertation employs Ghanaian examples which eventually gesture to an African identity. Unlike Korang's work however, the focus here is not on bourgeois personalities or well-known texts; rather, the concerns revolve around examining specific examples of Ghanaian e-lit within African literature and electronic literature contexts. I analyze these examples to ultimately theorize on African e-lit as a cohesive but diverse entity. ${ }^{17}$ The choice of examples in the following analysis chapters demonstrates that while the research is largely restricted to Ghana, the outcomes relate to African e-lit on a general level. This connection is informed by the similar cultural, historical, and socio-economic situations in other African countries, as well as scholarship on African literature, whose arguments tend to cut across nations and regions in Africa. Ghanaian and African literature thus function as concentric circles with a common center

${ }^{16}$ As Geraldine Lawless points out in her introduction to Modernity's Metonyms: Figuring Time in Nineteenth-Century Spanish Stories, focusing on the associations created by metonyms does not cause the entities to lose specific meanings. Rather this focus highlights connections between the texts. Thus, the stories (in the case of this dissertation, the disciplines) "remain the principal focus, while simultaneously setting them within the broader discursive field, thus both enriching readings of the texts, and contributing to our understanding of the context in which they were both written." (xvi).

${ }^{17}$ African literature is acknowledged as multifarious, with regional, stylistic differences for instance. Yet, it is helpful to consider African literature as a body of literature, following scholarly convention. 
- both terms are thus sometimes used as complements to each other. This crucial relationship between Ghanaian and African literature allows for a significant focus on African literature in this chapter, until the dissertation narrows down to Ghana in the ensuing chapters.

Following on from the introduction and subsequent outline of the stakes on this project in the previous chapter, this current chapter seeks to construct a theoretical framework from which the analysis chapters of the dissertation will assume a structure. While this framework is inspired by Korang's outline of the relationship between Ghana and Africa, this dissertation departs from Korang by working from a foundation informed by technological and regional relationships. There is the obvious benefit in adopting Korang's general metonymic strategy, yet the analyses and surveys require different modes of engagement because the subject matter is more aesthetically inclined. Prior to this set-up however, there is a review of relevant literature that not only historicizes the project, but also eventually contextualizes the relationship between these examples of Ghanaian e-lit and the parent disciplines of African and electronic literature. This two-fold thrust of this chapter aims, then, to serve as a structural, theoretical, and scholarly bridge between the introduction and the subsequent analytical exercises through questions largely related to technology.

African electronic literature (or African e-lit) does not have much scholarship attached to the discipline - this absence is evident in both parent disciplines: African literature and electronic literature. Despite the regular use of electronic technology in creating literature in Africa, very little research in African literary scholarship has covered the work being done. Similarly, research into electronic literature scholarship lacks a 
noticeable sub-category that connects effectively with examples by African literary artists, as academic conversations gravitate toward other geographical and cultural regions. Because of the lack of research, a review of scholarship in a project like this dissertation benefits from taking a step back to broadly consider the evolution of research attached to both African literature and electronic literature. And instead of pursuing the impractical route of surveying all African literature and electronic literature scholarship, it is beneficial to narrow the area of study to the technological relationship between oral technology and print technology for African literature on the one hand, and print technology and electronic technology for electronic literature on the other hand. This focus is helpful because these technological relationships introduce African e-lit as the next logical step for both African literature and e-lit - both technologically and regionally. In using different examples of scholarship for each exercise, this next section sheds light on these relationships.

\section{African Literary Scholarship: A Technological Affair}

As noted at the beginning of this chapter, this project understands Ghanaian literature as ensconced in African literature - scholarship connected to most nationalist literature in Africa (including Kenyan, Senegalese, Nigerian, South African, and Ugandan literature) tends to acknowledge this parent relationship. In a similar vein, and as is shown subsequently, inter-national African literature research draws connections between works from different countries in order to highlight a relatively uniform idea of African literature. ${ }^{18}$ Within this uniformity lies a versatility that is broken down regionally and

\footnotetext{
${ }^{18}$ See Ato Quayson's Strategic Transformations in Nigerian Writing, for example.
} 
nationally in complex ways. ${ }^{19}$

Research has repeatedly traced the evolution of African literature; investigations into African literature work with the implied consensus that this discipline stems from a long tradition of using available media technology to create different ways of engaging with social, textual, and political concerns. ${ }^{20}$ African literature is usually categorized as oral literature and print - or "modern" - literature. Important research in the former includes Ruth Finnegan's Oral Literature in Africa (1970), which as its name suggests, surveys various genres of oral literature across the continent. This ground-breaking work shed light on performance as a vital aspect of the African creative imagination and demonstrated the fact that unlike other regional varieties of literature including British literature, American literature, or Western European literature where print literature assumes most of the scholarly attention, in African literature oral tradition presents itself as a uniquely important aspect, with heavy influence on print varieties in the discipline. Accordingly, surveys of African literature usually pay homage to the folklore, folktales, epics, proverbs, and other examples of orality that position the discipline differently from other regional varieties of literature. Oral tradition thus helps to ground this project within a level of authenticity that is not made possible by print literature. This is not to say that print literature is not important in African literature - its relationship with orality is subsequently discussed.

${ }^{19}$ Bernth Lindfors for instance draws connections between Francophone West African literature, Anglophone West African literature, South African literature, and East African literature in "Politics, Culture and Literary Form in Black Africa."

${ }^{20}$ African literary scholarship including seminal work as Bernth Lindfors's "Politics, Culture, and Literary Form" (1979) and Isidore Okpewho's African Oral Literature: Backgrounds, Character, and Continuity (1992) use examples restricted to available technology. 
One common thread of African literary research explores the relationship between oral literature and print literature. The consensus tends to point to the former as crucial to creating and understanding the latter, which became mainstream on the continent long after orality had established itself. In Proverbs, Textuality, and Nativism in African Literature (1998), Adélékè Adéèkó categorizes elements of orality in the works of print literary artists such as Oladejo Okediji, Chinua Achebe, Ayi Kwei Armah, Ngugi’ wa Thiong'o, and Femi Osofisan through classifications of what he terms "nativism", which he defines as a call for authenticity and identity. For Adéèkó, "native ways of knowing" outline a complex relationship between orality and African culture - these complexities are informed by his classifications of nativism.

For example, Adéèkó proposes "thematic" or "classical" nativism, understood as addressing "the everyday material concerns of the African reading public in readily accessible forms" (ix) and being inspired by an Africanized aesthetic theory of what he calls "use" and "relevance" (6). While this issue of use and relevance veers into politics (21), for the purposes of this dissertation it is important to note that thematic nativism allows proverbs and other examples of orality to "Africanize" contemporary African literature by rooting it in tradition. Since these forms of expression utilize traditional African worldviews and are immersed in traditional culture, they attach a "natural" sense of identity that print literature genres struggle to achieve. While this point should not necessarily imply that written varieties are less authentic, Adéèkó underlines the conventional importance of orality to the African imagination. ${ }^{21}$ Adéèkó proceeds to posit

\footnotetext{
${ }^{21}$ See Culture, Tradition and Society in the West African Novel by Emmanuel Obiechina and Eileen Julien's African Novels and the Question of Orality, for further explanation of the importance of orality to African literature.
} 
that the moral and didactic function of such literature is enmeshed in its structure, and suggests that proverbs deploy rhetorical structures that should function both as text and inter-text. For Adéèkó, African literature addresses routine material concerns of African audiences in readily accessible forms; highlighting the role of oral literature is therefore an effective way of preempting opposition to its validity.

Another thread of nativism, which Adéèkó terms "structuralist" or "speculative," is rooted in "conventions and philosophies of representation derived from recognizably indigenous practices" (ix) and "proposes idealistic interpretations of the formal dimensions of "traditional" theater, fiction, and poetry upon which contemporary practices out to be based" (6). This category further underlines the influence of oral tradition on print forms, but in a formal sense. Like classical nativism, Adéèkó's interpretation of this connection is admittedly idealistic, but still lends credence to the linkages between the formal dimensions of oral tradition and its print relatives. Using print literature by Armah (Two Thousand Seasons) and Achebe (in Arrow of God) as basis, the major point Adéèkó makes here is that tradition is meant to have a positive relationship with modernity; in this sense, modern African literature derives its sources, conventions, and philosophies of representation from recognizably indigenous practices. In Two Thousand Seasons for instance, Armah highlights an indebtedness to oral tradition through Akan oral folklore that traces an evolution from Ancient Egypt through the ancient Ghana empire to modernday Ghana. It is a writing style which hearkens to traditional forms of Akan folktale storytelling through Armah's heavy employment of repetition, imagery, the call-and- 
response strategy as well as his use of what Kofi Anyidoho calls the "collective hero.",22 These stylistic choices reinforce the significance of community and multiplicity over the (isolated) individual. In using the novel form (usually considered an individualized genre) to privilege multiplicity, Armah complicates the relationship between print and oral technology in nuanced ways that work against simplistic binaries that would position the novel as always individual and oral tradition as always multiple. The connections between oral tradition and print literature are explored further by other scholars.

Another major contemporary explication of the relationship between oral tradition forms and print literature is Abiola Irele's The African Imagination: Literature in Africa and the Black Diaspora (2001), which situates orality as important to the larger evolution of African literature. Irele contextualizes his argument by underlining the importance of approaching African literature not as "literature" but as "imagination." After all, the label "African literature" has a "particular ambiguity of reference" in its usage (5). This reorientation thus circumvents pedantic criticism that denies orality as literature (because it is not written), while simultaneously providing oral tradition equal legitimacy with written alternatives because, regardless of structure, both types of literature communicate a structure of feeling, utilize aesthetic technologies, and serve as a vehicle for ideas features of imagination (and by extension, literature). Irele thus manages to acknowledge oral and print literature as simultaneously unique and interconnected. Through his analysis of print literature such as Amadou Hampata Ba's Fortunes of Wangrin, Irele finds a masterful formalization of the mediation between traditional African forms and Western

\footnotetext{
${ }^{22}$ See Anyidoho's "Literature and African Identity: The Example of Ayi Kwei Armah."
} (43) 
narrative conventions. This mediation is stylistically reflected in the protagonist's ability to deceive both the African chiefs and the colonial administrators. Similar to Adéèkó, Irele also examines Achebe's Arrow of God and suggests in his analysis that processes of subject formation and subjectivity open an example of the African consciousness to the possibility of transcendence as well as to the historical chance of collectivity. In this regard, he also underlines the strong connections between oral tradition and written literature. Ultimately, Irele's analysis is premised on the logic that the formidable nature of written African literature is informed by its debt to its foundation in oral tradition.

These two examples of research are but representative of multiple works of African literary scholarship that demonstrate the vibrant relationship between orality and print literature by consistently gesturing to the importance of examining traces of orality in modern or print African literature. And if oral literature and print literature transition into and from each other in complex ways as suggested by these scholars, then the relationship between African literature and modes of production lay the foundation for further research into the influence of orality in digital literature. This is because, print literature became popular on the continent when print technology became pervasive from the middle of the twentieth century onward. ${ }^{23}$ As literary artists then adopted and appropriated this technology to enhance the nature of African literature, they allowed oral tradition to inspire their work. In a similar vein, then, digital technology allows literary artists to widen the scope of African literature; its use will also be influenced by oral tradition.

\footnotetext{
${ }^{23}$ The fact that print literature became widespread on the continent prior to the wave of political independence in the 1950s and 60s is not to imply that Africa does not have a tradition of writing. In "Africa and Writing" for example, Alain Ricard points out that Africa has a long history of writing (14), even though the examples he provides are scattered and include "illiterate writing" (9).
} 
However, it is also important to understand that Africa approaches digital technology differently from other regions like Europe, North America, and Asia due to socio-economic and logistical differences. Melinda B. Robins and Robert L. Hilliard suggest in their introduction to the collection Beyond Boundaries: Cyberspace in Africa that most African governments grapple with fundamental needs like healthcare and access to basic amenities, and thus would not be positioned to apportion resources to widen access to digital technology for purposes such as literature. While this concern is both valid and rooted in the notion that poverty exists in Africa, it also wrongly assumes that African governments and citizens cannot focus on "advanced" needs; more crucially, it is flawed to suggest that digital technology cannot be used to solve (or at least address) the major problems facing African countries. There is the need for a more nuanced approach to development issues in Africa. Admittedly timing of this collection - 2001 - makes it dated; similar to Irele's gesture to technology then, Robins and Hilliard can therefore only anticipate the diverse directions that electronic technology in Africa would later take. For instance, there is not much in the collection about mobile technology, which is currently popular across the continent; neither does the scope of research extend beyond capital cities and other urban centers. Again, internet access has dramatically increased since 2000 in places like Kenya, Nigeria, Ghana, Botswana, and South Africa ${ }^{24}$ - a trip in September 2016 by Mark Zuckerberg, the CEO of Facebook to the first two countries, brought to the attention of the Western mainstream media the exciting digital projects

\footnotetext{
${ }^{24}$ In 2004, the International Telecommunication Union named Africa as the fastest growing market for mobile technology; and according to Internet World Stats, Internet usage grew in Kenya (from $0.7 \%$ in 2000 to $69.6 \%$ in 2015 ); in Nigeria (from $0.1 \%$ in 2000 to $51.1 \%$ in 2015 ); in Ghana (from $0.2 \%$ in 2000 to $19.6 \%$ in 2015); Botswana (from $0.3 \%$ in 2000 to $28.4 \%$ in 2015); and in South Africa (from 5.5\% in 2000 to $52 \%$ in 2016)
} 
being undertaken. Improving access and narrowing the so-called "digital divide" allows for the unearthing of massive potential. Still, underneath the potential lies teething problems that need to be addressed.

In "Myths of Digital Technology in Africa: Leapfrogging Development?," Gado Alzouma considers the excitement behind the strides from various stakeholders in African ICT development (339-342), but then acknowledges that logistical and socio-economic challenges shape access in different ways. Alzouma critiques the tendency to reduce the question of access to digital technology to the number of computers and telephone lines in a country (344), and rather foregrounds social context concerns that arise when adopting ICT in Africa. This issue is important because governments and companies across Africa tend to adopt ICT technology without considering possible negative implications on existing social conditions, including geographical and gendered disparities (343-44). Furthermore, content is usually generated from Western sources, leading to the fear that Africans could be "passive 'receptors' and 'consumers' in the chain of information" (344). Importing technology without critically considering the ways in which the target environment can shape the technology can alienate the very people that the technology is meant to serve.

Using Niger as his area of focus, Alzouma thus argues that even though governments and multi-national companies tend to adopt digital technology to influence social conditions, the technology should also be shaped by existing contexts. Alzouma points out the fact that women, less affluent people, and people in rural areas tend to face formidable obstacles in accessing digital technology (347). Reorienting the use of ICT in African countries by catering to these drawbacks in terms of gender, class, and regional 
issues does not necessarily mean that ICT is a negative endeavor. Accordingly, Alzouma implies that digital technology must work closely with existing modes of knowledge, prominent among which tends to be knowledge passed down through oral tradition.

This need to understand different forms of literacy recalls Stuart Selber's Multiliteracies for a Digital Age (2004), which advises teachers on how to facilitate computer literacy programs that not only are effective, but also consider other forms of literacy that are "subject to local conditions" (183). Context is important in this sense, as the strategy for one setting might not necessarily work in another setting - hence multiliteracy is needed. Multiliteracy, for Selber, involves technical, pedagogical, circular, departmental, and institutional requirements (184-88). Selber further connects the "impoverished" nature of computer literacy with "its parameters ... defined and understood primarily in technical terms or in terms that are dictated by the private sector" (22). ${ }^{25}$ The capitalistic nature of the private sector tends to commercialize interventions into digital technology to the detriment of more sustainable practices. In response to this threat, a more symbiotic, rather than parasitic relationship between digital devices and orality in African spaces indicates that both technologies will benefit from each other.

If African interaction with digital technology acknowledges these contextual and environmental factors, then the integration of African literature with digital forms of creative expression will not necessarily be shorn of shortcomings, but will lead to a more effective transition into the field of African electronic literature. This argument is not to

${ }^{25}$ In 2016 for example, Liberia outsourced reform in their education sectors to Bridge Academy, a private US-based firm. There was criticism from different quarters, including the United Nations in the article "UN Rights Expert Urges Liberia Not to Hand Public Education over to a Private Company." 
imply that digital technology is now being introduced to the continent, and this dissertation does not focus on assessing the adoption of digital technology, but rather uses such information as a contextual basis for the research. I therefore depart from this area to proceed to examine the issue of technology from a regional angle by considering the evolution of electronic literary scholarship in terms of recognition, value, and development.

\section{Electronic Literary Scholarship: Technological Relationships in Western Contexts}

There is virtually no scholarship on African electronic literary production, a situation that means this dissertation follows the strategy from the previous section of this chapter to look back at examples of established research in electronic literature criticism (primarily from Western regions and cultural contexts) that can tie in with this project. Similar to what was found in investigating African literary criticism, a significant portion of electronic literature research also has a technological bent, as scholars acknowledge the relationship between electronic and print literature, sometimes as a way of establishing credibility or contextualizing the field. These scholars also work against a perceived condescending perspective, which is coupled with flawed approaches to analysis, on the part of some proponents of print literature with regards to electronic literature (as addressed by Katherine Hayles in "Electronic Literature: What is It?”). E-lit scholars including Katherine Hayles, Markku Eskelinnen, and Lori Emerson, rather than counterattack or break away, seek to negotiate a middle ground of synthesis, where the two fields can coalesce in positive ways. One can accordingly argue that while there has been a struggle to avoid critique based on outmoded print aesthetics, these scholars and more have embraced this struggle in order to find positive directions connected to the problem 
and thence productively engage with it. In decoupling from a print aesthetic that downplays the relevance of electronic literature then, these scholars demonstrate the ways in which print and electronic literature collaborate by updating the tools of critique. These updated tools, which consider genres of both print and electronic literature, then position electronic literature as a field of endeavor that can simultaneously work in tandem with print literature and stand on its own, an outcome that has positive implications for this dissertation, not least because the argument about technology facilitates an examination of the relationship between orality and digital technology.

In How We Think: Digital Media and Contemporary Technogenesis, Katherine Hayles works with the notion that people have always thought and engaged with technology. Irrespective of whether the technology in question is oral, print, or digital, the general mode of engagement does not differ greatly. Thus, similar to the earlier argument about African literature being technological, transitions from print to digital technology need not be problematic; the underlining focus should be on the nature and implications of these new ways of utilizing media as cultures evolve and discover newer forms of technology. The difference for Hayles between the adoption of print and digital technologies largely stems from the types of networks that were prevalent for the former versus what is present for the latter. Understanding the nuances of different epochs is key to promoting the uniqueness and importance of digital technology in creative contexts.

While there is the potential to not adapt well to newer forms of technology, Hayles is confident because history has consistently proven human beings to be capable of keeping pace with change. While she acknowledges criticism that digital technology has influenced the ways in which people think (hence the title), Hayles does not agree that the 
influence is generally negative. The physical, cognitive, and pedagogical changes concomitant with this change reflect technogenesis, a concept that postulates that both humans and technics evolve contemporaneously. The concept of technogenesis is important because for Hayles, new forms of technology are replacing (print) forms, and yet the structures to adequately cater for these digital forms are not yet thorough enough to speak to the complexities of digital technology. Therefore, the presence of the novel forms should lead to commensurate levels of critique. This need is crucial.

Hayles notes that the engagement with digital material is steadily increasing in the humanities $(14,60)$. Therefore, there is the need to embrace the ramifications of this shift by exploring examples of digital literacy, which involves practical competence, skills, and knowledge of digital devices. As such, she is interested in the practices that stem from the implications of this change such as "hyper-reading", a reader-directed and computer assisted practice which includes Google searches, hyperlinking, and skimming (61) these are very different from print literacies which tend to privilege close reading and other traditional forms of engagement with text (12). Hayles opines that such examples of digital literacies, rather than replace print literacies, seek to complement them and indicate the ways in which newer generations of people differ from older ones in their construction, perception, and treatment of knowledge. In this way, digital reading will no longer be pushed to the margins (60). Regardless of the standards of a print aesthetic which is the dominant aesthetic, Hayles argues that it is important to acknowledge the role that digital media plays. After all, it would be difficult to harness the potential of digital literacy if we examine its examples through outmoded standards. This point is important for the fourth chapter of this dissertation, which considers the nature of African conceptual 
poetry: a genre that forces the reader to not read a text in its entirety, and thus responds to some issues that occur with digital literacies, including the tendency for people tend to retain information less and less.

Another benefit of reviewing Hayles stems from the way in which she deals with the question concerning decoupling electronic literature from a print-biased aesthetic. When faced with the controversy over whether the digital humanities should become a separate field from traditional humanities, her response is to theorize on a new branch of academic inquiry labeled as "Comparative Media Studies": a discipline that would homogenize both disciplines. As Hayles argues, the adoption of a Comparative Media Studies program would be adequately placed to create a "rubric" from which both printbased and digital humanities scholars can "explore synergies between print and digital media" (6). The space for exploration does not elide the differences between print and digital media. With this proposal, the outmoded standards that are associated with print media, rather than be abandoned, can evolve to acknowledge the importance of the past while exploiting the present (and maybe even anticipate the future). In a sense, this move could be paradoxical because on the surface it would probably be advisable to create an independent set of standards to regulate electronic literature. However, in seeking middle ground, Hayles succeeds in enriching the two disciplines because their existing connections means that they can then speak more directly to each other through a shared framework. The synergy created from this synthesis speaks to this dissertation because the subsequent genres that have a print history can then be implicitly seen as extensions of their print antecedents, rather than as new genres. 
Because her focus is on print and digital technologies, Hayles does not delve into orality beyond gesturing to the fact that Comparative Media Studies covers the relationship between oral and literate cultures (7). This direction reinforces the suggestion that Western literary history does not privilege its oral tradition forms as much as African literature does, and Hayles's oral/literate binary is itself problematic due to the assumption that oral cultures are not literate. Despite this flaw, it is still important to think about the implications of considering orality under the larger umbrella of Comparative Media Studies. If "the Digital Humanities are not a monolithic field but rather a collection of dynamic evolving practices" (10), then there is space for a more nuanced understanding of orality as not necessarily a binary to print, but as yet another form of technology that can speak to strides being made under the Digital Humanities discipline. This space is what this dissertation aims to explore in the next three chapters.

In the meantime, even though Hayles advocates an environment of positive influence between print and digital literature, there are other ways of looking at the issue that involve downplaying the importance of print - not to render print literature obsolete, but to enhance digital practice as a legitimate field. An example of this argument occurs in Cybertext Poetics: The Critical Landscape of New Media Literary Theory, as Markku Eskelinen uses the shortcomings of print standards in dealing with digital literature to stake a claim for an evolved form of analysis that acknowledges digital literature as a formidable discipline. Eskelinen rightly argues that the expansion of literary genres afforded by the advent of electronic technology means that there is now an almost infinite number of new works and new text types that can no longer be accounted for within the framework of print-based literary analysis. Eskelinen's discussion of digital texts, 
including electronic games - the focus of a chapter in this dissertation - buttresses this point, as using traditional print aesthetics risks missing out on features in electronic games that are absent in print literature.

While Eskelinen is harsher in his consideration of print literature, he does gravitate toward Hayles in his solution, which is not to split print aesthetics from electronic literature, but to regulate them with standardized aesthetics. For Eskelinen, both print and electronic texts - which he terms "cybertexts" - should be studied with the help of expanded conceptual and analytical devices, and throughout Cybertext Poetics, he demonstrates the importance of this underlining approach. Since cybertexts require an active intervention by a user or reader, they are both similar to and different from print texts (and even oral texts); it is this starting point of similarity that the shared framework can be built upon. Finally, while not central to this dissertation, it is helpful to observe Eskelinen's practical use of traditional evaluative criteria of print literature in an updated sense, as is the case with Gerard Genette's seminal narratology theory. Eskelinen warns against losing Genette's original focus on the regulation of information, due to its "strong ties to media positions and media-specific ways" of engaging with narrative and nonnarrative information (174). Ultimately, Eskelinen uses a theory-heavy approach to understanding the relationship between print and digital media. Similar to Hayles, Eskelinen does not cover orality; however, it is still possible to extrapolate his findings onto oral tradition.

In Reading Writing Surfaces: From the Digital to the Bookbound, Lori Emerson complements Hayles and Eskelinen in a practical manner by demonstrating the pervasiveness of technology in literature through an examination of poetry. As her title 
suggests, her methodological approach is unique in temporal terms as well, as she analyzes the implications of interfaces on text engagement backward (from current to earlier times). This anachronistic approach, rather than suggest haphazardness, undercuts the chronological privileging that would imply that some texts are more advanced than others. Emerson finds that irrespective of time period, media, or context, poets have worked with and against interfaces to undermine the assumed transparency of conventional reading and writing practices. While Emerson focuses on Western texts, her argument is important for the next chapter, which looks at the implications of considering symbols of oral tradition via an electronic interface.

One of the mistakes that proponents of electronic literature risk making is characterizing print technology as obsolete. For Emerson however, making the interface "user-friendly" causes users to not understand, appreciate, or know the inner workings of a device. Emerson accordingly shows one way in which the past can inform the future. Emerson employs different the work of different poets including Emily Dickinson, whose poetry is important to the study because twenty-first century readers tend to access her poetry without recourse to the role that fascicles played in creating the poetry. Emerson posits that the fascicles worked as an interface to challenge the assumed coherence of print literature while repositioning the nature of both reading and writing. Such arguments imply, then, that applying a previous critique based on print aesthetics to electronic literature is outmoded and therefore needs to be overhauled moving forward; African electronic literature can learn from these precedents in many ways. 


\section{African E-Lit Scholarship: Beginnings}

It would be unfair to unduly criticize the research by scholars into African literary criticism and electronic literary criticism for their failure to acknowledge African e-lit mainly because their temporal, technological, regional, and theoretical viewpoints did not allow them to embrace how far technology and region could take their disciplines. With the benefit of hindsight as well as current directions, this dissertation thus attempts to consider this space. Rather than copy and paste the successes (and even failures) spelled out in existing scholarship, I attempt a contextual reframing of the various landmarks that will ultimately allow for an "African" appropriation of electronic literature to thrive in an "organic" environment. In this manner, African literature can conversely influence Western/Non-African electronic literature. After all, inter-cultural exchange involves exactly that: exchange, as no stakeholder is afforded undue value to the detriment of another.

The gap in research rendered by mainstream conversations in African literature and e-lit scholarship thus require interventions to address this gap; there have been inchoate steps in this regard. An intervention of note comes from Shola Adenekan who considers the role of the internet in the proliferation of creative writers in Kenya and Nigeria. In "Transnationalism and the Agenda of African Literature in a Digital Age", Adenekan argues that while the internet shapes the nature of writing for this new generation of writers, the writings of these literary artists also present a unique contribution to the digital landscape. Even though Adenekan's work considers aesthetic value in poetry from emerging Kenyan and Nigerian poets, he gravitates toward the question of logistics as he posits that digital technology removes the publishing barriers 
that African literary artists faced in the past. Leading to implications for audience and context, Adenekan's research sheds light on the ways in which digital technology influences traditionally print genres in African countries. This dissertation moves Adenekan's argument further by not only considering more centrally the evolution of different genres electronic spaces; there is also an evaluation of the relationship between electronic and oral tradition forms of African literature. After all, the scholarship reviewed argues for an examination of literary relationships from a technological perspective.

\section{Logistics, Orality, and the Digital}

Features of electronic literature such as the multi-layered nature of some of its genres, as well as the ability of electronically generated texts to have endless repetitions, resonate with oral tradition, not least because the performative nature of oral tradition leads to endless variations of the same template tale (this point is further explored in the next chapter of the dissertation). Therefore, the findings of a comparative study between the two disciplines would not only enrich our understanding of both disciplines, but also speak to the position of print literature as looking back to oral tradition while simultaneously looking forward to electronic literature. It must be noted at this juncture that examining digital texts in tandem with orality does not have to take a temporal route, where emphasis is placed on the marked disparity in the two technologies with regards to how dated/modern they are. Even though orality appeared long before electronic literature, the two disciplines are examined in a side-by-side approach in order to place focus on the aesthetic qualities, rather than the difference in time periods.

This dissertation accordingly gestures to Lori Emerson's employment of the term "media archaeology" (49-50), where the present is not necessarily the inevitable 
consequence of the past, but is rather just one direction that the heterogeneous past could have taken. At the heart of media archeology is the quest to avoid "ossifying into a set of inflexible methodologies" (88). The flexibility afforded by such an approach allows different theories and texts to be yoked together in the subsequent chapters. Avoiding the implications of a simplistic paradigm as Emerson does recalls an earlier argument in the previous chapter that oral literature, print literature, and electronic literature do not function in a temporal continuum; rather, such an idea situates all the genres in a complex conversation, which will have the added benefit of ascribing neutral values while gleaning as much capital from the comparisons as possible. Issues of temporality are crucial to understanding the relationship between orality and electronic literature due to existing conditions including access.

We thus return to the question of access, an important question because compared to other places, Africa does not generally enjoy ready access to stable/fast electricity, internet, and state-of-the-art computers/mobile phones. ${ }^{26}$ Such a set of challenges, usually processed as an outright liability (and cause for labeling the continent as "underdeveloped" or "undeveloped") can be redefined as utile, because majority of users are forced to consider the interface of their machines more closely than a typical French or South Korean user who might not necessarily think about slow/unavailable internet or an outdated digital device. Such a possibility again recalls Emerson, especially in an insightful chapter where she examines poets from the early 1960s to the mid-1970s

\footnotetext{
${ }^{26}$ According to data from the World Bank (taken from Global Economy), in 2012 while countries such as USA, Bahamas, New Zealand, Germany, and South Korea enjoyed $100 \%$ access to electricity, African countries including Ghana (64.06\%), Senegal (56.50\%), Nigeria (55.6\%), and Kenya (23\%) lagged behind.
} 
century who deliberately foregrounded the noise of the typewriter as a way of focusing attention on the interface (87-128). Moreover, there is a gesture to Eskelinen's argument about ergodic literature, where he quotes Espen Aarseth's argument that a user undertakes "non-trivial" work, rather than interpretation, to "traverse" a text (43). In some instances in Africa where the "noise" of the computer is an inevitable part of internet usage, such an organic alternative can lead to enriched readings of engagement with digital texts. This point is important in the fifth chapter, where the lack of development in the gaming sector in Ghana influenced the making of the two video games under study.

The dissertation additionally benefits from Hayles's argument about a direct correlation between the environment and the development of both the individual and society in How We Think. Hearkening to the classic nature/nurture debate, she demonstrates the importance of social environments to the ways in which people approach contemporary technology (124). These contentions are made in relation to Hayles's understanding of the American environment; as an example of the "developed" world her notions are thus markedly different from developments on the African continent. With this in mind, examining the implications of the successes of scholarship as discussed in this chapter in a more diverse environment - as will be demonstrated in the analysis chapters will not only challenge, but also extend the findings made by Hayles, Emerson, and Eskelinen.

In analyzing these associations, it is imperative to keep in mind Walter Ong's argument in Orality and Literacy: The Technologizing of the World that oral literature in contemporary times does not exist in a vacuum, but relates synchronically with print literature and electronic literature. This thought is important to avoid the notion that these 
different forms of literature necessarily replace each other. These technologies co-exist and share similarities that have allowed the scholars mentioned previously to theorize on their connections. Even though oral literature, print literature, and electronic literature are all legitimate forms of creative expression, a significant (and maybe undue) emphasis is placed on print literature. Both oral literature and electronic literature therefore operate from a position of relative obscurity, in that they contend with having the bulk of attention on print literature - this level of attention typically creates negative implications for approaching the other two forms of literature.

One of the fallouts from this unbalanced reception involves using print terminology to address concerns in electronic literature. In "Print is Flat, Code is Deep: The Importance of Media-Specific Analysis," Hayles connects “unrecognized assumptions specific to print" to differences in media, locating one of these assumptions in the screen. The "temptation" to think of the text on a screen as "essentially identical" to the text on a printed page is, according to her, "seductive" because of the powerful sense of imitation that the computer possesses (71). As an alternative, Hayles advocates a "careful consideration of what difference the medium makes" in any form of analysis (68). The equivalents between print literature and electronic literature should not imply that they are identical despite the advances in digital technology (based on print): their separate media make them different in a fundamental sense. Such an argument can and should necessarily spread to oral literature as well. Scholars appreciate these differences as they theorize on their similarities.

Hayles recalls observations on Roland Barthes by Jay David Bolter and George Landow that print and electronic literature share distinct commonalities such as 
"dispersion, multiple ownership, and rhizomatic structure" which gesture to hypertext features (68) ${ }^{27}$ Some of these arguments appear tenuous especially with regards to print literature. Daniel Gervais argues in "Spiritual but not Intellectual? The Protection of Sacred Intangible Traditional Knowledge" that in terms of print literature, joint authorship is "generally inapplicable because rarely would the entire community qualify as the author of a unique, "versioned" derivative copyrighted work, because joint authorship requires collaboration on the work and an intent to merge the contributions of each author into "inseparable or interdependent parts of a unitary whole" (482). Even though the role of a publisher, typist, editor, etc., could mean that print works require multiple "authors," such a case expands the definition of author beyond its traditional confines. Likewise, an argument for the rhizome demands detailed examination of the print work at hand in order to validate these claims - especially if one considers the classic theory of the rhizome as postulated by Deleuze and Guattari. ${ }^{28}$ All three characteristics are explicitly present in oral literature. Concentrating on multiple ownership reveals that most oral literature has no known author; a community, society, or even larger ethnic group tends to lay claim to the ownership of a folktale, symbol, performance, or any genre of oral literature. ${ }^{29}$ These shared characteristics help to explain why oral literature transitions relatively smoothly

\footnotetext{
${ }^{27}$ Dispersion is referred to by Landow as one of two types of structures: the first is "closely reliant upon that of the linear book", while dispersion is realized through the "multiply centered network organization inherent in electronic linking" (9). Multiple ownership on the other hand simply refers to the possibility of texts having more than one author, while the rhizomatic structure theory was developed by Deleuze and Guattari in $A$ Thousand Plateaus, and "connects any point to any other point, and its traits are not necessarily linked to traits of the same nature" (21).

${ }^{28}$ See $A$ Thousand Plateaus: Capitalism and Schizophrenia by Deleuze and Guattari.

${ }^{29}$ See Boatema Boateng's The Copyright Thing Doesn't Work here: Adinkra and Kente Cloth and Intellectual Property in Ghana (35) for instance.
} 
into "literate" cultures.

One of the best-known theorists on these transitions is Marshall McLuhan, who argues in the seminal Understanding Media: The Extensions of Man that the emergence of electronic devices presents tremendous changes in the relationship between human beings and technology. McLuhan's assertions are from the 1960s but still hold value, especially in contemporary times when devices such as the smartphone have revolutionized social interaction. McLuhan's other bold claim was the concept of the "global village", a term which has become mainstream and implies a theoretical shrinking of distances between cultures, nations, and communities. Even though the claim ignores the inherent political, social, and cultural hegemonies at play in this relationship, the importance of contemporary technology to the evolution of communication underscores the need to theorize on the transitions between orality and its print and electronic counterparts.

As Friedrich Kittler notes in his introduction to Gramophone, Film, Typewriter, media “determine our situation" (xxxix). Kittler's work is similarly dated like McLuhan's, but he also anticipated the effects of electronic technology on culture (49, for instance). Even though it is obvious how digital technology has influenced various aspects of life, it is important to keep in mind Ong's admission that understanding the ways in which oral and print cultures illuminate each other is not a simple task (2). If this task is complex despite the mainstream nature of print culture, then substituting orality for print technology can lead to a more arduous task but nevertheless produce illuminating outcomes for the relationship between these two forms of technology. Such outcomes can in turn extend to yet other forms of creative expression, with oral literature being the prominent beneficiary of this direction. 
In How to Read an Oral Poem, John Miles Foley argues that non-electronic media deserves some of the attention that is given to print and electronic media, and rightly so, because of the precious insights that can be gained from a comparative analysis (23). Oral tradition cannot be reduced to a monolith, as various cultures utilize and experience this form of expression in different ways, Foley posits (26). Even though Foley's arguments are consciously limited to oral poetry, they can easily translate into other forms of oral tradition due to the various shared features - as such, it is important to work with oral literature. Accordingly, this dissertation seeks to break new ground by looking at various examples of texts that connect oral literature with electronic literature.

\section{Conclusion}

In its attempt to lay the conceptual and scholarly framework for the rest of the dissertation, this chapter has reviewed academic research that looks at technological relationships in literature in two different disciplines: first in African literature through the influence of oral tradition on print literature; and then in electronic literature through the transitions between print literature and electronic literature. These choices were deliberate responses to the lack of research into African electronic literature, and were intended to demonstrate the ways in which African electronic literature is anticipated by scholarship both in a technological and regional manner through the focus of scholars into areas other than African electronic literature. With this work now covered, the dissertation proceeds to analyze genres of African e-lit.

The next three chapters are analysis chapters that first theorize on the potential of symbols of oral tradition to function as literature when placed in digital environments in the context of concrete poetry; examine conceptual poetry through the context of social 
media; and then consider mobile video games as creative renditions of oral literature. It is hoped that the outcomes of this chapter inform the subsequent analysis so as to consistently demonstrate the manner in which these genres of African e-lit stand on their own as unique genres while simultaneously dovetailing with established examples of e-lit. 


\section{Chapter 3 - Looking Back while Moving Forward: The Case of Concrete Poetry and}

\section{Sankofa ${ }^{30}$}

\section{Introduction}

The previous chapter's importance to the dissertation rested in its ability to lay the conceptual and scholarly foundations for the subsequent exploration of distinct forms of African electronic literature. This current chapter transitions from the framework established by starting a trio of analyses chapters that together explore various intersections between e-lit and African literature; each chapter uses Ghana as the focal point. In this chapter, the focus is on concrete poetry and the sub-branch of oral literature that deals with traditional African symbols. ${ }^{31}$ Concrete poetry and these symbols share overlapping concerns with shape and form, a connection that informs the starting point of the comparative and contextual analysis. From the resultant findings, it is important to consider the implications - for both African literature and e-lit - of examining oral literature symbols in the context of concrete poetry, while acknowledging the general importance of shape and form to literary aesthetics in general, and poetry in particular. Before any such issues are addressed however, the next section attempts to engage with concrete poetry, with stress on its unique properties, as suggested by its emphasis on shape.

\footnotetext{
${ }^{30}$ This chapter is adapted from "Looking Back while Moving Forward: The Case of Concrete Poetry and Sankofa," which appeared in a special issue of Hyperrhiz and published in 2017.

${ }^{31}$ The term "oral" in oral literature is a misnomer because it implies that oral literature genres are produced via the mouth. In fact, the genres range from symbols through dances to folktales. The inadequacy of the term oral has led scholars including Pio Zimuru to label the discipline as "orature" (qtd. in Jackson 5). Due to the focus of this dissertation, the debates around the label are not examined.
} 


\section{Conceptual Poetry, Shape, and Context}

The general association between poetry and its shape has long been debated by scholars and audiences as well as by poets themselves, who interrogate this relationship not only via poetics, but especially through their creative process. ${ }^{32}$ Conscious experimentation with shape boasts a long history in the Western tradition for instance, with diverse examples stretching back to such Classical Greek poems as "Egg" by Simias of Rodes and "Pan Pipes" by Theocritus, through George Herbert's $17^{\text {th }}$ century poetry which includes "The Temple" and "Easter Wings", to E. E. Cummings's work in the $20^{\text {th }}$ century and Calligrammes: Poems of Peace and War by Guillaume Apolinaire. Such examples of poems that foreground shape are predecessors to (as well as illustrative of) concrete poetry, a genre that is created when the arrangement of words in a written poem is intended to shift attention from the constitutive words to the general form and shape. ${ }^{33}$ This genre of poetry is unique among other poetic genres like the epic, ballad, sonnet, or haiku in the sense that for concrete poetry while the words that make up the poem might carry some amount of relevance and meaning, the larger shape tends to capture most of the focus. Visual rhetoric thus plays an important role in analysis, and informs various definitions of the genre.

The Encyclopcedia Britannica (2013), for instance, describes concrete poetry as “poetry in which the poet's intent is conveyed by graphic patterns of letters, words, or symbols rather than by the meaning of words in conventional arrangement." In this

\footnotetext{
32 Poets who postulate their theory through poetics range from William Wordsworth through Kofi Awoonor to T.S. Eliot; none of which, however, is the focus of this chapter. ${ }^{33}$ Concrete poetry has expanded from this initial definition, as will be shown in this chapter.
} 
definition, the relationship between the letters, words, and/or symbols does not necessarily lie in say, syntax - as is the case in other more mainstream poetic genres -rather, the creative impulses behind the concrete poet's choices lead to an examination of the resultant shape, which garners the bulk of attention; the visual is thereby favored over semantics. Johanna Drucker in The Princeton Encyclopedia of Poetry and Poetics (2012) on the other hand, situates concrete poetry in a "distinct approach" where form and meaning "would be as close to each other as possible ... [suggesting] a unification of the word with its presentation" (294). While enhancing the intimacy between making form and meaning implies a reluctance to separate the constituent parts from the whole (and thus suggests an organic entity while sharply contrasting with the preceding definition), the offerings from both encyclopedias share an emphasis on text, shape, and the visual as well as related sensory features - in making meaning out of a concrete poem. The relationship between form and content therefore leads to different ways of approaching and understanding works of concrete poetry.

The strong link between constitutive words and shape in concrete poetry has enabled the genre to evolve and broaden its scope, even coalescing its borders with similar genres. Foregrounding shape and form, for instance, allows for intimate comparisons with visual poetry, which is the focus of Willard Bohn's Reading Visual Poetry. ${ }^{34}$ Bohn defines visual poetry as "poetry that is meant to be seen ... Words no longer serve as simple notational devices but as building blocks in a visual edifice" (13). Rather than simply (or necessarily) represent information, the words are primarily components of a larger shape,

\footnotetext{
${ }^{34}$ In this book, Bohn includes a chapter entitled "Brazilian Concrete Poetry" and by this mere act strengthens sensory associations as he examines concrete poetry in tandem with the visual.
} 
and thus function in such a way as to point to its importance. As a result, the constitutive words typically do not "make sense"; thus, like concrete poetry, it appears more worthwhile to pay attention to form. ${ }^{35}$ Even though scholars like Michael Davidson use concrete poetry and visual poetry interchangeably as he does in Ghostlier Demarcations: Modern Poetry and the Material Word (15), it must be noted that other researchers including Drucker emphasize differences between the two terms. While her temporal criteria for categorizing these two genres ties in with a specific (or even narrow) set of what Brian J. McAllister in "Narrative in Concrete/Concrete in Narrative" calls "formal concerns" (249), these issues deflect from the core purposes of this chapter. ${ }^{36}$ Thus it is safe to note that the similarities between concrete poetry and visual poetry have led to a wider definition of creative work that can relate to poetry that foregrounds the visual in such a manner.

Such broad designations are due in no small part to the work of poets related to this category. Major concrete and visual poets include the Brazilian brothers Augusto and Haroldo de Campos (of the group Noigandres), the Spaniards Rafael Casinos-Asséns and Guillermo de Torre (known as the Spanish Ultraists), the Italian Ignazio Scurto (a proponent of futurist aeropoetry), the American Mary Ellen Solt, the Swiss-Bolivian Eugen Gomringer, and his mentor Max Bill, all of whom in the twentieth century experimented with this relationship between form and poetry to sometimes extreme ends.

\footnotetext{
${ }^{35}$ Brian McAllister posits that visual poetry blurs formal boundaries between the poetic and the visual, and the organization of the text can matter even more than the semantic content (234).

${ }^{36}$ It must still be noted that McAllister contends that visual poetry blurs formal boundaries between the poetic and the visual, and like concrete poetry, the organization of the text can matter even more than the semantic content (234).
} 
While all of these epochs and poets have been anthologized and researched, missing from these conversations are examples from Africa, a situation which is not so much oversight as it is reality: the usual anthology of African poetry is often restricted to examples from oral literature as well as contemporary print poetry. ${ }^{37}$ Apart from the South African Willem Boshoff, there are no major African (or for that matter, Ghanaian) concrete poets. And yet the visual aspect of traditional symbols in Africa share similarities with concrete poetry. With this in mind, oral literature can provide a starting point from which this relationship can be explored, especially since these traditional symbols can influence and be influenced by concrete poetry, as will be shown shortly. The importance of engaging with the potential in this relationship has at least a two-fold impact - in relation to practitioners of concrete poetry who do not cover the relationship between African literature and concrete poetry; and with regards to African poetry theorists who have not yet acknowledged the importance of concrete poetry to African literature. The immediate implications of achieving these aims will be to improve conventional understanding of concrete poetry while underscoring the versatility of African oral literature.

Extending this relationship within the context of electronic literature helps to complicate these different fields, and it is important to keep in mind that this extension does not stem from an incompatible or improbable association; after all, concrete poetry

\footnotetext{
${ }^{37}$ Even aside from collections of different types of African literature that cut across drama, prose, and poetry, poetry-specific anthologies like The Penguin Book of Modern African Poetry and New African Poetry: An Anthology for instance tend to not so much overlook concrete poetry as to not even mention concrete poetry in passing, a dearth that underlines the absence of the genre within African poetry scholarly and non-scholarly conversations.
} 
and electronic literature share a rich history of affiliation. ${ }^{38}$ In New Directions in Digital Poetry Chris Funkhouser contextualizes the relationship between concrete poetry and digital poetry, recollecting an Augusto de Campos reference in an interview to Oswald de Andrade's contention that cultural imperatives such as anthropophagy influenced the evolution of digital poetry (228). ${ }^{39}$ The role of anthropophagy in this case is metaphorical and philosophical, highlighting the cross-cultural relationships that characterized not only digital poetry and concrete poetry, but also the rise of concrete poetry in Latin America due to Western influence. After all, consuming - or cannibalizing, as it were - European high culture would feed the hunger of the poets who were interested in new directions of creativity. De Campos reveals in this same interview that as a result of influence from Ezra Pound, Cummings, and James Joyce, Brazilian concrete poetry "valuated ever more the semantic dimension" while being minimalist and radical: the feeding off another culture is reflected in multiple ways, including through stylistic terms.

The cultural relationships here concern Latin American and Western culture, but are relevant to any conversation related to the cross-cultural influence of literature and its implications. ${ }^{40}$ This chapter accordingly extends the conversation to Ghana, but apart from

\footnotetext{
${ }^{38}$ Willard Bohn traces the evolution of concrete poetry from print to electronic media, and posits further that the availability of different types of electronic media has encouraged poets to redefine art and poetry in revolutionary ways (141). Similarly, in Prehistoric Digital Poetry Chris Funkhouser identifies concrete poetry as one of the major influences on electronic literature (9-11)

${ }^{39}$ According to Funkhouser, both concrete poets and digital poets approach anthropography through processing and redefining the "language of 'original' writings"; via direct incorporation of external elements (such as multiple languages, images and symbols); and in the "mechanical presentation" of the resultant work (230).

${ }^{40}$ Artistic influence between Africa and Europe is well documented, including Pablo Picasso's imitation of traditional African forms, as shown in "Picasso, Africa, and the Schemata of Difference" by Simon Gikandi; and the influence of modernists such as
} 
the difference in terms of geography and culture, any examination of the potential of a symbol of African oral literature to influence concrete poetry and vice versa has to keep in mind the thought that while the Latin American poets created works individually, features of oral literature such as the sense of the collective (both in terms of an anonymous author and nebulous audience) can propose a unique set of findings - after all, the lack of an identified author means that even though a rendition of the symbol in question can be examined, a story associated with this symbol will not have a stable version. Thus, the subsequent examination is not done to copy previous examples of inter-cultural exchange, while in order to address the presence of oral literature features, the perception of the symbol starts with but eventually departs from conventional modes of receiving concrete poetry.

In the introduction to her dissertation entitled "Concrete Poetry in Canada and Quebec, 1963-1975”, Caroline Ann Bayard recalls that "Concrete poetry was defined by its theoreticians and creators as sensuous objects meant to be perceived rather than composed to attract the spectators' attention to its component parts" (1). While the sensuous aspect of the concrete poem cannot be stressed enough, the choice to focus on perception rather than composition privileges the result over the process in interpreting the work in question. And yet the component parts can be equally, if not even more, valuable in approaching a work of concrete poetry. This point is important because the constituent parts of the work suggest an emphasis on the performative, which in turn recalls oral literature, where performance becomes the main driver of directing and interpreting the

James Joyce on Wole Soyinka (seen in Biodun Jeyifo's Wole Soyinka: Politics, Poetics, and Postcolonialism) 
event. ${ }^{41}$ In other words, form and content can and should interchange more meaningfully during an enactment or reading of the work under consideration.

With these thoughts in mind, the specific direction for this chapter relates to the use of Adinkra symbols from Ghanaian oral literature to theorize on concrete poetry. The Sankofa symbol is used to represent the potential of Adinkra to ultimately influence the evolution of concrete poetry within an electronic space. In order to arrive at this point, the following section historicizes Adinkra and Sankofa and considers the latter in the context of concrete poetry. The fact that Adinkra and Sankofa in particular are already associated with literature makes for a more straightforward analysis, and is seen below.

\section{Adinkra and Sankofa: A Brief History}

The Akan ethnic group that populates the coast of West Africa, mainly concentrated between present-day eastern Ivory Coast and western to central Ghana is said to own the Adinkra symbols. ${ }^{42}$ Like most examples of oral literature (which typically do not have an identified author - and are therefore "communally" owned), it is unclear when Adinkra symbols were created; they are however at least a couple of centuries old. ${ }^{43}$ These symbols can represent concepts, proverbs, or general philosophies of life, and were initially the preserve of traditional rulers, who used them to signify their power and position of honor (Boateng 3). Today, their use is more widespread and democratic: Adinkra symbols are prominent on clothing, as company logos, in advertising, and on earthenware material; they are again carved on stools and other such items for both public

\footnotetext{
${ }^{41}$ Ruth Finnegan explains this point in Oral Literature in Africa (373-375).

${ }^{42}$ For more contextual information, see Alfred K. Quarcoo's The Language of Adinkra Symbols.

${ }^{43}$ While Claudia Owusu-Sampah opines that Adinkra symbols were created in the $19^{\text {th }}$ century (6), Quarcoo traces Adinkra as far back as to the early 1700 s.
} 
events and in domestic settings and are used by people from all walks of life. They are used in both traditional and modern contexts, and are increasingly being found in electronic media. While traditionally they have fixed meanings, their proliferation in diverse ways means that they are used with intentions that vary from their original denotations.

In contemporary times, the various meanings attached to these symbols may or may not be explicitly referred to by the user or wearer. In other words, while a person might wear a specific symbol to deliver a message or feeling (such as love, success, sorrow, or determination), or to be even worn on particular occasions including traditional festivals and funerals, another person might just have the symbol on a piece of clothing for cosmetic or aesthetic purposes. Popular Adinkra symbols include Gye Nyame (translated to mean "Except God" - representing the supernatural), Adinkrahene (translated as "King of the Adinkra" representing power and authority), Akoma (translated as "The Heart", representing emotions), and Sankofa (representing a return). ${ }^{44}$ Even though these symbols are used idiosyncratically, their connection to their original meanings are evident for anyone who knows how to "read" them, as is the case with Sankofa.

Sankofa is literally translated as "Go back and take it" and connects closely with the Akan proverb: "se wo were fi a, wo san ko fa a yenkyi" (To wit, "it is not wrong to return to take something if you forget it"). ${ }^{45}$ Unlike most Adinkra symbols that have one

\footnotetext{
44 The Website http://adinkra.org/ has a comprehensive list of Adinkra symbols.

${ }^{45}$ In The Language of Adinkra Symbols, Alfred Quarcoo explains further that the symbol is a constant reminder of the need to learn from or "pick up the gems" from the past, since not all parts of the past are shameful; indeed, the future may be profitably built on these gems of the past, which "must be picked up from behind and carried forward on the march" (17).
} 
designated symbol, Sankofa has two major variations. The first is the original, which was created with the other Adinkra symbols and is in the shape of the popular image of a heart, but with pairs of curves at the top and bottom (See Figure 1). The second variation is the Sankofa bird, which is itself represented in different ways: with or without an egg on its back (See Figure 2 and Figure 3 respectively). Regardless of the presence or absence of this object, the bird has an elongated neck that arches backward to its back. It picks the egg on its back if this object is present; if it is absent, the bird's neck still remains in the same position.

This bird is the protagonist in an oral folktale that is common among the Akan. The story concerns the Sankofa bird, who leaves her village without informing anyone (an action that is considered disrespectful of norms) and promptly gets lost in a nearby forest. While wandering through the forest, she meets another bird who insults her. This confrontation births self-doubt in her. She then manages to find her way back to her village where her community helps rebuild her self-confidence after which she returns to the forest again, this time informing the elders of the village. She meets this other bird again, but this time overcomes its antagonism due to a renewed sense of self-worth ostensibly gained from embracing the communal spirit of her village. Her first attempt to leave her village is seen as disregarding communal custom and tradition, and after her exploits in the forest are made public, a statue is carved with her neck turned backward so as to warn others of the dangers of forgetting or abandoning their roots (both in terms of disregarding custom as well as leaving home surreptitiously). The bird as the second variation of Sankofa allows for wider interpretation because of the story attached to it. Thus, even though the original Adinkra symbol has a fixed physical representation, the 
Sankofa bird is rendered differently by various artists: it is sketched in diverse colors and sizes, and can face different directions (as can be gleaned from the different renditions of the bird in Figure 2 and Figure 3).

There is a strong connection between Adinkra and storytelling, as the folktale demonstrates. It should be noted that consistent with (but not necessarily related to) this idea of different renditions, as an example of oral literature, the above story is simply a "template story" from which alternative narratives have been (and can be) told at any given time: there are numerous variations of this same story that tend to change details, characters, and plot structure. The type of bird with whom the heroine has the two verbal exchanges might change, or even be represented by a different predator from story to story. Again, (usually minor) events can switch places in narration - after the first encounter, the bird might stay in the forest overnight or return the same day; alternatively, the bird might live with human beings or other animals, or both, in the village. Another feature worth noting is musical performance, as song and dance intersperse with the plot of the story at different times. These aesthetic features tend to embellish, complicate, or enhance the story. Finally, the relationship between the storyteller and the audience is nebulous because any member of the audience can assume the role of storyteller during narration: there are countless examples of narration in oral literature, where an audience member interjects and appropriates narration, switching roles with the narrator (who promptly joins the audience).$^{46}$ Due to the strong connections to storytelling, performance,

\footnotetext{
${ }^{46}$ In African Philosophy: An Overview and a Critique of the Philosophical Significance of African Oral Literature, Victor Ahamefule Anoka further explains the relationship between the audience, narrator, and narrative situation (36, 40-41).
} 
and audience, all of which are prominent in oral literature, Sankofa as a symbol roots itself in literary contexts.

The original Sankofa symbol and the different adaptations of the Sankofa bird are designations of the same idea of a return. Thus like a typical signifier, the relationship between the sign and the referent can be arbitrary or even tenuous. But in her dissertation entitled Adinkra, Claudia Owusu-Sampah makes a distinction between signs and symbols. She opines that unlike signs, which usually stand for a tangible idea, symbols typically represent something less palpable than the representation itself. In the case of Sankofa, the overriding use of the curve to represent the notion of a return is a helpful way of complicating this arbitrariness, because the idea of "going back" can easily be physically represented by a curve. Still, the representation of something more abstract than the symbol allows Sankofa a wider room for interpretation and usage. ${ }^{47}$

\section{Sankofa, Concrete Poetry (and Visual Poetry)}

Beyond grounding Sankofa in oral literature, the foregrounding of abstraction (through the meaning of "return," as linked with the different Sankofa designations) allows the textuality of Sankofa to relate closely with concrete poetry. And with concrete poetry evolving in terms of reach and meaning, it is helpful to think about this symbol in relation to the genre. Even though any Adinkra symbol could be used for this exercise, Sankofa is chosen because of its iconic nature, strong roots in oral literature, and versatility in terms of global appeal. With all of this in mind, this section grapples with

\footnotetext{
${ }^{47}$ Karin Barber notes in "Text and Performance in Africa" that attaching verbal expressions to material objects, as is the case in Adinkra symbols, testifies to the "impulse to generate verbal formulations that pass over space and time by means of an objective correlative; thus, such objects "transcend time, to fix or trap text in a material form" (327).
} 
three connected questions: how can we see Sankofa as an example of concrete poetry; what does it mean for both oral literature and concrete poetry if we analyze Sankofa as concrete poetry; and how does Sankofa eventually relate to examples of concrete poetry in electronic literature? Examining the various designations of Sankofa can help answer these questions, even though it is helpful to note that prior knowledge (or lack of it) heavily influences a reading of the text.

Similar to Bayard's claim, despite the potential that results from the relationship between performance and interpretation in concrete poetry, the audience is more inclined to see connections between the constituent text and the larger work, rather than isolate the component parts in order to make meaning. This inclination explains the logic behind Roland Barthes's comparison of linguistics with concrete poetry; Bohn notes in American Poets and Poetry: From the Colonial Era to the Present that in doing so, Barthes remarks that just as the sentence is the largest unit within the scope of linguistic enquiry, the word functions as both the fundamental building block as well as an independent entity in concrete poetry (119). As it were, if linguistics stops at the sentence, then concrete poetry stops at the word.

This logic holds for conventional examples of concrete poetry such as Augusto de Campos's "Caracol” (written in 1960 and translated as "Snail”) and latter electronic-based examples like "Basic Con" or "Grammar" (both by William Poundstone and coming from his "Four Poems" collection of 2000), all three of which reveal explicit authorial attention to an intricate interplay between constitutive words and shape. After all, de Campos was a co-author of the "Pilot Plan for Concrete Poetry", which outlines the following: 
Concrete Poetry aims at the least common multiple of language. Hence its tendency to nounising and verbification. "The concrete wherewithal of speech" (Sapir). Hence its affinities with the so-called isolating languages (Chinese): “The less outward grammar the Chinese language possesses, the more inner grammar inherent in it" (Humboldt via Cassirer). Chinese offers an example of pure relational syntax, based exclusively on word order (see Fenollosa, Sapir and Cassirer).

Concrete poetry does not easily allow regular syntactic and semantic analyses, as is the case with other more well-known genres of poetry. On a surface level, analyses of these conventional genres tend to be achieved through traditional close readings, which risk reinforcing linear understandings of language ${ }^{48}$ One of the appeals of concrete poetry is therefore a relatively non-conformist mode of literary appreciation. Connections to isolating "Non-Western" languages such as Chinese are also clear because the relative lack of morpheme development means that inflections (and other such word-class influencing affixes) play a minimal role in understanding. Forcing a different form of analysis thus opens up space for novel ways of engaging with poetry.

Sankofa on the other hand requires an even more nuanced analysis, not least because it does not fall neatly into a language category. The features of Adinkra in general make it difficult to compartmentalize Sankofa as a language. Even though the Oxford English Dictionary's definition of language as a "system of spoken or written communication ... typically consisting of words used within a regular grammatical and syntactic structure" means it is a stretch to consider Adinkra symbols as conventional

\footnotetext{
${ }^{48}$ Arguments by the likes of Franco Moretti have undercut an emphasis on close reading.
} 
language, Sankofa is still "language" or at least a "text", in the sense that it achieves communication. It must be noted that in "The Emergence of Sankofa Practice in the United States," Christel N. Temple makes the striking but valid claim that naming elements of the Adinkra system as "symbols" or "designs" is "seemingly innocent" but "incorrect," becoming another example of "European-inspired oversimplification of African culture" (130). She thus posits "communicators" as an alternative. While the intention behind describing Adinkra elements as communicators is laudable - in that they then express "timeless values and philosophies" (130), one could also argue that regardless of how "shallow" a symbol might be, its designation also achieves the same aims of communication; and depending on its definition, it can achieve the same goals as a "communicator". Temple's argument, then, could benefit from the word "symbol" embracing the meanings that she attributes to "communicator."

Even though the case against using "symbol" for Sankofa is viable, it relates more closely to the larger struggle of parsing indigenous African thought forms in a foreign language, as K. A. Myles points out in the introduction to a Ghanaian poetry collection (qtd. in Temple 130). While European modes of communication straitjacket the understanding of such traditional African terms (as is the general case in translation), on the other hand this situation highlights the shortcomings of a Western mode of communication in adequately catering for the strength of a traditional African term, throwing into sharp relief the uniqueness and agency of Adinkra. ${ }^{49}$ Thus, whether "symbol," "design," or "communicator" is used as a designation, the shared properties of

${ }^{49}$ This argument hearkens to the tradition made prominent in Chinua Achebe's Things Fall Apart, where many Igbo words remain untranslated because there are no English equivalents. 
language overlap with Sankofa. It is safe, then, to say that without the inherent grammatical properties of a word, meaning for the original Sankofa symbol is more concentrated on the image, which is a "word" in oral literature (due to the fact that the image conveys a coherent and cohesive message). Concentration on the image allows for visual analysis, as is attempted below.

The notion of return is seen (or at least meant to be seen), as mentioned previously, primarily in the curves. Scrutiny of the original Adinkra symbol reveals six curves presented in three pairs: two on the outer edges of the symbol, two within the space created by the outer curves (both pairs are at the top), and the final two at the bottom, curving outward. The constituents of each pair mirror each other and thereby imply symmetry, balance, and uniformity, not just in terms of the visual, but also with respect to the ensuing message. This notion of balance is supported by the appearance of a "stand" at the bottom of the image, which completes the symbol by providing a foundation. Due to the plethora of curves, one thus gets the impression that there is a consistent message that is then told in different ways. The uniformity in diversity is accordingly enhanced by repetition. Having three complementary pairs, or six curves, suggests an anxiety of disburdening the message of a return (recalling Quarcoo's note about the constant reminder) - as is the case with having curves repeated at the top, within, and at the bottom of the image. All of these choices underline the necessity with which one must return to history in order to move forward. Furthermore, the fact that the symbol is not a perfect circle tells its viewer that the return is neither straightforward nor meant to be a return for the simple sake of a return. Going back to glean the positives of the past is intended to enrich progress into the future. 
While being an example of oral literature means that the Sankofa symbol is in many ways diametrically opposed to written text, there are also avenues for complementing this other mode of communication. One should keep in mind for instance that even though the symbol connects with oral literature, it is a physical entity; and as such is in a sense, a "printed" or "written" text. Of course, the symbol does not refer to a specific aspect of history; still, the fact that it calls for the both reverence of and thorough engagement with history complicates any binaries between written and spoken modes of communication because it presently refers to all kinds of history, whether written, spoken, or performed.

Considering the fact that this symbol was created at a time when oral tradition was not yet complemented by written language in present-day Ghana, the importance of returning to history speaks to the importance of understanding customs, traditions, and norms that prevailed in traditional Akan societies. After all, and on a very basic level, oral tradition does not enjoy the relative stability of the written word; in other words, the spoken word is ephemeral, making it difficult, if not impossible, to achieve the same rendition of any given topic as is the case of written history. Repeating and re-repeating the Sankofa curves thus highlights a culture's awareness of the fleeting nature of the spoken word; the community is accordingly careful to mitigate the negative implications of this ephemerality. In present times, the general call for an engagement with history obviously includes written history, and as such the relationship between oral literature and print literature in the context of this symbol adds yet another layer of understanding. There is another set of meanings that come with the bird. 
The Sankofa bird leads to even wider possibilities, if examined as concrete poetry, due to it being a symbol from a narrative. Narrative is an aspect of concrete poetry that is not usually taken into consideration during analysis of concrete poetry, McAllister notes. McAllister traces this tendency to practitioners of concrete poetry such as Gomringer, the de Campos brothers, and Carlo Bellolo, all of whom explicitly disown the presence or utility of narrative in their work. McAllister still manages to undercut poetic intention in his article, going to great lengths to point out the elements of narrative in various examples of concrete poetry. The examples he uses typically have words from which he perseveres in establishing his version of close reading; yet he admits that "it would be hard to make a case" for a "strongly narrative text" in the examples he employs (243). In the case of Sankofa, the absence of conventional words suggests a different form of analysis in order to embrace the presence of narrative.

Bohn contends that the textual relationship embedded in concrete poetry creates the ability to translate ideas into visual images ("Concrete Poetry" 119); by extension, the relationship between idea and image with respect to Sankofa foregrounds the importance of the symbol as text. On the surface, then, Adinkra symbols and concrete poetry again share a relationship due to the issue of typography. Sankofa became part of Akan culture before written literacy was introduced into the Ghanaian socio-cultural fabric. It can therefore be argued that the symbol comprises the background story, which helps shape the reading of the text. The bird's association with narrative means that even before the symbol is analyzed as narrative, narrative is already always present, allowing for thematic and stylistic appreciation. Further focus on the associated story then, can allow for an enrichment of animal studies (by discussing the implications of anthropomorphism - as 
the bird and people interact on a level field in the folktale); gender studies (by examining the gender relations, roles, and expectations - since the protagonist is female and the villain is male); and narrative studies (through the intricate plot structuring and restructuring); among other sub-disciplines of literature. As such conversations risk veering from the purpose of this chapter, the next step here is to consider the Sankofa bird.

When analysis is concentrated exclusively on the image, the presence or absence of the egg on the bird's back leads to different interpretations. In Akan tradition, the egg signifies the delicateness of power, recalling an Akan proverb that is translated as "Power is as fragile as an egg; those who hold it too tightly and those who hold it loosely risk breaking it." ${ }^{50}$ The sacredness of eggs in traditional Akan custom informs their use in important rituals during events such as festivals. Moreover, boiled eggs are usually eaten to mark important milestones in a person's life. ${ }^{51}$ Positioning the egg as the bird's target therefore underlines the importance of history as a powerful and influential construct: in basic terms, history becomes power. The one who controls history is therefore in a strong position to benefit from power relations.

In addition to contextual knowledge, there are other possible interpretations. In literal terms for instance, the egg represents offspring from the bird; as such, the bird could be reaching out to its child in order to teach it, protect it, or just be nearer to it. In this case, the inter-generational relationship comes to the fore, as the image points out the

\footnotetext{
${ }^{50}$ In Cloth as Metaphor: (Re)reading the Adinkra Cloth Symbols of the Akan of Ghana, Kojo Arthur identifies three different Adinkra symbols that signify this proverb $(38,76$, 154)

${ }^{51}$ Thomas Kyei provides more examples and context in Marriage and Divorce among the Asante: a Study Undertaken in the Course of the Ashanti Social Survey (1945).
} 
importance of reaching out to younger people in order to steer them on the right path. Representing the younger generation as unborn also underlines their lack of knowledge, unawareness, and fragility and reinforces the importance of reaching out to them before other competing influences negatively affect them. Without the egg on the back of the bird, the importance of arching backward still highlights the necessity to return. Not having an object in mind implies that returning to the past is not only intended for issues of societal importance; accessing the banal can also yield positives in moving forward.

In representing a thought or maxim, the Sankofa symbol connects with its audience by complicating the interplay between the image and the message it conveys (or is supposed to convey). Similar to mainstream examples of concrete poetry, Sankofa condenses information in order to interrogate the relationship between constituent parts and the whole. While the association between Sankofa and its conceptualization implies a limited set of possible meanings, when viewed in the context of concrete poetry these meanings explode the boundary while interrogating the notions of concrete poetry. Placing Sankofa in conversation with examples of electronic concrete poetry by Poundstone and Brian Kim Stefans allows us to explore the uniqueness of Sankofa. For example, Sankofa's connection to orality largely lies in its inherent story and association with community and folklore, while these individually created works typically interpret the issue of sound very differently from African perspectives on orality. In other words, the aural aspect of the signifier is intricately woven into its orality; this unique feature helps us to think more about the ways in which sound and image coalesce, even in a multimedia space. 
R. P. Draper's view of concrete poetry as the creation of verbal artifacts that exploit possibilities of sound and space (329), in this light, would consider Sankofa in ways different from modes associated with oral literature. As Walter Ong points out in Orality and Literacy, written texts all have to be related somehow, directly or indirectly, to the world of sound, the natural habitat of language, to yield their meanings (8). Symbols like Sankofa on the other hand include another aural layer in terms of the contextual story, which provides another complex layer of grounding. Irrespective of whether the Sankofa symbol is the original or the bird, the story therefore performs the role of the contextual signifier. With this in mind, a prominent Western example of concrete poetry such as "The Dreamlife of Letters" by Brian Kim Stefans is rooted in an episteme or paradigm of thinking that favors visual logic. The visual, while also important in the case of Sankofa, is heavily complemented by oral tradition.

As mentioned before, the relationship between oral literature and electronic literature is not one that has yet been explored. Still, shared features such as the relationship between performance, interface, and audience allow the two genres enough commonality. The versatility of Sankofa is also seen in other spaces; one of such spaces is geo-political, and its ability to cut across borders in this sense primes it as an entry point for electronic literature into African creative endeavor.

\section{Sankofa as an International Signifier}

There is a story from 1991 of an excavation of a building during which a cemetery for both freed and enslaved African Americans was discovered in Manhattan, New York. Out of the 419 remains that were found and examined, one particular coffin caught the attention of officials due to a design that the New York Times called "an enigmatic, heart- 
shaped design. ${ }^{.52}$ Upon further investigations, it was suggested and later generally agreed that the emblem was Sankofa. ${ }^{53}$ Internationally Sankofa is probably the most widely known of the Adinkra symbols, with its popularity undoubtedly tied to the significance imbued in it by members of the African diaspora who, according to Ann Reed in "Diaspora Tourism: The Heritage of Slavery in Ghana" employ it as a connection to Africa as their motherland (528). Aside from this early example, there are more contemporary uses of Sankofa, one of the most famous being the singer Janet Jackson, who has a Sankofa tattoo on her wrist. Furthermore, there are many commercial enterprises, museums, tours to Africa from America, and films and books that use the name Sankofa. The symbol is thus marketed to Africans of the diaspora as artificial memory since the past is physically inaccessible. Temple notes that in most African Diasporic communities, Sankofa has a formal legacy in relation to forming a unique identity (128). The constructed-ness of this artifact does not necessarily undermine authenticity among Diasporic Africans, especially due to the unique tragedy of the TransAtlantic Slave Trade.

While this connection stresses temporal, emotional and political concerns, other adaptations of Sankofa range from tattoos through jewelry, attire and other products. One cannot expect every single use of Sankofa to necessarily partake in the notion of a return. Like any other fashion trend that goes viral, interpretation will move in multiple and

\footnotetext{
${ }^{52}$ See the New York Times article "Coffin's Emblem Defies Certainty” for further information.

${ }^{53}$ Even though the historian Erik R. Seeman expressed doubt as to the legitimacy of the claim in "Reassessing the "Sankofa Symbol" in New York's African Burial Ground", the likes of Kwaku Ofori-Ansa and Cheryl Laroche and Michael Blakey have sought to validate the symbol as indeed Sankofa.
} 
sometimes competing directions. There is a threat posed for instance by Chinese artisans who mass-produce cheap and affordable imitations of Adinkra products (Boateng 2011). Despite the negative implications of mass-production, Sankofa as a visual symbol is thus not restricted to people of African descent but rather circulates as a commodity, available everywhere and fetishized as a result. And it is from this context that practitioners of electronic literature can appropriate such symbols to creative ends, whether familiar or not.

\section{Conclusion}

This chapter has attempted to read a symbol in oral literature as an example of concrete poetry, inspired by the notion that the poetic effect of a work arises from the interplay between page and text space. McAllister argues that this interaction prioritizes gaps in poetry, focusing on meaning through a negotiation of these gaps (236). This argument is radically extended in this chapter, as the poetic effect of the Adinkra symbol is seen in physical and oral terms. The iconicity of Sankofa is thereby informed by familiarity and context, even though these factors are not binding in how the symbol can be interpreted.

When Michael Herzfeld defines iconicity as the principle of signification that is derived from semblance (28), he grounds the importance of a signifier in the issue of familiarity. This linkage is vital because social connections within any given field of communication are established on a set of agreed upon codes and conventions. These connections therefore appear "natural" and are thus "effective in creating self-evidence" Herzfeld notes (27). An implicit understanding of the use and value of these signs, in other words, informs an engagement with icons. One must keep in mind that interpretation of 
these signs is relative and therefore dependent on a set of complex situations. Irrespective of how culturally embedded these codes and conventions are, the lack of an inherency gestures to arbitrariness. Signifiers are unstable entities that shift meaning due to prevailing conditions and contexts. The derivation from semblance, then, should make space for semblance as defined by interplay between the members of the communicative field in context.

Both Adinkra and concrete poetry can influence each other in the context of new media while keeping in mind the implications of contemporary and historical geo-political concerns. The politics of memory and ownership with regards to Adinkra is not only an international issue due to the actions of some Chinese entrepreneurs. Historically, Adinkra has been claimed by different ethnic groups in Ghana - the Ewe who live predominantly in the east of Ghana as well as parts of Togo and Benin have claimed ownership (Boateng 117). The Asante who are conventionally accepted as the owners, according to their own oral tradition seized the technology behind fashioning the symbols from a subjugated leader of a neighboring kingdom. On the literary side, Adinkra expands its set of meanings when viewed as concrete poetry especially in relation to the ways in which its traditional uses have evolved to include a plethora of usages. The "loss of the sacred" thus leads to novel ways of understanding these symbols.

One disadvantage of a writing culture is that it presumes a circulation and loss of memory of a culture that does not emphasize literal writing. As an icon that generates both narrative and memory, Sankofa complicates context through a simultaneous loss and repetition of the same context. Adinkra symbols in this sense present a useful avenue for thinking about new media because of their iconic nature coupled with the tendency to be 
hung up on text. Rather than think about symbols, in other words, there is the risk of privileging text. In working against this notion, Adinkra gives us a better approach to thinking about the visual aspects of electronic literature rather than textual approaches even though they start from the iconic.

While this chapter has focused on the potential of oral literature to relate more strongly with an aspect of electronic literature, the next chapter works with an example of African electronic literature to theorize on conceptual poetry.

\section{Appendix}

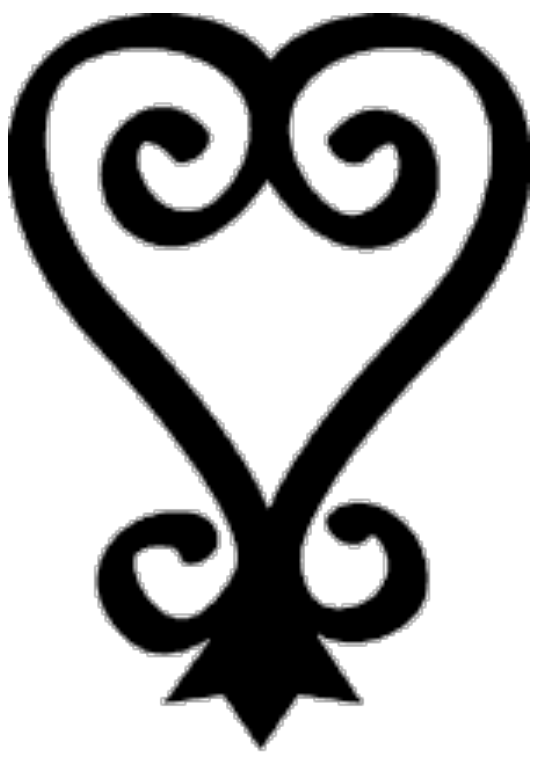

Figure 1: Original Sankofa Symbol 


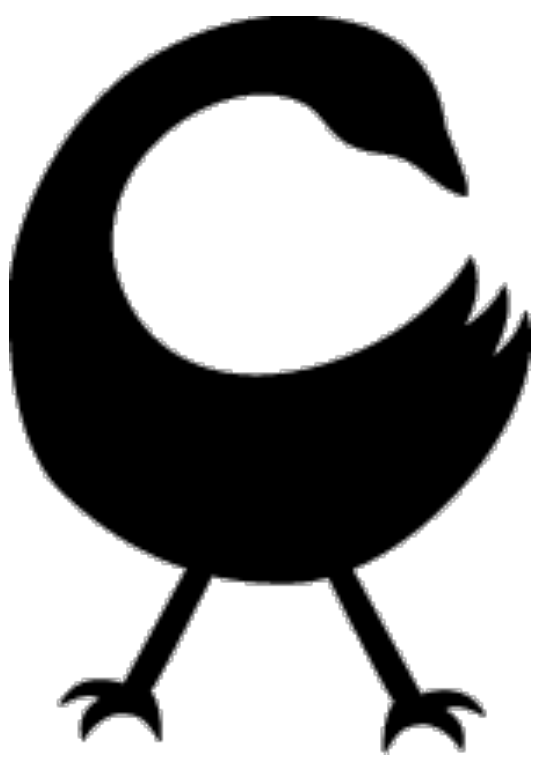

Figure 2: Sankofa Bird without the Object on its Back

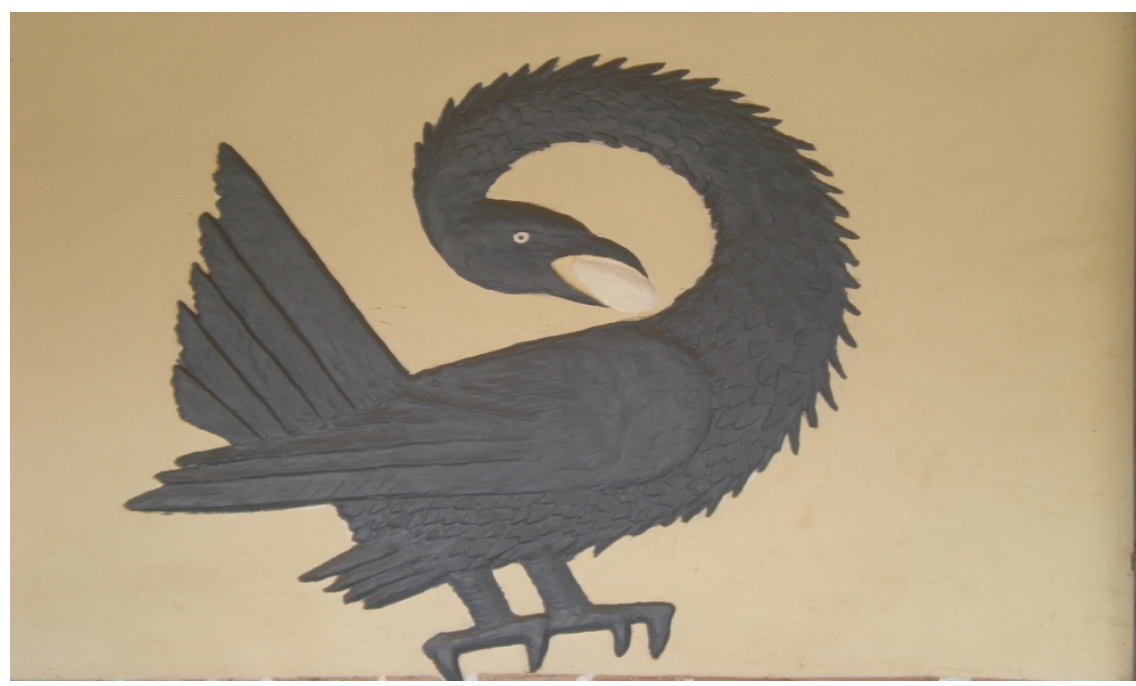

Figure 3: Sankofa Bird Picking Object from its Back 


\section{Chapter 4 - Magpie Poetry: My Book of \#GHCoats and African Conceptual Poetry Introduction}

The third chapter of this dissertation looked at the relationship between concrete poetry and Adinkra symbols - specifically, Sankofa - to argue that through its links with concrete poetry, the versatility of Sankofa lends the symbol strong potential to extend an appreciation of both electronic literature and African literature as disciplines of creative expression. The engagement with concrete poetry is just one new area of endeavor in African electronic literature, and this chapter continues with the theme of looking at new fields in African literature; in this case, a move from the previous focus on oral literature symbols to a consideration of conceptual poetry in African literature, specifically with Ghana in mind.

The basis for this consideration is a project that was heavily indebted to social media, the proliferation of which affords literary innovations of all kinds in Ghana. While many users produce genres of literature that already enjoy a long history of engagement in Ghanaian literature (such as verse poetry, creative non-fiction, the short story, and even longer fiction), there are also moves into conceptual poetry, which is a lesser-known genre in Ghanaian literary scholarship. This relative lack of popularity is mirrored in the global (or at least Western) situation with regards to reception of conceptual poetry. ${ }^{54} \mathrm{In}$ focussing on conceptual poetry, the following research fills gaps in scholarship, but more importantly provides more information on the state and role of new genres in the field of African literature.

\footnotetext{
${ }^{54}$ Similar to the argument in the previous chapter, mainstream poetry anthologies hardly acknowledge conceptual poetry, underscoring its position on the margins.
} 
Examining the inchoate stages of the relationship between conceptual poetry and Ghanaian (and for that matter, African) literature through the specific example allows for an analysis of the influence that conceptual poetry and African literature can have on each other. Thus, this chapter contextualizes the specific project and provides an overview of the various stages of the project. A close reading of the finalized work follows these sections to better appreciate its literary value especially in relation to satire, which features heavily in the work. Prior to these sections, the following sub-heading is structured along long-standing conversations in conceptual poetry that include ways in which the genre has been processed and understood by its Western theoreticians and practitioners.

\section{Concrete Poetry and Africa}

As a well-patronized genre of electronic literature, conceptual poetry has enjoyed a rich and diverse evolution, with representation cutting across different regions and cultures. Due to work from conceptual poets such as the American Kenneth Goldsmith, the United Kingdom's Emma Kay, Uruguay's Alejandro Cesarco, and Shigeru Matsui from Japan, among others, there is the potential for research to map out the manner in which conceptual poetry from different parts of North America, Europe, Asia, and South America not only develop as individual regional sub-genres, but also intersect with each other. ${ }^{55}$ It is in this vein that even a cursory examination of the work of these conceptual poets can reveal overlapping and distinct ways in which conceptual poetry relates with different cultures.

Despite having a transnational identity, conceptual poetry is not associated with

${ }^{55}$ See Thomas H. Ford's “Conceptual Poetry, Nonconceptual Poetry, Postconceptual Poetry" for instance. 
Africa, as is evidenced by the scope of mainstream historical and contemporary conceptual poetry anthologies like Mary Ellen Solt's Concrete Poetry: A World View (1968) and Against Expression: An Anthology of Conceptual Writing (2011), edited by Kenneth Goldsmith and Craig Dworkin. And even when marginalized conceptual poets are the focus, as Caroline Bergvall notes in her foreword to I'll Drown My Book: Conceptual Writing by Women (2012), African conceptual poets are still absent. In terms of scholarship, nothing seems to have been written on African conceptual poetry either, as major academic conversations related to the genre focus mainly on North America and Europe with gestures to South America and Asia.

This lack of attention is not necessarily a blind spot as it is a reflection of reality; after all, by the time these anthologies and related research were published, there had not been major (or minor) attempts at creating conceptual poetry in Africa. Thus on the other hand, despite the presence of digital technology, coupled with the familiarity with and mastery of poetic forms all over Africa, it must be noted that conceptual poetry has not been actively adopted by literary artists on the continent. As a result, conceptual poetry, either as a literary genre or area of scholarly interest, has not yet been actively explored within African literature circles.

Considering the absence of a tradition in conceptual poetry in Africa, the Ghanaian Nana Awere Damoah's My Book of \#GHCoats (2013) is arguably the first known example of the genre from Africa. As an example of African conceptual poetry, \#GHCoats thus charts a new path for endeavors in this field. In focusing on this work, the following research addresses a massive gap in scholarship, and more importantly provides additional information on the state and role of e-lit genres in the field of African literature. 
Examining the inchoate stages of the relationship between conceptual poetry and African literature through a specific example from Ghana allows for an analysis of the influence that conceptual poetry and African literature can have on each other. In order to complete these tasks, this chapter contextualizes the project that birthed \#GHCoats and provides an overview of the various stages of the project, an important step because social media was the vehicle that drove this project. There is then a preliminary analysis of the finalized work, which is done so as to better process questions related to literary value. Prior to these sections however, the following sub-section is structured along long-standing conversations in conceptual poetry that include ways in which the genre has been understood by its predominantly Western theoreticians and practitioners, who constitute the major voices in the academic field.

\section{Definitions}

Conceptual poetry is related to conceptual art and conceptual writing, two terms which are heavily intertwined: it is no coincidence that some of the conceptual poets mentioned in the introduction are also known as conceptual artists or conceptual writers, for instance. The poet and critic Kenneth Goldsmith has perhaps the best known example of this relationship in his infamous 2005 essay "Paragraphs on Conceptual Writing," a rendition of Sol LeWitt's 1967 "Paragraphs on Conceptual Art" in which he substituted "writing" and "writer" for "art" and "artist" respectively, while maintaining the rest of the essay word-for-word. The obvious implications of these actions lie in the suggestion that if Goldsmith's reiteration of LeWitt's work does not essentially change the meaning of the original, then these terms (conceptual art and conceptual writing) can be used interchangeably in even wider contexts; after all, Goldsmith practices conceptual art by 
writing this essay. Such implications extend to conceptual poetry: in a more direct manner Marjorie Perloff talks about conceptual poetry, conceptual writing, and conceptual art as different sides of the same concept - she refers to the same essay by Goldsmith to make the point that it is short-sighted to not see these genres as making the same statement. ${ }^{56}$ Perloff does acknowledge the impossibility of a "neat parallel between conceptual art and conceptual poetry"; however, like conceptual art, the visual can and should still play an important role in conceptual poetry. Thus, even though conceptual poetry is used for the majority of this chapter, its relationship with conceptual writing and conceptual art help to contextualize this genre.

Conceptual poets tend to double as theorists and teachers as well; their versatility allows them to approach an understanding of conceptual poetry in different ways. Poet and theorist Vanessa Place and her colleague Robert Fritterman, for example, start Notes on Conceptualisms with a bold claim connecting conceptual art to "allegorical writing," which is explained as "writing of its time, saying slant what cannot be said directly, usually because of overtly political regimes or the sacred nature of the message" (15). This allusion to Emily Dickinson's famous line-_"Tell all the truth but tell it slant"acknowledges a radical break from other creative genres. On another level, Place and Fritterman use this allusion to imply an intentional influence of the flow of information in such a way as to prevent the visual dimension from reducing the text to its visual properties (akin to concrete poetry, for instance), thereby complicating further the arguments by Perloff and Goldsmith. While conceptual poetry is typically oblique, this

\footnotetext{
${ }^{56}$ In "Conceptual Poetry and the Question of Emotion," Perloff argues that the objections to Goldsmith's conceptualist thesis proved Goldsmith's point about the varying receptions to image and text. For Perloff, poetry is thus "way behind" (5).
} 
comparison is ultimately a narrow move that does not fully embrace the wider ability of the genre to directly engage with the banal as well as the politically blatant. The versatility of the genre allows it to cater to all kinds of themes and styles, and the two authors further complement this comparison by arguing that allegorical writing is "necessarily inconsistent," containing literary techniques that "recombine both to create the allegorical whole, and to discursively threaten this wholeness" (17). While such contentions hold true, there are more substantial definitions attempted by others.

In Against Expression for instance, Dworkin calls conceptual poetry "nonexpressive" poetry in which "substitutions" that relate to the use of metaphor are "replaced by the direct representation of language itself' (xliii). Dworkin thus identifies a conscious move away from traditional notions of creativity, with the visual becoming a substitution. Rather than the result of what William Wordsworth terms the Romantic spontaneous overflow of powerful feelings recollected in tranquility, the poetry is created as the poet finds and works with existing data or information. Instead of Robert Frost's call for emotion to find thought, which in turn finds words to give it expression, the words are already there, fully-formed, and thus already signifying the emotion or thought that the poet attempts to capture. As such, the relationship between emotion and expression is not necessarily the focus of conceptual poetry, which subsequently can be argued as presenting an absence or as it were, an itch to be scratched. With such features in mind, Dworkin calls conceptual poetry a "gap" that is the antithesis of creative art. $^{57}$

Such "uncreativity" can be historicized by situating conceptual poetry in relation to

${ }^{57}$ Ford adds to this argument that conceptual poets followed Ezra Pound's charge to 'Make it New!' "by making their texts un-new" (51). 
other poetic movements. T.S. Eliot and James Joyce were famously criticized by contemporary critics for lifting material from existing work in crafting The Wasteland and Ulysses respectively. ${ }^{58}$ Remixing, sampling, and remaking are also popular creative approaches to music genres such as the mainstream hip-hop and hip-life, its Ghanaian cousin, while in African creative expression there is extensive scholarship on literary genres copying heavily from various periods, places, and people. From William Butler Yeats' influence on Chinua Achebe to Pablo Picasso's debt to Congolese art forms - the anxiety of influence, as it were - examples abound. However, conceptual poetry stretches such borrowing to more extreme ends, bringing into question the place of ownership and creativity in this genre.

All of these delineations as well as criticisms converge on Goldsmith's claim that conceptual poetry is an act of "uncreative writing" - a form of copying, recycling, or appropriation that "obstinately makes no claim on originality." as far as to suggest that his work be seen as unimaginative and "boring." ${ }^{\circ 0}$ For Goldsmith, transforming data into poetry is an act that positions conceptual poetry against other poetic movements that favor close reading and similar engagements. The convention in conceptual poetry has therefore not been to read the final product carefully, but to rather understand the general initial concept. In interviews and essays, Goldsmith recommends that his work never be read in its entirety, and in that vein, reinforces Place and Fritterman's call for conceptual poetry to require a "thinkership" rather than a readership -

\footnotetext{
${ }^{58}$ See Perloff's Unoriginal Genius: Poetry by Other Means in the New Century. ${ }^{59}$ Ibid.

${ }^{60}$ See Nikolai Duffy's “Reading the Unreadable: Kenneth Goldsmith, Conceptual Writing and the Art of Boredom."
} 
the audience needs to merely think about the idea of the work, rather than read the whole work. Such thinking assumes that due to the typical lack of coherence as a result of compiling unrelated - or indirectly related - data into a poem, the frustration that comes from trying to find consistency would put off the prospective reader from engaging with conceptual poetry as one would other types of poetry.

Major examples include Goldsmith's Seven American Deaths and Disasters (2013), a collection of media accounts of different tragedies that color contemporary American history; Eunoia (2001), in which Christine Bök uses a single vowel for each chapter; and Stephanie Barber's Night Moves (2013), a collection of YouTube comments of an American song by the same name. Works outside the Western cannon include Matsui's Quantum Poem (2006), Alejandro Cesarco's Dedications (2003), and Pablo Katchadjian's Mucho Trabajo (2011). Added to these examples is Damoah's \#GHCoats.

The subsequent overview and analysis seeks to show that, as an example of African avant-garde literature, \#GHCoats interrogates notions of access, ownership, plagiarism, place, creativity, and context, in ways that complement existing academic conversations on conceptual poetry. In terms of the actual literary work of art, it is again helpful to note the similarities and differences between an African notion of conceptual poetry and its Western mainstream relatives. With these issues in mind, the rest of this chapter includes a review of the origins of the project, an analysis of the work itself, and a consideration of the implications of such a work of art on both conceptual poetry and African literature.

\section{My Book of \#GHCoats and the Evolution of a Project}

In November 2013, the Ghanaian Writer Nana Awere Damoah posted on Facebook: "Never introduce your child to the delights of the tilapia head until he or she is old 
enough to buy for himself or herself' - Abraham Lincoln." Around the same time, a Ghanaian journalist called Abubakar Ibrahim posted the following also on Facebook“'Having an okro mouth does not mean you will be given banku to go with it' - Albert Einstein." Both Facebook users put these posts up for obviously humorous purposes, and their Facebook audience who are mainly Ghanaian responded with comments acknowledging the disjunctions in the two posts. After all, from a Ghanaian (and probably any other) point of view, it is hilarious to imagine a $19^{\text {th }}$ century American president with no known connection to West Africa extolling the virtues of savoring the head of fried tilapia (which is a very Ghanaian thing to do), just as a Ghanaian would typically find ridiculous the notion of Einstein idiomatically connecting an "okro mouth" (which signifies gossip due to the slimy and slippery nature of okro soup) to banku, a staple food which accompanies actual okro soup.

Ibrahim and Nana are friends on Facebook and have Facebook friends that are considerably higher than average numbers. ${ }^{61}$ Their sizable audiences thus allowed their posts to gain a lot of attention from their predominantly Ghanaian Facebook audiences. As Damoah and Ibrahim's posts got shared and commented on, other Facebook friends started to come up with their own creative responses along similar lines. The posts become increasingly creative and diverse, as Facebook users included context. Thus, Facebook users created posts such as '“'Fermented sobolo never got anyone drunk' - a young Angela Merkel at the 1972 Oktoberfest”; “"The fufu must always sink completely beneath

\footnotetext{
${ }^{61}$ While Ibrahim's number stood at 2,998 friends as of December 1, 2013, Nana's friends list had already reached the 5,000 limit; he also had 1,436 followers at the time. The average number of Facebook friends a user tended to have stood at 388 in 2013 according to research by Pew Research.
} 
the soup' - Leonardo da Vinci (1452 - 1519) on Fluid Mechanics"; and "No matter how much you bed-wet, you cannot create a lake on your bed' - Mansa Musa”. Users also continued to tag friends; through the subsequent ripple effect the project became viral in less than a week. This sharp rise in popularity created the need for organization and a tighter control of the direction of the project's evolution, and it was in this light that Damoah came up with a \#GHquote hashtag (a combination of "Ghana" and "Quote"). ${ }^{62}$ Clicking on the \#GHquote hashtag was a convenient way of tracking and streamlining the posts, thus cordoning them off other status updates and providing thematic grounding.

During this process of creating, sharing, remixing, and responding to these posts, the hashtag was changed to \#GHCoats. The replacement of "quote" with "coat" was primarily to give the hashtag a Ghanaian feel, and is an inside joke for those familiar with Ghanaian phonetics: some Ghanaians pronounce "quote" as "coat", eliding the /w/ sound. The play on words thus elicited notions of the bourgeois since in Ghana the middle class is associated with formal dressing, which includes wearing coats. ${ }^{63}$ After further discussion, both hashtags were used so as not to lose the trail started by \#GHquotes. Even though the fun eventually spread to Twitter, the relative freedom of space on Facebook (unlike the 140-character restriction on Twitter) allowed for lengthier posts.

As the project continued to evolve in real time, Damoah created a Facebook note to collate all the submissions - the fluid nature of the Facebook note meant that as users

\footnotetext{
${ }^{62}$ In "Switching in Twitter's Hashtagged Exchanges", John Jones identifies the hashtag as crucial to building communities as "expressions of network power" as well as a "direct expression of digital, networked writing" (103-4).

${ }^{63}$ This phenomenon can be quite humorous considering the irony that middle class people prefer such warm clothing in tropical weather - writers like Ayi Kwei Armah and Kofi Awoonor have satirized this bourgeois tendency in Fragments and "We Have Found a New Land" respectively.
} 
created more posts the note was edited and expanded accordingly. This note is important in the overall process because it served as a receptacle for the posts, and afforded users the convenience of tracking the growth of the project. With the view to preserving the submissions in a place outside Facebook so as not only to avoid relying exclusively on social media for the viability of the project, but to also widen the audience to people outside Facebook, Damoah turned the project into a free e-book entitled My Book of \#GHcoats.

Users who created their submissions had interaction primarily with their Facebook friends as well as the friends of people whom they tagged in posts. As per regular Facebook interactions, while some people would comment acknowledging the humor, others would also submit their own quotes as replies to these posts. Such features of Web 2.0 thus gesture to the actions surrounding the posts as performance. They moreover connect creativity to context, something that Anthony Giddens argues "connects the most intimate and detailed components of interaction to much broader properties of the institutionalization of social life" (119). Even though Giddens theorizes on context and social life long before the proliferation of social media, his sense of context is important for this conversation because it aids in structuring an understanding of the text through its connections between individual relationships and wider aspects of community. This in turn leads to regionalization, which zones time and space "in relation to routinized social practices" (119) and in other words, enables a reader to approach the text in a way that undercuts the potential lack of coherence that an e-book of random quotes would present.

With these ideas in mind, admittedly the posts and note might lose what Giddens terms as "something of [their] aesthetic and semiotic function" (qtd. in Ensslin 76) when 
transposed into the e-book format. Still, the e-book gains a form of stability and traction, which can lead to categorization and subsequent analysis as a whole. It is also important to note that unlike Barber's Night Moves which consists of a multitude of YouTube comments made by users with loose connections to each other due to their engagement with Bob Seger's song, \#GHCoats contains posts generally driven by satirical humor and authored by 51 Facebook users, many of whom are personal friends with Damoah. The relationship between the users therefore builds a more compact multi-voice community. Damoah lists the names of the contributors at the beginning of the e-book, but does not attach their names to the individual quotes in the e-book itself. Even though the quotes do not create a coherent chain but are randomly put together, removing the authors of the individual quotes ensures that attention shifts to the quotes themselves, allowing readers to draw more direct connections between the quotes.

\section{Categorizations}

The eventual e-book's constitutive posts can be structurally (not thematically, in this sense) categorized into four types with examples:

\section{Fictional Quotes Misattributed to Famous People}

These examples initiated the movement and were generally made-up quotes that were credited to famous people. The connection between the person who supposedly made the quote and the quote itself was contextual or coincidental and laden with Ghanaian humor. They included the following:

- "He who eats jollof with stew has trust issues" - Confucius (\#GHCoats 15). ${ }^{64}$

\footnotetext{
${ }^{64}$ Adding stew to jollof rice is presumed to be superfluous because of the amount of tomato used to prepare the meal.
} 
- "Adding kanwie to your okro might make you lick your lips after a meal, but this practice is not advisable 30 minutes to your next boxing match" - Muhammad Ali (\#GHCoats 8). ${ }^{65}$

\section{Real/Modified Quotes Misattributed to a Well-Known Person}

These examples included famous sayings which contributors either lifted whole or edited to suit the credited author:

- "20 years from now you will be more disappointed by the things you did than the things you did not do. Explore!" - Okomfo Anokye (\#GHCoats 8). ${ }^{66}$

- "Fermented sobolo never got anyone drunk" - A young Angela Merkel at the 1972 Oktoberfest (\#GHCoats 18$){ }^{67}$

\section{Proverbs Misattributed to a Famous Person}

These were mainly traditional Ghanaian proverbs that were usually translated into English and credited to a famous author. They were a popular choice due to the accessibility of proverbs to the average Ghanaian:

- "He who has diarrhea has no business in a flatulence competition" - Chairman Mao's opening statement at the 1950 Olympic Games (\#GHCoats 24).

- "Never laugh at the sloppiness of your mother-in-law's breast, since your wife's may turn out to be just like that when she grows older" - Marilyn Munroe (\#GHCoats 22).

\footnotetext{
${ }^{65}$ This quote was created in reference to the Ghanaian boxer Joshua Clottey who blamed the decision to eat okro right before a fight with his Filipino counterpart Manny Pacquaio as reason for his loss.

${ }^{66}$ This quote is attributed to Mark Twain even though the earliest documented publication of the quote is in P. S. I Love You by H. Jackson Brown Jr.

${ }^{67}$ This quote was adapted from the saying "a little work never hurt anyone" and M. L. Forman's "a little rain never hurt anyone".
} 
- "If you want to see your in-law's behind, give her a farm on a hill." - King Henry VIII (\#GHCoats 17).

\section{Common Ghanaian Parlance Misattributed to Famous Names}

These examples included idiomatic expressions or typical Ghanaian phrases, mostly in Akan:

- "Killer bewu last show"68 - George W. Bush to Al Gore before the Florida votes were counted in the 2000 American Election (\#GHCoats 26).

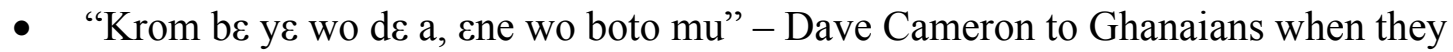
introduced the $£ 3000$ visa security deposit (\#GHCoats 26). ${ }^{69}$

\section{Modified Quotes from Actual Authors}

- "The qualification of the Black Stars to Brazil is meaningless unless it is linked with the total liberation of Olele from international football" - Osagyefo Dr Kwame Nkrumah, speaking from Fathia's house in Cairo (\#GHCoats 9$).^{70}$

- "Ask not what GYEEDA can do for you, but what you can do for GYEEDA" John F Kennedy, 1962 (\#GHCoats 13). ${ }^{71}$

\footnotetext{
68 Translation: A Hollywood movie villain - called the "killer" because of the tendency to "kill" many characters - does not die until the end of a movie.

${ }^{69}$ This saying refers to the connection between enjoying life and the amount of money in one's pocket, and referred to the British Prime Minister's announcement in 2013 that certain countries including Ghana would have to pay a large security deposit before traveling to the UK.

70 This post was an adaptation of Nkrumah's famous line concerning the total liberation of Africa and referenced a Ghanaian goalkeeper who is deemed too old to be playing international football.

${ }^{71}$ This submission was adapted from Kennedy's famous line about self-sacrifice and referred to the GYEEDA corruption scandal that occurred in mid-2013.
} 


\section{Analyzing My Book of \#GHCoats}

According to Goldsmith, an engagement with conceptual poetry is premised on a lack of reading. ${ }^{72}$ As mentioned previously, conceptual poetry is hardly read in its entirety because this genre involves the organization of a huge amount of data into a usually incoherent piece of work, which is then labeled as poetry. ${ }^{73}$ Even though Goldsmith and other practitioners focus on a lack of creativity, it is obvious that the mere act of combining existing information into a "new" work is in itself a creative act. The interplay between authorial intent and the finalized work thus leads to an interrogation of what it means to create new work, and when it comes to analyzing the subsequent work, context becomes important.

Furthermore, analyses of conceptual poetry tend to focus on the initial concept rather than the final product - the "poem", as it were. As Peter Jaeger opines, Goldsmith's recasting of the LeWitt essay flags a tendency in contemporary poetics where the idea or concept is the most important aspect of the work. ${ }^{74}$ Jacqueline Ardam's extensive analysis of Goldsmith's work on the other hand proved that the opposite is possible. ${ }^{75}$ This chapter posits that engagement with conceptual poetry need not be constricted to an either/or argument: the initial concept and the final product, as well as the evolution of the particular project under study, are all important to appreciating the nuances and choices

\footnotetext{
${ }^{72}$ See Goldsmith's "Conceptual Writing: A Worldview."

${ }^{73}$ Such an idea recalls Franco Moretti's argument in Graphs, Maps, Trees: Abstract Models for a Literary History, which called on scholars to not necessarily read texts but rather focus on textual engagement that involves charting, graphing, and mapping. ${ }^{74}$ See Jaeger's “'Sentences on Christian Bök's Eunoia: Writing after Language Writing, Oulipo and Conceptual Art."

${ }^{75}$ See Ardam's "The ABCs of Conceptual Writing”, an analysis of Goldsmith's No. 111 2.7.93-10.20.96.
} 
that inform a conceptual poem, especially when the relationship between these various stages is as close as \#GHCoats.

Damoah lists the names of the contributors at the beginning of the e-book, but does not attach their names to the individual quotes in the e-book itself. Even though the quotes do not create a coherent chain of thought but are randomly put together, removing the authors of the individual quotes ensures that attention shifts to the quotes themselves, resulting in the proverbial "death" of the author as well as increasing the potential for close reading. It is important however to note the difficulty in performing close reading exercises with conceptual poetry. Ardam's admirable attempt to close-read Goldsmith's No. 111 2.7.93-10.20.96 demonstrates what she calls an ability to complicate "the alphabetized and alphabetical, the encyclopedic and the literary, the uncreative and creative, the procedural and non-procedural text" binaries that are inherent in such an incoherent piece (155). Critiquing these binaries allows her to question the work's supposed incoherence.

\#GHCoats is similarly incoherent in terms of not having transitions - the quotes read as they present themselves: as a random collection of quotes. The incoherence engendered is nevertheless not as severe as Goldsmith's 606-page behemoth which includes such content as “... pesky critter, Pete the Puma, Peter Fonda, Peter Sellers, peter meter, peter parka, ...” (39); and “...Isabel Archer, it becomes sincere, It Can’t Happen Here, it can't happen here, it just India, it might be a chair, it tastes like flowers, ..." (52). This style of writing allows Ardam to create a largely textual analysis, as she focuses on the stylistic concerns raised by Goldsmith's work in relation to the English alphabet. Still, underlying socio-political questions can reside in conceptual poetry due to the meta- 
commentary that can be revealed in the information that constitutes the work in question, an example being another of Goldsmith's works: Seven American Deaths and Disasters. As a collection of media accounts of different tragedies that color contemporary American history, Seven American Deaths indirectly comments on these various events through its use of the accompanying media reports, giving the reader room to compare the different narrations of the events in a direct manner and to contextualize the events, examining them from a nostalgic or reflective perspective.

\#GHCoats similarly shares connections with political and social commentary because of the content in the constituent posts, leading to a relatively straightforward analysis of resultant themes in the context of satire, which is prominent in the quotes. It must be further noted that having just over 50 contributors to \#GHCoats invariably implies wildly varying styles of writing. Added to the diverse writing styles is Damoah's conscious refusal to edit the quotes: in an interview, he stated that copying and pasting the posts allowed an explicit acknowledgement of their diversity. The medley (or even cacophony) of writing styles therefore allow for a comparative analysis in some cases, as will be seen in the subsequent analysis.

Damoah chose My Book of \#GHCoats as the title for the work, influenced by similar titles such as the Jehovah's Witness staple My Book of Bible Stories, which is a popular book in Ghana and, like \#GHCoats, is a collection. The similarities end there however, as \#GHCoats, unlike My Book of Bible Stories, makes no claims to authenticity or authority. Its disclaimer points out that the quotes are borne out of the contributors' creative impulses; this is followed by the warning that anyone who takes the quotes as facts "obviously has no business holding a Nokia 3310 phone" (3). The sarcasm in the 
disclaimer positions the unlikely believer of the quotes as archaic, as someone who would use the outdated Nokia phone, which is a source of ridicule, especially in urban Ghanaian settings including in contemporary songs. The intentional reminder to the fictionalized nature of the quotes is reinforced by the epigraph "Coat and Uncoat!" (7). Positioning this local play on words before the quotes is a reminder of the nativized mischief and trickery intertwined with the casualness of linking personalities with fictionalized quotes.

In between the disclaimer and the epigraph lies a short dedication to the contributors, as Damoah consciously deflects credit to the people who created the quotes and is more of a copy editor than content editor. The listed contributors themselves number 51 in total. A perusal of names reveals different Ghanaian ethnic backgrounds, and the large number of contributors suggests a wide variation of the quotes in terms of style. Sometimes, the contributors even played with the same proverb as is the case in the socially deviant quote "If you want to see your in-law's behind, give her a farm on a hill. King Henry VIII" (\#GHCoats 17); and "If you relish the sight of your mother in-law's behind, give her a land atop a hill to till. Galileo Galilei” (\#GHCoats 20). Similar to Night Moves, then, there is a plethora of voices; unlike Barber's work where the constitutive YouTube posts vary wildly in terms of purpose and content, these quotes follow a similar syntactic structure, with a quote and an attribution. The relative cohesiveness does not necessarily birth coherence; even if Damoah had arranged the posts chronologically, there would not have been much of a "flow" to the quotes.

At first glance, \#GHCoats reads like a Top 50 Jokes or 101 Most Famous Quotes collection. As can be seen from the above structural categories, however, there are underlying political, social, and economic commentaries by Ghanaian social media users 
that transcend the local environment to portray a transnational bent. Moving from American presidents through Japanese television stars to Hollywood celebrities allows for both a wide range of selection, as well as a glimpse into the ways in which some Ghanaians view globalization.

On the other hand, the collection of quotes goes further than simply observing issues: by demonstrating the shared creativity of contributors, a reader gains a glimpse into ways in which ordinary citizens process localized and global news. The quotes captured foreign incidents such as the Clinton-Lewinsky scandal as well as local incidents like the sacking of a deputy minister in Ghana over corruption issues and the public reprimanding of the mayor of Accra, the capital of Ghana, due to his decision to rename a national hockey stadium after a former president.

Such perspective is especially important in a digital space that according to Adenekan affords a different type of engagement with literature in terms of issues related to ownership, audience, and tone. ${ }^{76}$ Adenekan also posits that the internet affords more controversy in African literature than its print counterpart, even though the presence of controversy is not necessarily linked to the medium of literature. In Ghana for instance, there are examples of controversial themes in the poetry of Kofi Awoonor and Kofi Anyidoho. Again, content, tone, and style, while varying wildly from genre to genre, all exhibit similar levels of controversy through their approach to themes of interest. Finally, even though there is relative freedom in publishing online (Adenekan 139), \#GHCoats

\footnotetext{
${ }^{76}$ See Adenekan's "Transnationalism and the Agenda of African Literature in a Digital Age."
} 
does not deal with its content in ways that are markedly different from oral and print poetry.

The choice of attributed authors also on the other hand reveals the privileging of cultural capital that functions as shared knowledge. The employment of primarily Western personalities functions as a bridge of access for people with that form of knowledge. While there is the presence of parody and humor, crediting these figures with the quotes is also a tribute to their effect on knowledge systems across cultural spaces. Furthermore, there is something to be said about stereotyping since the figures have a relationship with the quotes due to the context created by the authors. On a surface level \#GHCoats can also read as a reaction to past incidents and current societal and political issues that caught the public eye. The outlandish logic behind yoking historical figures with unrelated incidents, as well as the presence of humor ensures that satire is a major aspect of the work. The next sub-section of this chapter thus looks briefly at satire in \#GHCoats, and recaptures some of the arguments in this section by extending them.

\section{Socio-Political Satire and \#GHCoats}

In accepting Juvenal's classic interpretation of satire as open to "whatever men do", the critic Dustin Griffin processes satire as "unruly, various", and materializing in "many different forms." (4) He links the nebulous nature of satire to the fact that it is not a "genre"; instead it functions as a "mode" or "procedure" (4). The absence of a static definition in favor of a process, while precluding a comprehensive and unified theory, does not prohibit the ability to offer a set of critical perspectives. Griffin is therefore able to examine different types of satire in diverse contexts. For the purposes of this section, satire is also understood as multifarious; however, when restricted to the realm of the 
social and political, satire works within parameters where elements of mockery, correction, irony, ridicule, and humor intersect in intricate ways. These connections are effective in \#GHCoats through a close reading of social and political commentary in the quotes, especially when enhanced through an explanation of context, allowing for a traversal of thematic, stylistic, and structural concerns.

Commentary on social matters such as marriage is immediately apparent in "A real trap is when a wife offers the last meat in the soup she is saving to the husband. $\sim$ Pope John Paul II... [well, I guess that's why he became a priest instead]" (\#GHCoats 8). On one level, there is the obvious attempt at humor in justifying the choice of the Pope to remain celibate and head the Catholic church, rather than fall victim to possible marriage shenanigans; on another level, the quote also considers the agency that a wife is traditionally expected to possess in the domestic space. While the convention of placing a woman in the kitchen implies that her position in the public sphere is tenuous, on the other hand she can utilize the power relations within the private sphere to her advantage. In Ghana, the woman of a household is typically expected to cook - multiple proverbs, songs, and folktales from different ethnic groups all over the country buttress this gendered expectation; this quote questions the supposed resultant weakness, as the woman's control over the preparation of food in the house provides her leverage over her husband and deepens male anxiety. ${ }^{77}$

Beyond the domestic space, marriage and romantic relationships are satirized in a political context through quotes like: "Bortos watching and admiring whilst your wife or

\footnotetext{
${ }^{77}$ The fear of having a woman utilize this power to her advantage is also captured in The Anatomy of Female Power by Chinweizu (1990), revealing masculine anxiety at perceived female agency.
} 
girlfriend is around you is not for the faint at heart--- Sarkozy 2009, to Obama at G8 summit)" (\#GHCoats 23). "Bortos" is Ghanaian slang for "buttocks", and similar to the use of "coats" in the hashtag, this word phonetically gestures to the lack of consonant endings in certain varieties of Ghanaian English. More to the point, the quote on a thematic level mocks the tendency of men to leer at (and thence sexualize) women's bodies while creating a binary between the woman whose body is looked at and the woman whose husband does the watching; on a contextual level the quote directly alludes to a viral picture of the American president Barak Obama appearing to ogle at an unidentified woman in the presence of his French counterpart Nicholas Sarkozy. It must again be noted that using these two quotes as basis, the female partner is positioned as one to be feared by her male counterpart, irrespective of whether the relationship is situated in private or public. This positioning follows from numerous examples in Ghanaian popular culture including music and posters, and whether this situation adds positive agency to the woman or simply gestures to the nagging female stereotype is dependent on the ways in which the audience approaches the quotes.

The open-ended interpretation of text is a feature of close reading, and the openendedness of \#GHCoats is again suggested by some contributors using the same source for creating some of the quotes; in such cases, the "authors" were different. An example is seen in the figure of the mother-in-law (thus extending the theme of relationships), who came in for particular treatment in the socially deviant quote "If you want to see your inlaw's behind, give her a farm on a hill. King Henry VIII" (\#GHCoats 17); and "If you relish the sight of your mother in-law's behind, give her a land atop a hill to till. $\sim$ Galileo Galilei" (\#GHCoats 20). Both posts are rooted in a popular proverb which suggests the 
ways in which a man can manipulate the body of his mother-in-law in response to interest in her. While the repetition of the same proverb with different authors underlines the randomness of the misattributions, the choice of the two authors also seems deliberately ironic, especially since King Henry VIII is known to have married six women (and executed some of them), whereas Galileo on the other hand did not marry the mother of his children due to contemporary concerns over the disparity in social status. Within both examples, then, the figure of the mother-in-law is paradoxically positioned as absent. Gesturing to these absent figures thus adds an extra layer of context to the quotes. In terms of theme, the consistent mockery of female domestic figures reveals the ways in which women tend to be ready-made targets for ridicule in familial relations.

If in $\# G H C$ Cats women directly bear the brunt of satire in domestic settings, then in the public sphere the burden is shared more democratically, with a more even amount of attention to both male and female characters indicating a different approach to both genders in public conversation. Such a reading can be seen as surface level, as within these examples the power relations between males and females were still unequal. Politically for instance, some quotes referenced international scandals like the ClintonLewinsky affair and Silvio Berlusconi's relationships. "Soft lips give the most sensuous kisses. Clinton to Monica 2002" (\#GHCoats 20) immortalized the American scandal and played on the information available to the public on the incident. Apart from the uneven power relations with regards a president vis-à-vis a White House intern, the mere reference to the incident hinted at the gender imbalance: Lewinsky's career virtually ended after the news broke while Clinton recovered from the scandal to finish his second presidential term. Furthermore, choosing the surname of the former American president 
while using the first name of his former intern (as opposed to "Bill" and "Lewinsky", for instance) hints at gendered ways of knowing in a Ghanaian space. The former Italian prime minister on the other hand retains both names. Similar to the Clinton-Lewinsky quote where the power relations are skewed to the advantage of the male as well as the afore-mentioned Obama/Sarkozy quote, in this instance the female counterparts in the scandal are not given voice. Berlusconi's quote is rendered with an idiomatic expression in "If you have okro mouth, your end comes faster than a sexually-starved housewife in a quickie Silvio Berlusconi, 1912, last paragraph in a private letter to Koku Headsroll” (\#GHCoats 22). An "okro mouth", which idiomatically refers to the slippery nature of okro stew and signifies the tendency to gossip or leak information, added to farce of the fictional auditor and out-of-sync date. Moreover, using a private letter as the means of communication ironically acknowledged the spread of the news of Berlusconi's parties, which caused the scandal. Leakage of information leading to controversy was satirically captured elsewhere.

On the local political front for instance, Victoria Hammah, a deputy minister of communications was sacked by the president in 2013 after her driver recorded and circulated a conversation of her planning with a friend to take advantage of her governmental position to make money through corrupt means. This scandal broke out around the time the quotes were going viral on Facebook, and Hammah was featured in "No matter how big a woman's buttocks is, it cannot intimidate the piece of cloth that covers it. Victoria Hammah's driver to Delilah (251 BC)" (\#GHCoats 21). The fictional conversation between the driver and the Biblical character highlights the sense of betrayal that the driver had wrought on Hammah, not least because he was reportedly her relative - 
Delilah's treachery to Samson in the book of Judges in the Bible is also a popular story among Ghanaians, and is referenced in highlife songs for instance. The reference to Hammah's backside was not coincidental either, as she was well-known in public circles because of her body shape. A media house which talked about the story for instance found space to describe Hammah as "voluptuous, broad-bottomed, pear-shaped" ("We Made Vicky Hammah a "Sex Symbol" 2013). Related to the media report, the quote's exaggerated emphasis on her body part, being an example of the satirical tendency to overstate features for mockery purposes - in the tradition of the French philosopher Henri Bergson's essay collection Le Rire or contemporary Ghanaian movie posters in urban centers - thus deflected from Hammah's alleged misdeed. This example did not mean that such mockery was necessarily gendered, as men also received such attention.

Another political issue for instance occurred in mid-2013, when the mayor of Accra Alfred Oko Vanderpuye, officially known as the chief executive of the Accra Metropolitan Assembly (AMA), decided to rename Ghana's national hockey stadium after John Atta Mills, the former Ghanaian president who had died the year before. There was public backlash because the stadium was already named after Madam Theodosiah Okoh, the woman who designed Ghana's national flag - also, a major road, with some buildings, had already been named after Mills. Similar to Hammah, Vanderpuye was typically referred to in relation to a physical feature, his being a thick beard. His beard was the focus in quotes like "It's only a fool who doesn't change his mind. $\sim$ AB Crenstil [in his song, Landlord Abodwese: The Renaming of Sports Stadia, Vol. 1 (2010) \& Remix (2013)" ((\#GHCoats 10); and "There is no place like home, and anywhere else feels just like an AMA office without a bearded boss. Charles Darwin, just before he shaved his 
beard a day before he died, 18th April 1882" ((\#GHCoats 10). Even though the first quote at the very least references the stadium renaming issue, the active mockery of the individual's physical feature is what takes center stage in both quotes - "Abodwese" is Akan for a "goatee", while the "bearded boss" in the second quote is the gesture to Vanderpuye's beard. Similar to examples of satire where people who commit wrongdoings are mocked into correcting their faults, the first Vanderpuye quote leaves room for redemption, while the second, like the Hammah quote, does not appear interested in correction. Regardless of whether the quotes allow for correction of wrongs, there is a demonstration of an acute consciousness of current affairs. It is obvious, then, that some of the quotes were not necessarily intended to directly correct socio-political ills, as can be the purpose of satire. Yet, the mockery in some of the quotes still contained the potential to address social and political wrongs.

The active political awareness evidenced in these quotes were not only limited to individuals, but also spread to institutions perceived as corrupt or incompetent. The Ghanaian police service for instance tends to feature as one of the most corrupt institutions in research and surveys such as the highly esteemed Afrobarometer research facility. ${ }^{78}$ Ghanaian literature also tends to lambaste police vice. Perhaps the best known example is found in Ayi Kwei Armah's The Beautyful Ones Are Not Yet Born which captures the particular phenomenon of bribery by Ghanaian policemen in its last scene, as a policeman clandestinely receives money from a commercial car driver at a road block. The quote "The nicer your vehicle, the more one Ghana notes you require while driving around

\footnotetext{
${ }^{78}$ In "Police Corruption in Africa Undermines Trust, but Support for Law Enforcement Remains Strong", the Afrobarometer revealed for example that in Ghana, trust in the police declined from $66 \%$ in $2005 / 06$ to $47 \%$ in $2008 / 09$ and $42 \%$ in $2011 / 13$.
} 
town. Adam Smith, Economist, 1810 (A Study of Ghana Police; foundational theories and thoughts on Demand and Supply)" (\#GHCoats 22) succinctly complements scenes like Armah's. Using the famous Smith as author of the quote highlights and then ridicules the economic logic behind the extortion of money from drivers.

As the use of Obama, Sarkozy, Clinton, and Berlusconi indicates, heads of government were a favorite source for the quotes. Angela Merkel, Chairman Mao, Winston Churchill and many others also received attention in \#GHCoats, but the most prominent head was Abraham Lincoln, who had four quotes dedicated to him. "Never introduce your child to the delights of the tilapia head until he or she is old enough to buy for himself or herself. Abraham Lincoln" (\#GHCoats 10), "Facebooking in Ghana is the preserve of idle hands. Abraham Lincoln [funny, he wrote this on his Facebook wall]" (\#GHCoats 17), “Any man who uses his teeth to cut wele from a bowl of pepper soup with his eyes open is not afraid of anything. Abraham Lincoln" (\#GHCoats 25), and "If school isn't the place to sleep, then home isn't the place to study. Abraham Lincoln, 1945, after failing his exam and leaving home" (\#GHCoats 26) demonstrate the variety of the misattributions and reinforce the tendency to use well-known figures of authority to make the various points, as the ironic juxtapositions continued to push the emphasis on satire.

Even though in an interview, Damoah pointed out that the contributions were essentially meant for fun purposes, these quotes also function as a post-colonial rewriting of the agency and wisdom of primarily Western authors and other such figures of authority. Especially because these authors include powerful individuals like heads of state, satire displaces their agency through mockery and unfamiliarity. As mentioned 
previously, the major source of humor was intended to be the ironical juxtaposition of familiar names with quotes that they were not typically associated with. Similar to their local counterparts, such rewriting speaks to re-imaginations of authority on the one hand, and familiarity on the other hand. The use of these authors thus serves as a theoretical bridge of access in terms of power relations, especially since the contributors to the volume come from different walks of life.

The overt social and political mockery was not the only result borne out of combining well-known local and international names with these quotes - some of the quotes leaned toward the absurd. "Whoever hasn't tasted brukina knows not what he is missing. John Milton [Paradox Lost]" (\#GHCoats 18); "20 years from now you will be more disappointed by the things you did than the things you did not do. Explore!

Okomfo Anokye" (\#GHCoats 8); "It will take scientists a century to discover the wonders of roasted plantain and groundnuts. $\sim$ Winston Churchill [on a visit to a plantain plantation in Alavanyo]" (\#GHCoats 19); and "A hungry man who patiently waits for his Saturday fufu to get ready has the makings of greatness. Thomas Edison" (\#GHCoats 11) were all examples that featured ironical juxtaposition in the context of humor. By placing emphasis on the ridiculous, such quotes hearkened to older forms of mockery in Ghanaian poetry.

\section{Relationship with Traditional and Modern Poetry}

\#GHCoats joins a rich stream of Ghanaian poetry that not only utilizes satirical structures to diverse ends, but also uses rhetorical and aesthetic structures for creative purposes. With features like multiple authorship through its various contributors, as well as the employment of proverbs, the collection acknowledges affinities with oral poetry: where authorship tends to be collective, and language is usually textured with proverbs, 
colloquialisms, and idiomatic expressions. In public readings of the work, Damoah reads random quotes in a non-chronological order. This conscious restructuring of plot again gestures to oral poetry, where the lack of fixity in a template story allows creative artists to organize the creative work according to their desires. Even though the work can be rearranged, textually the \#GHCoats e-book has a fixed outlook and is thus similar to print poetry. The license to refer to various personalities, institutions, and incidents cuts across both oral and print varieties of poetry.

In terms of actual satire, the brash examples of mockery in \#GHCoats are not as acerbic as oral poetry examples such as performances during traditional festivals such as the Apoo, where people from areas in the present-day Brong Ahafo Region take advantage of license during this celebration to lampoon their traditional authorities; and Halo poems - self-explanatorily known known as songs of abuse -created and performed by traditional Ewe poets. ${ }^{79}$ The portrayal of personalities like Hammah and Vanderpuye can still be seen as insulting; satirical modes however allow for such excesses.

In relation to modern poetry which is usually written down, the use of satire can be compared to the work of poets such as Kofi Anyidoho and Kofi Awoonor. Anyidoho's "Oath of Destiny", contains lines such as

By all the thunders of Xebieso

By all the incurable infirmities of Sakpana

We swear to post copies of the Judgement

to your God, who is in Heaven

${ }^{79}$ On the Friday of the week-long Apoo festival for example, people can walk through the principal streets of urban centers in the Brong Ahafo Region like Techiman, Nkroranza, and Wenchi, insulting the traditional ruler for perceived injustices. 
Whose address we shall look up

in the opening chapters of the

Holy Bible, Unrevised Version (61)

In this excerpt, Anyidoho rains curses on advocates of Christianity for destroying established tradition. The disappointment in a new order is less harsh but also forthright in Awoonor's "The Cathedral", where a tree whose boughs "stretched across a heaven/ brightened by the last fires of a tribe" is cut and replaced by "A huge senseless cathedral of doom." Using Apoo and Halo poetry as well as work by Anyidoho and Awoonor as basis for comparison, one can argue that the satire in \#GHCoats is not markedly different from its antecedents.

On a surface level \#GHCoats can be read as a reflection of societal and political issues: from past incidents to contemporary issues, the quotes capture the essence of news items that caught the public eye while also dealing with everyday issues. On the other hand, the collection of quotes goes further than simply observing events: by demonstrating the shared creativity of contributors, a reader gains a glimpse into ways in which ordinary citizens process local and global news. Such perspective is especially important in a digital space which according to Adenekan affords a different type of engagement with literature in terms of issues related to ownership, audience, and tone. However, even though Adenekan posits that the internet affords more controversy in African literature than its print counterpart for instance, in Ghana, content, tone, and style, while varying wildly from genre to genre, all exhibit similar levels of controversy through their approach to themes of interest. Finally, even though there is relative freedom in publishing online 
(Adenekan 139), \#GHCoats does not deal with its content in ways that are markedly different from oral and print poetry.

The social media angle is crucial to understanding the process through which \#GHCoats came into fruition. Facebook usage in Ghana for instance has grown exponentially since 2007 . As a result, various demographics can utilize the space to various ends. African social media networks tend to engage with current events in complex ways, as evidenced by movements related to hashtags such as \#MuseveniChallenge, \#MugabeFalls, \#WhatWouldMagufuliDo, \#KenyaVsNigeria, and \#TheAfricaTheMediaNeverShowYou: some of these hashtags are restricted to one or two countries, or embrace the whole continent. Preceding these movements, \#GHCoats serves as an early mode of mobilizing social media users - in this case primarily for humorous purposes.

\section{Conclusion: The Political, the Contextual, Place, and Ownership}

Conceptual writing is collaborative in nature and is "particularly intent on breaking the widely held belief that writing is a solitary activity characterized by the creative genius and originality of an expressive artist." ${ }^{80}$ The conceptual artist functions as a gatekeeper who sieves information - even though one can argue that each contributor is (whether consciously or inadvertently) a co-author of the created work. In this particular case, Damoah did not leave any of the quotes out of the e-book, but simply copied and pasted from the Facebook note. As such, Damoah is simply the channel of the posts, a role he acknowledges in the interview - he also lists himself as editor of \#GHCoats. The finished product is nevertheless as important as the creation process. Thus, while conceptual

\footnotetext{
${ }^{80}$ See Perloff's entry in The Princeton Encyclopedia of Writing and Poetics (292).
} 
writers such as Vanessa Place, Christian Bök, Caroline Bergvall and Robert Fitterman are typically interested in the initial concept rather than the final product, one does not necessarily have to be emphasized over the other.

The question of place is an interesting one because of the dimension brought by social media and the Internet. The work resides in multiple places: as disparate Facebook posts, together in the Facebook note and in the eventual e-book. In each spatial context the work differs with its own set of implications: the Facebook posts, which have kept growing have their own trail of comments by their various audiences; the note also has comments even as it expands; the book on the other hand is not interactive in the same sense due to its isolationist nature. Beyond these issues, other questions arise concerning the relationship between the creators of the submissions, the authors they attribute the quotes to and the original authors (where these apply).

Damoah does acknowledge the possible pitfalls that come with misattributions in a disclaimer authored by Prosper Afuti, another contributor. Damoah's response to this issue was:

...whoever can believe [despite the disclaimer] that Johannes Diderik van der Waals, a Dutch scientist who lived from 1837 to 1923 actually said that "Hausa kooko should never be drank from a glass; the molecular structure in the glass destroys the covalent bonds of the kooko and disturbs the taste" needs a rude shaking! 


\section{Epilogue}

After examining two vastly different types of electronic poetry, this dissertation delves into the world of mobile gaming by looking at two games in a comparative analysis. The choice of video games thus adds another dimension to this project by looking at a genre that is usually not thought of in tandem with poetry genres. 


\section{Chapter 5 - Lost/Gained in Translation: Oware 3D and Ananse: the Origin ${ }^{81}$ Introduction: The Ghanaian Video Game Space}

In the 1990s, it was a young person hammering away at a Sega Mega Drive directional pad or Nintendo Gameboy while playing one of the Sonic the Hedgehog, Super Mario Brothers, or Contra franchises, among many others somewhere in a Ghanaian urban center like Accra, Kumasi, or Cape Coast. Ten years on, these video game consoles were replaced by the Nintendo GameCube and PlayStation Two, with franchises including Pro Evolution Soccer and Tekken dominating gaming spaces. Ghana has been associated with video games for at least 30 years, and in recent years, people still own and play the latest Nintendo and Sony generation game consoles. Recently, a new phenomenon has emerged where consistent with the spread of mobile gaming, people download and play the latest mainstream high grossing gaming apps such as King's Candy Crush, Zynga's Words with Friends, and Temple Run by Imangi Studios. Ghanaians are however not only consumers of these games, with individuals and start-up companies making games intended for audiences both within and outside the country. These games allow for research into the ways in which they relate to the culture that informs their creation.

Continuing with the dissertation's engagement with relatively untouched literary genres in African literature, this chapter examines video games and Ghana from a literary angle. As suggested at the end of the previous chapter, the choice to analyze video games brings a unique angle to the project in the sense that the form and overall nature of video games are very different from genres of poetry. Like other forms of creative expression

${ }^{81}$ This chapter is adapted from "Lost/Gained in Translation: Oware 3D, Ananse: The Origin and Questions of Hegemony", which appeared in Journal of Gaming and Virtual Worlds in 2014. 
however, gaming is universal. And similar to concrete poetry and conceptual poetry, video game-making does not have an established tradition in Ghana (or Africa for that matter). Thus, adopting this technology implies an importation of foreign culture. The move into the settler culture results in a unique genre that comes across as having an African identity.

The ensuing cultural exchange is not necessarily innocent, but is born out of contesting cultural spaces. Thus, there is a consideration of two simultaneously distinctive and overlapping ways in which Ghanaian mobile video game creators have adapted signifiers of traditional Akan culture in video game-making, focusing especially on the general implications of making and playing these games in Ghana. These two games are the strategy game Oware $3 D$ (2014), inspired by the traditional board game Oware; and the action/adventure game Ananse: The Origin (2014), influenced by an Akan folk tale featuring the trickster Kweku Ananse. The contributions of these games are eventually assessed within the larger context of globalization, in order to complicate the trite dichotomy of developed/developing countries.

\section{New Global South Frontiers in Video Gaming}

While video games have had an immense impact on virtually every aspect of cultural life in 'industrialized' countries, they also have a presence, even if less telling, in 'developing' countries, and especially in nations that have had a similarly colonized past. Many urban dwellers in the Indian sub-continent and in Sub-Saharan Africa for instance find popular franchises such as Super Mario Brothers, FIFA and Tetris familiar. Beyond simply having people in these countries play these games as consumers, the video gaming industry is growing in such places as game-makers harness video game technology to their 
own ends. It is in accordance with such actions that industry stakeholders view these areas as having the potential for economic viability.

While the gaming industry in India is relatively advanced, its counterpart in SubSaharan Africa is at a more inchoate stage. This situation is symptomatic of the larger issues related to such technology on the continent. Banda et al. note in African Media and the Digital Public Sphere for instance that despite significant time passing after the introduction of new media into Africa, "old questions" concerning the problematic nature of adaptation abound (1). Some reasons attributed for the slow pace of video gamemaking in Sub-Saharan Africa have included financial challenges as well as the lack of access to stable electricity, video game consoles, televisions and other such apparatuses necessary for the gaming experience. However, the boom in smartphones has led to a potential market via mobile technology, as Gado Alzouma contends; thus game-makers like Celestial Games, Leti Arts, Kuluya, Kola Studios and Gamsole exist in countries like Ghana, Nigeria, Kenya, Uganda and South Africa.

Game developers such as Eyram Tawiah and Kobla Nyomi (Ghana), Hugo Obi and Lakunle Ogungbamila (Nigeria), Wesley Kirinya (Kenya), and Gavin Mannion and Arn Richert (South Africa) are among the talented creators at the forefront of the SubSaharan Africa gaming industry. They largely combine and adapt traditional and contemporary aspects of their culture to present a unique gaming experience. Gradually they aim to turn video games into a cultural product with significant political, social and economic influence on local, interregional and intercontinental levels. Abiola Irele in The African Imagination: Literature in Africa \& the Black Diaspora posits that since African literary artists increasingly had no other choice than to produce literature in European 
languages, they actively utilized their notions of the "traditional" for inspiration and as a response to the appropriation of foreign media (57). This amalgamation of cultures obviously gestures to the political history of Africa, which is tinged with the specter of colonialism (as well as neo-colonialist influence after political independence was gained). For game-makers in Africa today, this situation is not markedly different: many adopt traditional aspects of culture to inform the creation of their games as a counterbalance to foreign influence.

Making mobile video games in Sub-Saharan Africa raises all sorts of questions, particularly when one thinks about the connections between tradition and modernity. This chapter restricts its focus to issues related to cultural relations. Hegemonic implications are important to explore in order to appreciate the ways in which the process of adaptation traces a continuum characterized by difference and similarity between the source of inspiration and the finalized product. Again, computer technology is typically treated as a signifier of western culture. Such a thought recalls Homi Bhabha's reading of the English book, whose discovery was "a moment of originality and authority... a process of displacement that, paradoxically, makes the presence of the book wondrous to the extent to which it is repeated, translated, misread, displaced" (144). Fascination with the foreign technology eventually resulted in the creation of novel products that were relevant to the cultures that had adopted the technology. These creative products shaped the social, political, and economic discourses of the colonized countries to which Bhabha refers. Katherine Hayles argues in How We Think that computer technology is rapidly replacing its print equivalent (55-56), and Jan Nederveen Pieterse contends in Development Theory that international politics continually shifts agency to western 
powers (9). If put in conversation with each other, one can argue then that the adoption of game making technology risks leaving an indelible western footprint on African spaces. Thus, Bhabha's position that the English book locates itself as "an insignia of colonial authority and a signifier of colonial desire and discipline" (29) continues to ring true even if the environment has morphed into the digital. In this light, when a traditional African cultural product or concept is parsed through an electronic format, there is the inevitable reaction concerning the extent to which the process of adaptation is a 'westernized' one. Finally, it is also possible to compare such games with western examples from the same genre. Each of these concerns shares a sense of movement, which simultaneously connotes displacement and gain. These issues therefore exhibit power relations, which ultimately connect to hegemonic structures.

\section{Oware 3D and Ananse: The Origin}

The connection to hegemonic structures reveals the inter-cultural relations at play, not only geographically but temporally as well. Aside from the traces of western culture that are present in these mobile video games, the central questions concerning hegemony relate to the movement from a traditional to a more contemporary space within Ghanaian culture, as well as to an analysis of the difference between what remains and what is done away with. The interplay that Jacques Derrida explores between presence and absence where absence rather than being 'a continuous modification of presence' is a "rupture in presence, the "death" or the possibility of the "death" of the receiver inscribed in the structure of the mark" (Limited Inc 180), in other words, is integral to understanding the nature of the analysis, which is done on a comparative scale because the games are made under differing circumstances. 
The two games under investigation are different from each other not only because of genre but more crucially also in terms of adaptation: while Oware is essentially a copy and paste job from a traditional board game to an electronic game (that is from a sociophysical into a new media environment), Ananse copies an oral folk tale, edits it through gamification, and then adapts the new product to a digital environment. With respect to creation, then, the two games demonstrate divergence. The nature of their source of origin to a large extent determines their mode of presentation - the extent of the adaptions and their divergence from tradition is dependent on the different complexities of the adapted texts then as well.

Oware in this light retains as much fidelity as possible to the original Oware game from which it was created, and its losing and gaining of material is mainly due to the context of the electronic space. Ananse on the other hand is the culmination of an arguably more extensive creative license because the creators of the game transformed a popular story from a folk tale series, viewing it through the lens of a game. They used the versatile nature of oral storytelling to make their product malleable and ductile. Examining the evolution of both games through comparative analysis foregrounds the implications of these two different forms of adaptation. I avoid the application of subjective value to these unique approaches, and by analogy we can process the two forms of adaptation as paraphrase and translation, respectively, due to the distance from traditional African cultural forms of expression - game to game as paraphrase, and story to game as translation. Regardless of the analogy, both forms of movement require an intertwining of spatial, aesthetic and temporal displacement in order for creation to occur. An analysis of the hegemonic distance between production and creation is what constitutes the majority 
of the remainder of this chapter.

\section{The Heresy of Paraphrasing and Translating Video Games}

In his famous essay "The Heresy of Paraphrase" from The Well Wrought Urn, Cleanth Brooks highlights the implications of paraphrasing a poem. For Brooks, rendering a poem in words other than its original while assuming that the poem remains the same is not just a fallacy; it is heresy due to the fact that connotations carry similar weight to denotations (295). In other words, the act of paraphrasing leads to a reworking of the poem's structure and other features, basically creating a new poem. Extending this argument to the realm of translation, it is widely accepted that interpreting a text from one language into another similarly leads to a new cultural product. Modifying this argument further to talk about adaptation of a cultural artifact from one media form into another leads us to follow the same line of logic.

Translation, adaptation and interpretation all share that sense of movement from one artifact to another through modification and interpolation. Like a paraphrase, they leave something behind while assuming a new skin, as it were. In a time when the definitions of literature have broadened to include diverse examples of new media, it is important to think about the implications of such positions on the adaptation of traditional aspects of culture into more contemporary aspects. The following analysis thus examines Oware as an example of paraphrase - due to the fact that the original board game and its electronic version are both originally games; and analyses Ananse as representative of translation because the transition in this case moves from story to game. Afterward, there is a brief comparative analysis. 


\section{The paraphrase of Oware $3 D$}

Oware $3 D$ was inspired by its namesake Oware, a game similar to Mancala and other variations of Pit and Pebble games played around the world. In Ghana, Oware is a very social game and is typically played with an on-looking audience. The name itself is translated from Twi into English as: 'she/he marries' and is explained by a story in oral tradition in which a couple that is about to divorce due to a marital misunderstanding play the game repeatedly and stay married due to its addictive nature. This story hearkens to the metanarrative that drives the folk tales that constitute the Indian, Persian and Arab Tales from the Thousand and One Nights, where the narrator tells multiple stories to postpone her impending execution. Even though marriage and death are different entities, the connection between narrative and entertainment underlines the importance of the social in cultural exchange, making the audience an integral part of the discussion. This connection, irrespective of its fleeting nature, also underlines the importance of the construction of gender and agency within the framework of the game.

The social aspect of Oware was one of the major driving forces that led to the creation of this electronic version. In an interview Nyomi stated that he aimed to craft a different experience that would be authentic to his intended audience, which was the average Ghanaian gamer. The paraphrase therefore takes significant consideration of the western environment and technology that has to be engaged with.

Nyomi created Oware $3 D$ partly due to an experience of playing an older version created by two French brothers. He revealed that the game is 'indigenously African' and therefore it 'felt right' that someone of African origin would work at making the game suitable for an African audience despite (or rather because of) its transposition into an 
electronic environment. While this position could be criticized as having essentialist undertones, implicit in this opinion is the idea that having been born and raised in the culture in which the game is found, his background would inevitably influence the way in which the game would be constructed in a more organic manner than someone with less explicit ties to Ghanaian culture. The aim here is therefore not to unduly critique Eurocentric versions, but to rather foreground the importance of having an African voice prominent in the conversation. Entering this conversation with his background would mean he also had the advantage of improving on existing Oware-inspired games. After perusing previous versions of the game, which he deemed unrealistic in design, 'dull' in gameplay and/or not close enough to the Ghanaian board game, Nyomi decided to create an example that foregrounded authenticity in various ways. He also wanted it to be fun and obey the Ghanaian rules of engagement. If games are ideally intended for leisure, then a strong interplay between pleasure and structure was necessary. By extension then, the educational value of a board game like Oware would carry over to an audience that plays its electronic inspiration.

While working on his game, Nyomi took various creative risks in order to capture his notion of an authentic African experience. Some of these choices include the use of default African names for characters. Even though this feature might appear cosmetic, Kofi Anyidoho argues that a Ghanaian writer like Ayi Kwei Armah employs Ghanaian and African names in his work not only to possess symbolic value but also to "frequently serve as keys to the cultural and social identity of characters. The loss or retention of a true African consciousness and identity is often indicated by the name a character bears" (36). The use of Ghanaian names, in other words, foregrounds authenticity in identity by 
adding local coloring through nomenclature. Nyomi uses the names Kweku Ananse and Okonore Yaa (Ananse's wife in oral folklore) to recall the origins of the game as well. These choices are deliberate, in other words, because they demonstrate the social emphasis of the game while eliciting the interdisciplinary implications of relating to an oral folk tale. Ananse and his wife for instance tend to engage in a battle of wits in many oral folk tales; Naana Opoku-Agyemang points out that Okonore Yaa still functions in the plot, even if she is usually portrayed "insofar as she plays a role in direct relation to her husband" (120). Having this husband-wife duo as the characters elevates Okonore Yaa to having the same level of agency as Ananse.

Another way Nyomi introduces change from the western precedents is the predominant use of black hands, a refreshing innovation away from the convention of white bodies that users are usually restricted to in mainstream western games. This decision therefore speaks to David Dietrich's argument that forcing an Anglo-western appearance on avatars that purport to represent difference among players risks reinforcing a sense of normative whiteness as well as shaping the social composition of online worlds into all-white virtual spaces, contributing to the creation of a virtual "white habitus" (83). Gamers are a cosmopolitan mix; therefore, having alternatives to typical expectations gestures to multiplicity and creates space for a wider audience engagement. Thus, in producing a game played in Ghana and modeled on the representative culture speaks to the existing racial imbalance in gaming avatars.

Overall, Nyomi recreates many of the elements present in the actual board game including a realistic-looking wooden board. For future updates and versions, Nyomi would like to expand by providing snapshots of traditional life around a regular game of Oware 
because as per his interview, it is problematic that existing digital versions are very basic with regards to presentation. Even though such choices can have minimalist explanations, a more vibrant background lends credence to the social diversity that the traditional board game propounds.

The final major inclusion is multiplicity, as seen through several camera modes as well as the online multi-player option (which according to Nyomi are absent in other versions). The plurality of aspects of African cultural forms is something that scholars like Ruth Finnegan have theorized on; Ayi Kwei Armah also foregrounds such issues in his novel Two Thousand Seasons, where his famous 'collective hero' achieves success due to their communal activism: unlike his other novels where his protagonists are isolated and accordingly end up as failures, his collective hero is made up of many characters who are united and function as a unit despite their legion-like nature. While it is impossible to argue multiple camera angles and multi-player mode as necessarily 'African,' highlighting the social aspect of the original game in this manner underlines the fact that the game is not to be played in isolation, but requires the skills of collaborators. Multiplicity, then, is not inherently 'African' but still rejects hegemony to the extent that more specific and relevant categories become part of the gaming process. Needless to say, the possibility of playing online means that inevitably the personal physical contact is no longer a given.

The electronic version therefore evidently loses a significant personal touch (figuratively and literally speaking), if we are to be reminded of the implications of a paraphrase. Yet, the fidelity to the original game implies the retention of a decent amount of the features. The creator understands the presence (and even utility) of western influence; he embraces some of these in terms of language - as noted from Figure 1, 
English is the language of instruction in the game. This choice recalls the famous language debates by Obi Wali and Ngugi wa Thiong'o on the presence of western languages in Africa, and demonstrates the importance of having an accessible language of communication not only for a Ghanaian audience where English is the official national language, but also for a worldwide customer base. Bhabha's argument about hybridity as the name for the strategic reversal of the process of domination through disavowal (154) again comes to mind. Beyond the use of English language, the language of code is western dominated, and as such it is clear that adopting computer codes to these ends illustrates the ways in which technology crosses cultural borders.

\section{The Translation of Ananse: The Origin}

Leti Arts is a Ghana/Kenya company with Eyram Tawiah and Wesley Kirinya as its founders. The company has wide-ranging interests in new media forms, of which gaming is a major component. In 2014, Leti Arts adapted a traditional story involving Kweku Ananse, the trickster figure in Akan folklore, into a video game resulting in Ananse: The Origin. Traditionally, Ananse is depicted variously as a spider or human being, depending on the mischief he gets into. However, in general terms, he is a man who turns into a spider at the end of a story when he is found out, escaping out of shame to the corner of the ceiling - which explains to children why spiders live in corners.

Based on the experimental release of The True Ananse digital comic and mobile video game series, Ananse: The Origin, according to the Leti Arts website, "reimagines the story of Ananse with a unique twist depicting Ananse as a superhero in modern times." The "modern," while at risk of sounding restrictive, provides a guide for the game creators to explore the postcolonial implications of narrative in the gaming sphere. Similarly, the 
'unique twist' allows for creative license in crafting the game from its foundational origin. The authors are aware of the venture into a foreign milieu through this adaptation. A western equivalent is the resurgence of the figure of the Norse god Thor, whose portrayal in the Marvel Comics and Hollywood films franchise gestures to modernization by an American society that is only distantly related to his original Scandinavian roots; yet to a large extent, this adaptation hardly requires justification in the way that the modernization of Ananse does. Perhaps such issues then demonstrate a function of hegemony as concerns normalizing (which involves selection and suppression among) 'white' cultural heritage as a matter of course, while simultaneously problematizing non-white traditions as having to traverse cultural boundaries. The adaptation of Ananse involves a western-like remake with Ananse buffed up to steroidal superiority thus implying a move from brains to brawn in terms of his expertise. The in-game experience however reminds the gamer of the need to use intelligence in order to succeed, thus connecting back to the Ananse folk tale.

Oral tradition by nature is a shifting phenomenon: the original creator of an oral folk tale is hardly ever known, so the story is community-owned; the narrator-audience dynamic also shifts frequently because any participant in a storytelling session can assume the responsibility of the narrator; again, because the story is not written down, no two renditions are typically identical. The shifting nature of oral tradition thus enhances, challenges, and interrogates the adaptation of Ananse into a video game. From the screenshots, coupled with a YouTube trailer for the comic (which is related to the game), the influences of notions of Greek mythology are apparent, as are western comic art conventions in terms of character profile. The presence of Greek mythology recalls previous connections to African traditional forms, as Ola Rotimi and Efua Sutherland 
demonstrated in their respective plays The Gods Are Not to Blame and Edufa. The former for instance shows how events in Oedipus Rex by Sophocles reflect Yoruba culture while the latter adapts the Euripides play Alcestis. Such connections again recall the work of Alain Bourgeois, who underlines the 'unsuspected richness' of the relationship between Greece and Negritude as noted by Mudimbe (20). Thus, while the western influence in the game is multifaceted, there are strong connections to African culture through the immersion into digital environments.

The player is asked to "[p]lay as Ananse and complete his quests in capturing the four most powerful forces on Earth to attain the throne as God of Wisdom and Storytelling." This overarching narrative is slightly more dramatic than the well-known template folk tale, which is the motivation behind the game. The template tale explains why stories are called 'Anansesem' in Akan (Ananse's stories) and not 'Nyankoponsem' (God's stories): God decides to sell his ownership of stories for a price, which constitutes capturing a python, lion, bees, and a dwarf, all of whom have to be alive. While no one is foolish enough to risk his or her life in achieving long lasting fame (different from the case of, say, Achilles in the Homeric epic), Ananse takes up the challenge - using his wiles and son as assets.

In the template story, he intentionally argues with his son within hearing of the python about its length, wagering high stakes to entice the python to settle the debate. They convince the python to tie itself to a pole to prove who wins the argument. Tying himself to the pole imprisons him. In a similar fashion, Ananse later argues with his son near the lion's home about whether the lion is big enough to fit into a sack - he promptly ties up the sack when the lion enters it; he later has his son pour water from a tree on a bee 
hive and then offers his pot as refuge for them since they detest rain; the pot becomes their jail. Finally, he captures a dwarf by placing his favorite meal by a sticky gum tree - as he eats it, he gets stuck to the tree. The triumphant Ananse presents his captured quartet to God and as a reward has stories named after him while being accorded the gift of narrating stories. These incidents play on greed, trust and cunning. More crucially, Ananse schemes his way into a place of privileged narration, thus recalling Michel de Certeau's theory in The Practice of Everyday Life $(35,37)$ of the weak having to use tactics to overcome the strategies of the powerful while illuminating the importance of voice and power in narration.

Similar to the template story, the gamer has four tasks and controls the character in Ananse: The Origin using his or her wiles to finally seize the ownership of stories. The super-athletic body of Ananse therefore does not belie the need for game-smarts in succeeding in the game itself. More optimistically, assuming control in the game can be read as reclaiming of the story by the colonized because success in the game ensures that stories are named after Ananse. In other words, success leads to story ownership.

This transformation from story to game recalls adaptations of Kweku Ananse in music, films and other aspects of popular culture. For this game, the connection between narrative and video games is made in the context of oral tradition, connecting to the possible narratives in the game (in relation to the outcomes of an oral literature plot where depending on a situation, the same story has different endings), the role of gamers in making these possible narratives (as opposed to audience considerations in oral literature, for instance) and the place of traditional African forms of storytelling within the larger gaming community. These connections foreground the effect of older forms of literature 
on new media, as well as the reverse.

As an example of the adventure genre, the game is characterized by teleological linearity, which is absent from the template story because depending on the proclivities of the narrator, Ananse can capture the quartet in any sequence. Failure in the game is again possible, dependent on the skill of the gamer; unlike most other Anansesem, it is virtually impossible to hear of a version of this particular story where Ananse fails to capture the four beings. Similar to Stan Lee's Spiderman superhero, the hero of the game can use his web in creative ways, unlike the folk tales, where typically Ananse weaves a web of shame when he escapes at the end of the narrative as previously mentioned. As such, this change from oral tradition to the mobile video game space presents itself as a semantic shift from the features of the former to the strengths of the latter.

\section{Conclusion: The Implications of "Translation"}

Robert Young points out that the Latin etymology of "translation" elicits the idea of carrying across; such connotations resonate with the Greek root for "metaphor", which maps on to the same meaning (138-39). Translation and paraphrase, as informed by the analysis in this chapter, connect with metaphor in order to symbolize the implications of transference. Video games have had diverse sources for inspiration from actual games through literature to aspects of culture. Board games such as chess, draughts, Monopoly and Snakes and Ladders for example have video game equivalents. Video games have also been based on novels authored for example by Agatha Christie, Robert Louis Stevenson, and J. K. Rowling, while stories in Greek and Roman mythology have inspired countless video games. Thus, it is no real surprise if a board game and story serve as the respective bases for creating these two games, especially when we consider the general importance of 
gaming and games to Ghanaian culture.

Nevertheless, in a place where computer games do not have a strong presence (relative to other places), examining these forms of adaptation highlights games as a prime example of cultural evolution. These two games demonstrate that the Ghanaian creative response to western technology in terms of video games is multifaceted, whereby one approach is not more effective than the other. Processing a traditional aspect of culture into a new media environment leads to the conclusion that 'true' authenticity, if a necessary topic for discussion, comes from the games being African authored. The nature of the word 'African' is obviously not stagnant or narrow. There is freedom to make changes to established aspects of culture in order to evolve with the times and show how tradition merges with foreign culture. After all, no culture lives in isolation, and one cannot find a computer game that does not incorporate some aspect of another culture into its design or other aspect of development. In using oral tradition as the source while employing a signifier of western culture as the destination, the hegemonic interplay places the two diametrically opposed entities in a complex relationship that avoids simplistic arguments that might question whether one game is a better rendition of another. More pertinent conversations can gravitate toward logistical challenges that face game makers in Ghana.

Both Nyomi and Leti Arts, despite the challenges to the Ghanaian/Sub-Saharan African games industry, are negotiating obstacles while driven by the yearning to make African culture more accessible to the younger demographic - this desire drives them to be innovative in their endeavors. Their ability to harness the influence that occurs by using western authored modes of communication and creation therefore add to the rich body of 
conversations that relate to inter-cultural exchange between Africa and its foreign counterparts.

\section{Appendix}

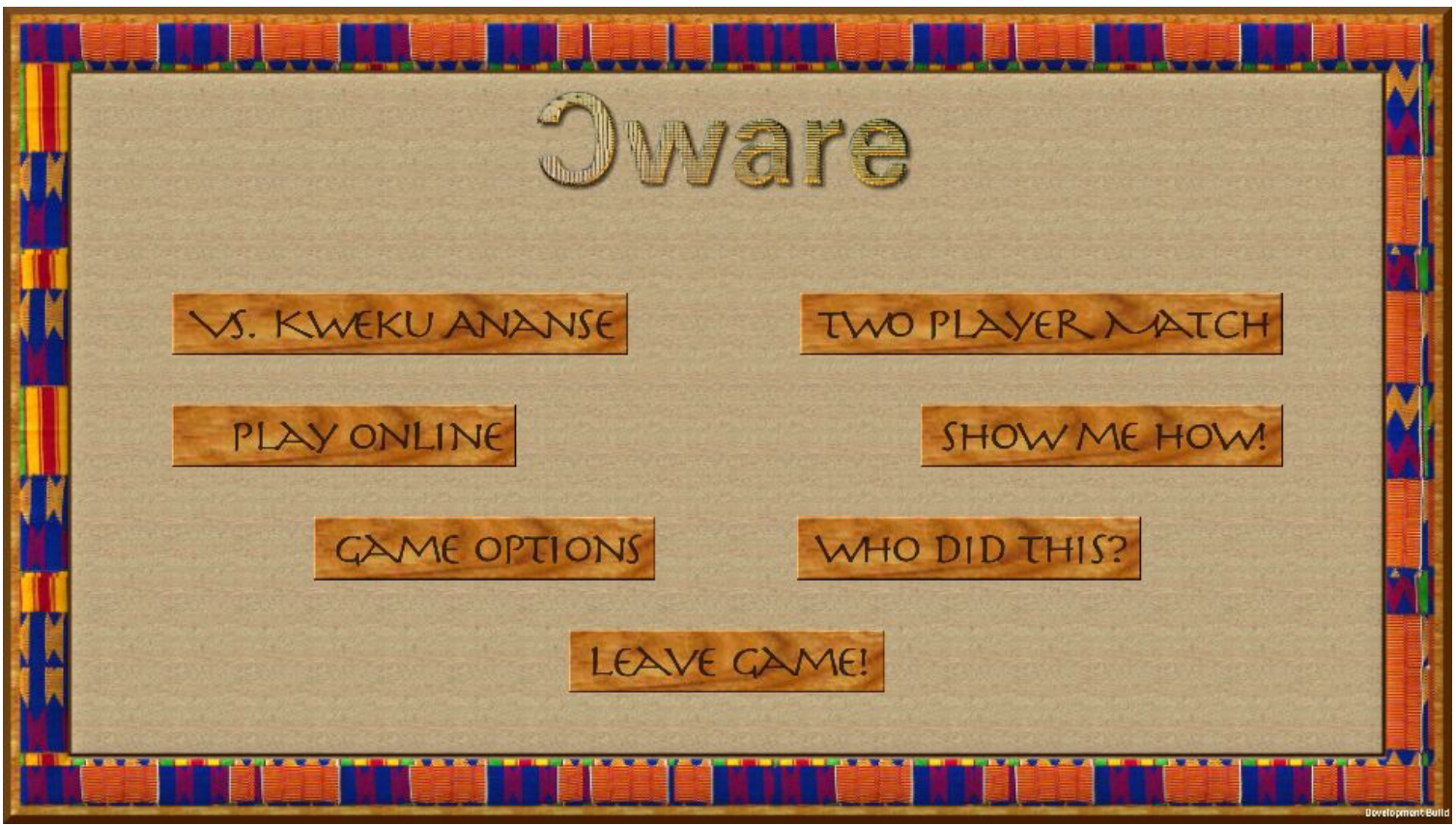

Figure 1: Oware 3D Menu Screenshot. 


\section{Chapter 6 - Conclusions and Further Directions}

\section{Why, What, and How: A Summation}

This dissertation has attempted to address aspects of the gap between the relatively prolific production of African electronic literature and its insufficient literary criticism by using examples specific to Ghana as basis for theorizing on the nature and scope of African electronic literature. While a series of monographs could more thoroughly address the general relationship between African literature and electronic literature, the breadth of a dissertation makes space for a much narrower focus. Accordingly, this project has examined aspects of electronic texts that speak to the presence and function of oral tradition in the chosen genres as a way to examine the relationship between two technologies that are usually considered in connection with print technology. Consistently underscoring the importance of orality in different electronic contexts has allowed for explicit connections between two technologies that are usually not considered in tandem with each other - more so in African literature; presenting the implications that arise from these connections has therefore been the main thrust of this dissertation.

To better understand the engagement between orality and digital technology in African literature in Ghana, it might have been helpful to use well-known Ghanaian literary artists and works. Such a choice would be informed by the assumption that the better-known the writers are, the more credible they would appear to be. African literary criticism tends to focus on major writers, after all. ${ }^{82}$ Additionally, prominent Ghanaian

\footnotetext{
${ }^{82}$ In Writing Ghana which is used in this dissertation as a guide to approaching the Ghana-Africa relationship, Korang employed the writing of the "intelligentsia" and upper middle-class people from pre-independence Ghana as representative of his push for alternative notions of modernity in globalized conversations.
} 
writers such as Ayi Kwei Armah, Kofi Anyidoho, Ama Ata Aidoo, and to an extent, Taiye Selasi all identify themselves not only in relation to Ghana but on a larger continental and Pan-African scale - in the case of Selasi, her identification goes beyond the continent with the "Afropolitan" label. ${ }^{83}$ It must be noted however that there are no major examples of Ghanaian electronic literature with the stature of Armah's The Beautyful Ones Are Not Yet Born, Aidoo's Dilemma of a Ghost, or Selasi's Ghana Must Go. The lack of major Ghanaian e-lit writers and texts notwithstanding, it was helpful to adopt Karin Barber 's overriding contention in Anthropology of Texts that analyzing lesser-known - and even lesser respected - forms of literature can also add significance to an appreciation of the literature of a country or culture. Thus, the concerns of this dissertation have rested with these lesser-known - and even unknown - creations, that can not only supplement the efforts of their more illustrious counterparts, but should also bring a different dimension to understanding the ways in which digital technology is being engaged with. This dissertation, in this light, can be placed in conversation with research into established genres of print literature and oral tradition in Ghana and elsewhere.

If relatively unappreciated genres of literature improve the scope and reach of literary scholarship, then under-researched modes of literary production can further enhance the larger engagement with literature. More specifically, the contributions of oral literature and print literature genres to scholarship have been relatively well publicized in African literary scholarship; this is not the case with electronic literature genres whose unique features add new dimensions to existing knowledge. Barber's seminal research focused on genres with unique features, but she looked at popular theater, a form of

\footnotetext{
${ }^{83}$ See Selasi's “Bye Bye Babar”.
} 
creative expression with a massive following in West Africa. Going beyond Barber then, rather than choose well-known writers or even genres that have a relatively sizeable audience and established history but lack the prestige of their mainstream counterparts, there is another step that presents itself in focusing on a relatively new form of creative expression.

In choosing to examine e-lit as a novel mode of creation, this dissertation has focused on analyzing the elements of orality that influence the form and nature of the genre. To do this required a structured analysis as has been attempted by the various chapters. The introductory chapter and subsequent theoretical and scholarly framing chapter for instance sought to theorize on what it means to process electronic literature in African contexts as an extension and complication of existing technologies, using Ghana as the metonymic representation. As unfortunate as it is, even in the $21^{\text {st }}$ century Africa still battles against negative stereotypes about underdevelopment; in the same vein, accounts in western narratives about the adoption of digital technology in Africa tend to border on negativity. As such, it is important to speak to these issues before considering the actual work being done. This consideration then has to acknowledge that the lack of research into African e-lit itself leads to different strategies for literature review.

Stepping into the relatively unknown, as it were, meant that this subsequent literature review would have to consider the evolution of technology, as captured by both African literary criticism and electronic literature research. Using specific major secondary texts in this regard (for both disciplines) helped to acknowledge the potential fissures and strengths that occur within the relationships between oral and print literature on one hand, and print and electronic literature on the other hand. It was then concluded 
that ultimately both sets of relationships, while complex and productive with multiple implications, create a space for African e-lit to further the ways in which creative artists harness new forms of technology to not only speak to these existing forms, but to advance African literature as a discipline in diverse ways. This conclusion led to the analysis chapters.

After laying out the stakes and foundation of the project while looking ahead, the third chapter explored the potential of Sankofa to interact with concrete poetry in an electronic space. The electronic context enabled a way of approaching Sankofa that simultaneously dovetails with and converges from oral and print based modes of engaging with the text, as aspects of oral tradition influenced the exploration. Elements of orality such as performance and narrative allow for an analysis of Sankofa through the lens of concrete poetry both in terms of its Adinkra variation and its folktale rendition. In reverse, the unique implications of this analysis extend definitions of concrete poetry due to the ways in which Sankofa impacts conventional understandings of orality and sound in concrete poetry. Unlike the next two analysis chapters, this section did not identify literary artists who use Sankofa in their work, but rather dwelled on the potential in the relationship between Adinkra symbols and concrete poetry. The element of potential was important because the circulation of traditional African symbols in digital and transnational spaces means that they are already being processed in these electronic contexts. The issue of potential can, by extension, allow for theorization on the evolution of other examples of oral tradition in digital spaces.

The next chapter examined arguably the first example of African conceptual poetry in My Book of \#GHCoats. Nana Awere Damoah's work demonstrated the ways in which 
oral tradition elements such as community, multiple voice, and appropriation function in electronic settings to not only critique tropes of power and recognition, but to also add to conversations on the use of social media in literary contexts. Through an overview of the project, coupled with an analysis of the literary nature of an "uncreative" work, this chapter helped to complicate notions of creativity in an electronic age where the mass adoption of a "copy and paste" culture raises questions concerning authorship. This question of ownership is another contentious issue in oral tradition due to the communal possession of texts, and this chapter demonstrated possible extensions of these issues through conceptual poetry.

After considering two different types of electronic poetry, the final analysis chapter entered the world of gaming, treating two mobile video games in a comparative analysis. With such gaming features as plot, character, setting, conflict, and symbolism overlapping with conventional types of literature, the lack of research into African gaming made this chapter critical not only to the dissertation, but to video game studies in general. In using a board game and an adventure game as basis for the research, it was clear that features of orality including folklore, community, non-linearity, and performance were key to ensuring that both Oware $3 D$ and Ananse: the Origin effectively highlighted the transition from oral tradition to electronic literature. This chapter argued that by using a traditional Ghanaian game and a traditional Ghanaian folktale as respective inspiration for creating the two texts, the relationship between oral tradition and electronic literature assumes a complex versatility that requires a nuanced approach. This nuanced approach has informed each analysis chapter in the dissertation.

\section{Moving Forward and Outward: Further Research}


The texts used in this study thus indicate a variety of ways in which Ghanaian literary artists use aspects of oral tradition in tandem with digital technology, and in shedding light on these methods, this dissertation opens space for endeavors into other related areas of interest - not only for researchers, but for writers, poets, and other literary artists. As access to the internet and digital technology increases, creative artists can embrace newer ways of harnessing electronic literature. There are popular e-lit genres such as mobile apps, bots, poem generators, interactive fiction, and works that use JavaScript that are popular in places like North America, Asia, and Europe but whose potential has not yet been adequately explored in Ghana and other African countries. Until creative artists adopt these forms of expression, research in African e-lit can either choose to look at prospective directions, as was the strategy in the first analysis chapter, or focus on genres that are already commonplace and are changing the literary landscape. While research in both directions exists, the potential to do the latter is immense.

Writers have for instance used websites such as WordPress to create numerous blogs that share short stories, poetry, and longer creative pieces. Flash fiction has become mainstream as well, with portals such as Flash Fiction Ghana that collect and curate submissions of flash fiction on its website www.flashfictionghana.com. Through these submissions, Flash Fiction Ghana has created a vibrant community of mainly young writers that explores themes of interest through very short fiction. Similar to the \#GHCoats example, social media also continues to be another preferred option for writers who share their work via social media sites including Twitter and Instagram, facilitating audiences that interact within the boundaries created by such portals. The peculiar features of both services, such as the 140-character limit for Twitter, and the picture-centric nature 
of Instagram influence the mode of production, presentation, and engagement all of which are worth exploring in further research, either in tandem with traditional African culture as has been the thrust of this dissertation, or in different but equally valid ways.

Beyond such examples of creative production, there are technological endeavors: Local and foreign organizations collaborate with secondary and tertiary educational institutions in Ghana to organize technology fairs where young people craft electronic based devices that can be used to create literature. As even more diverse examples of Ghanaian e-lit populate the electronic literature space, research will hopefully engage with these texts in a scholarly manner not only in isolation as this dissertation has done, but in connection with work from other African countries such as Kenya, Nigeria, Egypt, Tanzania, and South Africa which are also producing many examples of electronic literature. There is by extension, more to be done by comparing African e-lit texts to e-lit texts from other regions in a deeper and more sustained manner than this dissertation has endeavored to. Having transnational and transregional research has the potential to glean lessons from the versatility that comes from studying the relationships embedded in such studies.

Research can further take the logistics route to assess ways in which the nature of access to the internet and digital technology in Ghana (and other African countries) has influenced the production and critical engagement with these texts - both positively and negatively. ${ }^{84}$ One way of doing this would be to look at an example like Okada Books,

\footnotetext{
${ }^{84}$ In "Dimensions of the Mobile Divide in Niger", Alzouma investigates Niger's relationship with computers and finds that access to these devices is stratified, particularly in a rural-urban sense. These findings are easily replicated in other Sub-Saharan African countries.
} 
which is a Nigerian app that according to its website "seeks to bypass the traffic in the Nigerian book publishing industry by making it easy to publish books, making it cheap to buy books but more importantly making it fun to read books on mobile devices.” This service allows readers and writers to interact through the sharing and publishing of work via its portal, and dramatically increases the number of published writers in countries like Nigeria and Ghana, where Okada Books is popular.

Yet another way of researching into access involves harnessing digital technology in ways that can be practically impactful on demographics similar to but necessarily beyond the aesthetic and creative implications of literature. App developers for example create apps that speak to logistical challenges related to the use of digital technology. Dumsor, a flashlight app created in Ghana by the developer KodeFusion GH in 2014 for instance, was a pun on the Akan phrase given to the frequent extended blackouts that characterized Ghanaian urban centers between 2013 and 2015. KodeFusion, according to a Ghanaian news website that carried a story about their app launch, infuses "disruptive technologies to create innovative solutions" with the view to solving societal needs. Such interventions are important because if the introduction of digital technology into Africa is usually contextualized with a lack of basic amenities, then why not use digital technology that can create e-lit in other ways?

\section{Connections with Digital Humanities}

Such questions of access lead to ethical issues that need to be addressed - these typically relate to the purpose and use of literature in African contexts. Chinua Achebe, who is widely considered the "father" of modern African literature demanded that African 
writers use their creative energy for socio-political purposes, rather than dwell on aesthetics. Even though in his last novel Anthills of the Savannah a character famously asserts that writers exist to give headaches rather than provide prescriptions, in a much earlier essay he titled "The Novelist as Teacher" (from the collection Morning Yet on Creation Day), he strikes a more decisive tone as he asks that African writers speak to the contemporary problems they face. He argues that writers cannot be "excused from the task of re-education and regeneration", but should rather "march right in front." (45). In critiquing the wrongs committed by colonialists, Nigerian civilian and military governments, and other figures of power in his novels, essays, poetry, and in both his private and professional life, Achebe followed his own admonition and influenced his and subsequent generations of African writers to foreground didactic concerns. And in an environment where access to digital technology can be interpreted as privilege rather than a right, one can ask whether its use should follow ethical guidelines in another sense - not only in addressing such concerns in the production of the literature, but also in the use of the technology that creates the said literature. In other words, is it necessary to consider "right" or "ethical" uses of digital technology in Africa?

This question appears to have plagued Eugenio Tisselli, a European artist and programmer who was noted in the early part of the turn of the millennium for e-lit work. However, he reconsidered his creative engagement with e-lit and subsequently veered from aesthetic concerns to develop socio-technical methodologies for communal practice in Tanzania. In 2011, Tisselli wrote "Why I Stopped Creating E-lit," an article in which he claims to have refused continuing to make e-lit works because he realized he was doing so "only for the sake of exploring new formats and supports"; he proceeded to "strongly 
disagree" with an exclusive engagement with e-lit "from within the academic field of Literature." Tisselli found it problematic that the production of and engagement with e-lit seemed to lack a practical impact on its audience. Tisselli was moreover conflicted by ethical concerns surrounding the slave labor that produced the material that artists would use for digital works; at the time his opinion was that a complete disengagement with the creative process was an effective way of not perpetuating the prevailing system. His polemic essay garnered several replies, one of which pointed out the inherent hypocrisy and futility of isolating oneself from digital technology. Regardless of the criticism, Tisselli started to use digital technology to work more with communities that he felt would benefit in tangible ways from this technology.

These concerns led him to the Sauti ya wakulima (translated from Swahili as "The voice of the farmers") Project, which per their website is a collaborative knowledge base created by 10 farmers from the Chambezi region of the Bagamoyo District in Tanzania. These farmers use smartphones to publish images and voice recordings on the Internet. The website lists Tisselli as a co-programmer and co-project leader, and by facilitating the farmers' passing of knowledge, he and his team find ways to overcome some problems that plague their farming practices. Even though this is the main purpose, there are creative by-products as well: in an email interview, Tisselli revealed that the farmers tend to tell stories after their work is done; this practice constitutes an example of oral tradition and involves complex performative and audience considerations. Consistent with his stance on digital technology and literature, however, he does not focus on capturing and using these folktales in an electronic space. 
Nevertheless, in suggesting a role between oral tradition (in the form of folktales) and digital technology (since these stories would be housed in an electronic format), Sauti ya wakulima illustrates the fine balance between electronic technology and creative expression in an ethical context, and extends the conversation to the role that the digital humanities can play in Africa. As Tisselli notes in his essay, despite being the predominant knowledge system in place, modern science has neither stopped poverty and hunger nor effectively linked these problems to non-scientific fields like the global markets and political instability. On a conceptual and contextual level, science does not adequately consider the oral tradition that informs the ways in which these farmers have passed on knowledge from generation to generation for centuries. Critiquing this lack of consideration is crucial because the farmers used these forms of knowledge to thrive despite the challenges they faced historically. Despite these deficiencies, science has still assumed the role of the dominant knowledge system, and by resisting true interdisciplinary and cross-sector research, Tisselli criticizes the fact that scientists appear to be the proverbial "blind leading the blinded." Similar to the argument in this dissertation, digital technology has to work in tandem with oral tradition in order to properly contextualize the two forms of technology. The role of oral tradition is therefore important because digital technology cannot be adopted in a vacuum: it needs to effectively integrate itself within a technological continuum that allows it to have a better impact on its target community.

On a larger scale in other contexts out of Africa, digital technology continues to connect productively with existing structures of knowledge. The Electronic Literature Organization for instance regularly compiles volumes of Electronic Literature Collection, 
the third of which was launched in February 2016. Drawn from over 500 submissions from different parts of the world, this Collection represents a wide range of forms and styles, such as Twitter bots, programming languages, hyperlinked texts, mobile apps, other such examples of e-lit. One of the glaring criticisms of this database however is the lack of representation from Africa, which joins Antarctica as the only two continents without representative work. As such, even though the Collection is a major statement on the significance, nature, and reach of the field of e-lit, it leaves room for improving its outreach.

Accordingly, scholars have taken steps to address this anomaly by initiating partnerships with African tertiary institutions such as the University of Ghana in Ghana and the Institut CERCO in Benin. In May 2016, representatives from Rochester Institute of Technology in the United States and Paris 8 in France, along with this author, organized workshops in both universities so as to learn about existing work and also share existing ideas on e-lit. The workshops have led to agreements between all the universities in these projects for further collaboration on pedagogical (with the University of Ghana) and creative (with the Institut CERCO) levels.

Another method of sharing, also initiated from a Western knowledge system, is the Consortium on Electronic Literature (CELL). This project seeks to develop partnerships among universities and research facilities at other organizations in order to better share and house information related to electronic literature. Through a series of grants from the National Endowment for the Humanities, officials of the CELL project have been able to link databases associated with major knowledge bases including the Electronic Book Review (EBR), Electronic Literature as a Model of Creativity and Innovation in Practice 
(ELMCIP), The Canadian Directory of Electronic Literatures (NT2), and the Digital Archive of Portuguese Experimental Literature (Po-Ex). Housing these various databases under one roof has allowed CELL to implement a web-based search engine which displays search results that are filtered from the source archives while creating a unified name authority system that improves the data harvested by the search engine. Moving forward, CELL seeks to add more databases from across the globe with the aim of creating a comprehensive catalogue of information that can help scholars, artists, and other stakeholders interested in engaging with electronic literature. Accordingly, digital humanism is in this sense practical, as it demonstrates a focus on institutional and fieldwide projects despite its limitations.

With this dissertation being one of very few research projects that examine African electronic literature, it will take a while before scholars can develop a more in-depth database for African e-lit criticism and research. Nevertheless, it is assumed that projects like CELL will incorporate such scholarship into its database in order to lend a cosmopolitan outlook to e-lit. This multicultural outlook will seek to avoid the problematic implications of the proverbial "white man's burden" that can arise when Western figures reach out to Africa by not appearing to be overbearing or unaware of the local conditions. ${ }^{85}$ Avoiding such repercussions offers hope for a future where fewer examples such as the cover of the March 12, 2005, edition of the Economist, which pandered to tired stereotypes in its portrayal of Africa, will be present in media spaces.

\footnotetext{
${ }^{85}$ For background to this argument, see David Spurr's exploration of the language that informs this phenomenon in The Rhetoric of Empire: Colonial Discourse in Journalism, Travel Writing, and Imperial Administration.
} 
Rather than such archaic ways of embracing African development, there will rather be a more careful relationship where all stakeholders relate on respectable, if not equal terms. 


\section{Works Cited}

Acemoglu, Daron, and James A. Robinson. "Why Is Africa Poor?” Economic History of Developing Regions, vol. 25, no. 1, 2010, pp. 21-50., doi:10.1080/20780389.2010.505010.

Achebe, Chinua. Anthills of the Savannah. London, Penguin Books, 2016.

. “An Image of Africa.” Research in African Literatures, vol. 9, no. 1, 1978,

pp. $1-15$.

. Morning Yet on Creation Day: Essays. Garden City, NY, Anchor Press, 1975.

Adenekan, Shola. "Transnationalism and the Agenda of African Literature in a Digital Age." Matatu, vol. 45, no. 1, Jan. 2014, pp. 133-151., doi:10.1163/9789401211093_009.

Adéèkó, Adélékè. Proverbs, Textuality, and Nativism in African Literature. Gainesville, Univ. Press of Florida, 1998.

Agbeja, Oyedokun, and Rafiu Oyesola Salawu. "Development in Sub-Saharan Africa: Overcoming the Digital Divide.” Information Technology Journal, vol. 6, no. 2, Jan. 2007, pp. 166-173., doi:10.3923/itj.2007.166.173.

Alzouma, Gado. "Dimensions of the Mobile Divide in Niger." The Digital Divide: the Internet and Social Inequality in International Perspective, edited by Massimo Ragnedda and Glenn W. Muschert, Routledge, London, 2013, pp. 297-308. . "Myths of Digital Technology in Africa." Global Media and Communication, vol. 1, no. 3, 2005, pp. 339-356., doi: $10.1177 / 1742766505058128$. 
Anoka, Victor Ahamefule. African Philosophy: an Overview and a Critique of the Philosophical Significance of African Oral Literature. Frankfurt Am Main, Peter Lang, 2012.

Anyidoho, Kofi. A Harvest of Our Dreams: with Elegy for the Revolution. Accra, Woeli Publishing Services, 1993. . "Literature and African Identity: The Example of Ayi Kwei Armah." Critical Perspectives on Ayi Kwei Armah, edited by Derek Wright, Three Continents Press, Washington, D.C., 1992, pp. 34-47.

Ardam, Jacquelyn. "The ABCs of Conceptual Writing." Comparative Literature Studies, vol. 51, no. 1, 2014, p. 132., doi:10.5325/complitstudies.51.1.0132.

Arenberg, Meg. "The Digital Ukumbi: New Terrains in Swahili Identity and Poetic Dialogue.” PMLA, vol. 131, no. 5, 2016, pp. 1344-1360., doi:10.1632/pmla.2016.131.5.1344.

Arthur, Kojo. Cloth as Metaphor: (Re)Reading the Adinkra Cloth Symbols of the Akan of Ghana. Legon, Ghana, Centre for Indigenous Knowledge Systems, 2001.

“Augusto De Campos." Augusto De Campos - Site Oficial - UOL, www2.uol.com.br/augustodecampos/home.htm. Accessed 17 Feb. 2016.

Awoonor, Kofi. "The Cathedral - Kofi Awoonor.” African Soulja, 30 July 2013, afrilingual.wordpress.com/2012/01/30/the-cathedral-kofi-awoonor/. Accessed 22 Apr. 2014.

Banda, Fackson, et al., editors. African Media and the Digital Public Sphere. New York, NY, Palgrave Macmillan, 2009. 
Barber, Karin. The Anthropology of Texts, Persons and Publics. Cambridge, Cambridge University Press, 2008. . "Text and Performance in Africa." Oral Tradition, vol. 20, no. 2, 2005, pp. 264-277., doi:10.1353/ort.2006.0001.

Bayard, Caroline. "Concrete Poetry in Canada and Quebec, 1963-1975." University of Toronto, 1976.

Bergvall, Caroline. "The Conceptual Twist: A Foreword.” I'Ll Drown My Book: Conceptual Writing by Women, edited by Caroline Bergvall et al., Les Figues Press, Los Angeles, 2012, pp. 18-22.

Bhabha, Homi K. "Signs Taken for Wonders: Questions of Ambivalence and Authority under a Tree Outside Delhi, May 1817." Critical Inquiry, vol. 12, no. 1, 1985, pp. 144-165., doi:10.1086/448325.

Boateng, Boatema. The Copyright Thing Doesn't Work Here: Adinkra and Kente Cloth and Intellectual Property in Ghana. Minneapolis, University of Minnesota Press, 2011.

Boateng, Kojo Akoto. "Ghanaian Tech Startup Launches 'Dumsor' App.” ModernGhana.com, Modern Ghana, 11 June 2014, www.modernghana.com/news/548494/ghanaian-tech-startup-launches-dumsorapp.html. Accessed 17 June 2016.

Bohn, Willard. "Concrete Poetry." American Poets and Poetry: from the Colonial Era to the Present, edited by Jeffrey Gray et al., Greenwood, Santa Barbara, Calif., 2015, pp. 119-120. . Reading Visual Poetry. S.L., Fairleigh Dickinson, 2013. 
Bowman, Margaret Warigia. "Digital Development: Technology, Governance and the Quest for Modernity in East Africa.” ProQuest Dissertations Publishing, 2009.

Brooks, Cleanth. The Well Wrought Urn. New York, Harcourt Brace \& World, 1947.

Certeau, Michel de. The Practice of Everyday Life. Berkeley, Calif., Univ. of California Press, 2008.

“CFP: ELO 2015 Bergen, Norway.” Electronic Literature Organization, eliterature.org/2014/09/2676/. Accessed 4 Mar. 2015.

Chan, Sewell. “Coffin's Emblem Defies Certainty.” The New York Times, The New York Times, 26 Jan. 2010, www.nytimes.com/2010/01/27/arts/design/27sankofa.html. Accessed 9 Nov. 2014.

Colburn, Forrest D. "Rethinking the 'Third World': Talking with Lakhdar Brahimi." World Policy Journal, vol. 24, no. 2, 2007, pp. 81-84., doi:10.1162/wopj.2007.24.2.81.

“Concrete Poetry.” Encyclopaedia Britannica, Encyclopædia Britannica, Inc., 20 July 1998, www.britannica.com/art/concrete-poetry. Accessed 17 Apr. 2014.

Damoah, Nana Awere, editor. My Book of \#GHCoats. Accra, Smashwords, 2013.

Davidson, Michael. Ghostlier Demarcations: Modern Poetry and the Material Word. Berkeley, Univ. of California Press, 1997.

De Campos, Augusto, et al. "Pilot Plan for Concrete Poetry." $U$ B UWE B :: Pilot Plan for Concrete Poetry (1958), Ubuweb, www.ubu.com/papers/noigandres01.html. Accessed 19 June 2015. 
Deleuze, Gilles, and Félix Guattari. A Thousand Plateaus; Capitalism and Schizophrenia, By Gillesdeleuze and Felix Guattari. Minneapolis, The University OfMinnesota Press, 1987.

Derrida, Jacques. Limited Inc. Evanston, IL, Northwestern Univ. Pr., 2008.

Dietrich, David R. “Avatars of Whiteness: Racial Expression in Video Game Characters.” Sociological Inquiry, vol. 83, no. 1, 2013, pp. 82-105., doi:10.1111/soin.12001.

Draper, R. P. “Concrete Poetry.” New Literary History, vol. 2, no. 2, 1971, pp. 329-340., doi: $10.2307 / 468606$.

Drucker, J. "Concrete Poetry ." The Princeton Encyclopedia of Poetry and Poetics, edited by Roland Greene et al., Princeton University Press, Princeton, 2012, pp. 294-295.

Duffy, Nikolai. "Reading the Unreadable: Kenneth Goldsmith, Conceptual Writing and the Art of Boredom." Journal of American Studies, vol. 50, no. 03, 2014, pp. 679698., doi:10.1017/s0021875814001248.

Dworkin, Craig Douglas., and Kenneth Goldsmith, editors. Against Expression: an Anthology of Conceptual Writing. Evanston Illinois, Northwestern University Press, 2011.

Emerson, Lori. Reading Writing Interfaces: from the Digital to the Bookbound. Minneapolis, University of Minnesota Press, 2014.

Ensslin, Astrid. "Playing with Rather than by the Rules." Analyzing Digital Fiction, edited by Alice Bell et al., Routledge, New York, 2014, pp. 75-93.

Eskelinen, Markku. Cybertext Poetics: the Critical Landscape of New Media Literary Theory. London, Continuum, 2012. 
Finnegan, Ruth H. Oral Literature in Africa. Cambridge, United Kingdom, Open Book Publishers, 2012.

Foley, John Miles. How to Read an Oral Poem. Urbana, University of Illinois Press, 2002.

Ford, Thomas H. “Conceptual Poetry, Nonconceptual Poetry, Postconceptual Poetry." Australian Literary Studies, vol. 28, no. 3, Jan. 2013, pp. 44-58., doi:10.20314/als.387f1bla85.

Funkhouser, Chris. New Directions in Digital Poetry. London, Continuum, 2012. . Prehistoric Digital Poetry: an Archaeology of Forms, 1959-1995.

Tuscaloosa, University of Alabama Press, 2007.

Gervais, Daniel. "Spiritual but Not Intellectual? The Protection of Sacred Intangible Traditional Knowledge.” Cardozo Journal of International and Comparative Law (JICL), vol. 11, pp. 467-495.

Giddens, Anthony. The Constitution of Society: Outline of the Theory of Structuration. Oxford, Wiley, 2013.

Gikandi, Simon. "Picasso, Africa, and the Schemata of Difference." Modernism/Modernity, vol. 10, no. 3, 2003, pp. 455-480., doi:10.1353/mod.2003.0062.

Goldsmith, Kenneth. "Conceptual Writing: A Worldview : Kenneth Goldsmith : Harriet the Blog : The Poetry Foundation." Poetry Foundation, Poetry Foundation, www.poetryfoundation.org/harriet/2012/04/conceptual-writing-a-worldview/. Accessed 17 Mar. 2016. . No. 111 2.7.93-10.20.96. Great Barrington, MA, The Figures, 1997. 
. "Paragraphs on Conceptual Writing." Paragraphs on Conceptual Writing, University at Buffalo, epc.buffalo.edu/authors/goldsmith/conceptual_paragraphs.html. Accessed 21 June 2015.

Griffin, Dustin H. Satire: A Critical Reintroduction. University Press of Kentucky, 1994. Hayles, N. Katherine. "Electronic Literature: What Is It?" Electronic Literature: What Is It?, Electronic Literature Organization, 2 Jan. 2007, eliterature.org/pad/elp.html. Accessed 10 Aug. 2015.

. How We Think: Digital Media and Contemporary Technogenesis. Chicago, IL, The University of Chicago Press, 2012. . "Print Is Flat, Code Is Deep: The Importance of Media-Specific Analysis." Poetics Today, vol. 25, no. 1, Jan. 2004, pp. 67-90., doi:10.1215/03335372-25-167.

Herring, Phillip F. Djuna: the Life and Work of Djuna Barnes. New York, Penguin Books, 1996.

Herzfeld, Michael. Cultural Intimacy: Social Poetics in the Nation-State. London, Routledge, 2014.

"Home Map." Sauti Ya Wakulima, sautiyawakulima.net/. Accessed 1 Aug. 2015.

"Internet World Stats." Internet World Stats, www.internetworldstats.com/. Accessed 17 Aug. 2016.

Irele, Abiola. The African Imagination: Literature in Africa \& the Black Diaspora. New York, Oxford University Press, 2001. 
Jackson, Thomas H. “Orality, Orature, and Ngũgĩwa Thiong'o.” Research in African Literatures, vol. 22, no. 1, 1991, pp. 5-15.

Jaeger, Peter. “Sentences on Christian Bk's Eunoia: Writing after Language Writing, Oulipo and Conceptual Art." Journal of Writing in Creative Practice, vol. 2, no. 1, Jan. 2009, pp. 45-53., doi:10.1386/jwcp.2.1.45_1.

Jeyifo, Biodun. Wole Soyinka: Politics, Poetics and Postcolonialism. Cambridge, Cambridge University Press, 2009.

Jones, John. “Switching in Twitter's Hashtagged Exchanges.” Journal of Business and Technical Communication, vol. 28, no. 1, 2014, pp. 83-108., doi: $10.1177 / 1050651913502358$.

Julien, Eileen. African Novels and the Question of Orality. Bloomington (Ind.), Indiana University Press, 2013.

Kittler, Friedrich A. Gramophone, Film, Typewriter. Standford, Calif, Stanford University Press, 2006.

Korang, Kwaku Larbi. Writing Ghana, Imagining Africa: Nation and African Modernity. Rochester, NY, University of Rochester Press, 2004.

Kozak, Claudia. "Digital Literature and Materiality. How We Read.” Artnodes, no. 15, 2015, doi:10.7238/a.v0i15.2580.

Kyei, Thomas E. Marriage and Divorce among the Asante: a Study Undertaken in the Course of the Ashanti Social Survey (1945). Cambridge, African Studies Centre, 1992. 
Laroche, Cheryl J., and Michael L. Blakey. "Seizing Intellectual Power: The Dialogue at the New York African Burial Ground.” Historical Archaeology, vol. 31, no. 3, 1997, pp. 84-106., doi:10.1007/bf03374233.

Lawless, Geraldine. Modernity's Metonyms: Figuring Time in Nineteenth-Century Spanish Stories. Lewisburg, Bucknell University Press, 2011.

Leti Arts. Ananse: The Origin. 2014.

Lindfors, Bernth. African Textualities: Texts, Pre-Texts, and Contexts of African Literature. Trenton, NJ, Africa World Press, 1997. . "Politics, Culture and Literary Form in Black Africa." Colby Library Quarterly, vol. 15, no. 4, 1979, pp. 240-251., Accessed 12 June 2015.

Mbembe, A. “African Modes of Self-Writing.” Public Culture, vol. 14, no. 1, Jan. 2002, pp. 239-273., doi:10.1215/08992363-14-1-239.

Mcallister, Brian J. "Narrative in Concrete / Concrete in Narrative: Visual Poetry and Narrative Theory." Narrative, vol. 22, no. 2, 2014, pp. 234-251., doi:10.1353/nar.2014.0011.

McLuhan, Marshall. Understanding Media: the Extensions of Man. Cambridge (Mass.), The MIT Press, 2013.

Mcpherson, T., et al. "Preface: New Media and American Literature." American Literature, vol. 85, no. 4, Jan. 2013, pp. 615-628., doi:10.1215/000298312367265 .

Megwa, Eronini R. “Bridging the Digital Divide: Community Radio's Potential for Extending Information and Communication Technology Benefits to Poor Rural 
Communities in South Africa." Howard Journal of Communications, vol. 18, no. 4, June 2007, pp. 335-352., doi:10.1080/10646170701653685.

Moretti, Franco. Graphs, Maps, Trees: Abstract Models for a Literary History. London, Verso, 2007.

Mudimbe, V. Y. The Idea of Africa. Bloomington, Indiana University Press, 1995.

Mwangi, Evan. Africa Writes Back to Self: Metafiction, Gender, Sexuality. Albany, State University of New York Press, 2009.

“Next Horizons: ELO 2016 .” Electronic Literature Organization, eliterature.org/2015/10/cfp-elo-2016-next-horizons-111515-610-1216-victoria-bc/. Accessed 14 Oct. 2016.

Nyomi, Kobla. Oware 3D. 2014.

Obiechina, Emmanuel Nwanonye. Culture, Tradition and Society in the West African Novel. Cambridge, Cambridge University Press, 1980.

Ofori-Ansa, Kwaku. "Update: Newsletter of the African Burial Ground and Five Points Archaeological Projects I.” 1995.

“Okadabooks Signup.” Okadabooks Homepage, Okada Books, www.okadabooks.com/faq. Accessed 5 Oct. 2016.

Okome, Onookome, and Stephanie Newell. "Measuring Time: Karin Barber and the Study of Popular Arts in Contemporary Africa." Research in African Literatures, vol. 43, no. 4, 2012, pp. vii-xviii., doi:10.2979/reseafrilite.43.4.vii.

Okpewho, Isidore. African Oral Literature: Backgrounds, Character, and Continuity. Bloomington, Ind, Indiana University Press, 1992. 
Olaniyan, Tejumola, and Ato Quayson, editors. African Literature: an Anthology of Criticism and Theory. Malden, MA, Blackwell Pub., 2010.

Ong, Walter J. Orality and Literacy: the Technologizing of the World. London, Routledge, 2007.

Opoku-Agyemang, Kwabena. "Interview with Eugenio Tisselli.” 7 Oct. 2014. . “Interview with Kobla Nyomi.” 21 Apr. 2014.

. "Interview with Nana Awere Damoah.” 8 June 2014.

Opoku-Agyemang, Naana Jane. "Gender-Role Perceptions in the Akan Folktale." Research in African Literatures, vol. 30, no. 1, 1999, pp. 116-139., doi:10.2979/ral.1999.30.1.116.

Owusu-Sampah, Claudia. “Adinkra.” Rochester Institute of Technology, 2014.

Perloff, Majorie. "Conceptual Poetry.” The Princeton Handbook of Poetic Terms, edited by Roland Greene et al., Princeton University Press, Princeton and Oxford, 2012, p. 292.

. "Marjorie Perloff, 'Conceptual Poetry and the Question of Emotion.” Events | UCI Department of Poetics | History | Theory, UCI, 2014, www.humanities.uci.edu/poeticshistorytheory/calendar/events.php?recid=4026\&d ept_code_val=62-9\&event_cat $=$ archive\&file_name=events_arch. Accessed 17 Aug. 2015. . Unoriginal Genius: Poetry by Other Means in the New Century. Chicago, University of Chicago Press, 2012.

Pieterse, Jan Nederveen. Development Theory: Deconstructions/Reconstructions. London, SAGE, 2013. 
Place, Vanessa, and Robert Fitterman. Notes on Conceptualisms. Brooklyn (N.Y.), Ugly Duckling Presse, 2013.

Quarcoo, Alfred Kofi. The Language of Adinkra Patterns. Legon, Sebewie Ventures, 1994.

Quayson, Ato. Strategic Transformations in Nigerian Writing: Orality \& History in the Work of Rev. Samuel Johnson Amos Tutuola, Wole Soyinka \& Ben Okri. Bloomington, Indiana University Press, 1997.

Raley, Rita. Tactical Media. Minneapolis, University of Minnesota Press, 2009.

“The Real Digital Divide.” The Economist (US), 12 Mar. 2005.

Reed, Ann. "Diaspora Tourism: The Heritage of Slavery in Ghana." A Companion to Diaspora and Transnationalism, edited by Ato Quayson and Girish Daswani, Wiley-Blackwell, Chichester, 2013, pp. 524-538.

Ricard, Alain. "Africa and Writing." African Literature: an Anthology of Criticism and Theory, edited by Ato Quayson and Tejumola Olaniyan, Blackwell Pub, Malden, MA, 2007, pp. 7-15.

Robins, Melinda Beth, and Robert L. Hilliard, editors. Beyond Boundaries: Cyberspace in Africa. Portsmouth, NH, Heinemann, 2002.

Royall, Julia, et al. "Crossing the Digital Divide: The Contribution of Information Technology to the Professional Performance of Malaria Researchers in Africa." African Health Sciences, vol. 5, no. 3, Sept. 2005, pp. 246-254., www.ncbi.nlm.nih.gov/pmc/articles/PMC1831932/. Accessed 20 Apr. 2015. 
Seeman, Erik R. 'Reassessing the 'Sankofa Symbol' in New York's African Burial Ground." William and Mary Quarterly: A Magazine of Early American History and Culture, vol. 67, no. 1, 2010, pp. 101-122.

Selasi, Taiye. "Bye-Bye Babar.” The LIP Magazine, 3 Mar. 2005, thelip.robertsharp.co.uk/?p=76. Accessed 7 Apr. 2016.

Selber, Stuart A. Multiliteracies for a Digital Age. Carbondale, Southern Illinois Univ. Press, 2004.

Shitemi, Naomi L. "Rethinking and Mainstreaming African Literature in the Academia." Journal of Literary Studies, vol. 28, no. 2, 2012, pp. 20-36., doi:10.1080/02564718.2012.676332.

Smith, Aaron. “6 New Facts about Facebook.” Pew Research Center, 3 Feb. 2014, www.pewresearch.org/fact-tank/2014/02/03/6-new-facts-about-facebook/. Accessed 15 Nov. 2015.

Spurr, David. The Rhetoric of Empire: Colonial Discourse in Journalism, Travel Writing, and Imperial Administration. Durham, Duke University Press, 2004.

Temple, Christel N. “The Emergence of Sankofa Practice in the United States.” Journal of Black Studies, vol. 41, no. 1, 2010, pp. 127-150., doi:10.1177/0021934709332464.

Thiong'o, Ngugi wa. Decolonizing the Mind: the Politics of Language in African Literature. London, J. Currey, 1986.

Tisselli, Eugenio. "Why I Have Stopped Creating e-Lit.” Netartery, 25 Nov. 2011, netartery.vispo.com/?p=1211+\%282011\%29. Accessed 17 July 2014 .

"The True Ananse: Now Available on Nokia Store and Windows Phone Store." Leti Arts, 1 Nov. 2013, letiarts.wordpress.com/tag/the-true-ananse/. Accessed 14 Sept. 2014. 
"UN Rights Expert Urges Liberia Not to Hand Public Education over to a Private Company." UN Rights Expert Urges Liberia Not to Hand Public Education over to a Private Company, www.ohchr.org/EN/NewsEvents/Pages/DisplayNews.aspx?NewsID=18506\&Lang ID=E. Accessed 17 June 2016.

Wali, Obiajunwa. “The Dead End of African Literature?” Transition, no. 10, 1963, pp. 330-334., doi:10.2307/2934441.

Wambua, Pauline. "Police Corruption In Africa Undermines Trust, but Support for Law Enforcement Remains Strong.” Afrobarometer, vol. 56, 2 Nov. 2015, pp. 1-18.

“We Made Vicky Hammah a 'Sex Symbol' - Leila Djansi.” GhanaGist.Com, 16 Nov. 2013, ghanagist.com/we-made-vicky-hammah-a-sex-symbol-leila-djansi/. Accessed 15 Apr. 2014.

"West African Wisdom: Adinkra Symbols \& Meanings." Adinkra Symbols of West Africa, adinkra.org/. Accessed 17 May 2015.

Young, Robert. Postcolonialism. Oxford, Oxford UP, 2003.

Younis, Eman. "Manifestations of the Arab Spring in Literature: 'Video Clip Poems' on You Tube as a Model.” Journalism \& Mass Communication Quarterly, vol. 6, 2016, pp. 33-42. 